\title{
AVTA Federal Fleet PEV Readiness Data Logging and Characterization Study for Department of Veterans Affairs - James J. Peters VA Medical Center, Bronx, New York
}

Stephen Schey Jim Francfort

October 2014

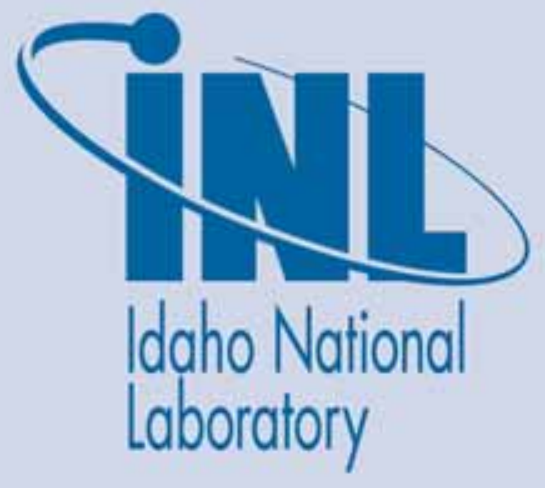

The INL is a U.S. Department of Energy National Laboratory operated by Battelle Energy Alliance 
INL/EXT-15-34284

\title{
AVTA Federal Fleet PEV Readiness Data Logging and Characterization Study for Department of Veterans Affairs - James J. Peters VA Medical Center, Bronx, New York
}

\author{
Stephen Schey \\ Jim Francfort
}

\begin{abstract}
Stephen Schey, Project Manager, Infrastructure Planning and Analysis, Intertek Testing Services,
Jim Francfort, Vehicle Systems Principal Investigator, Idaho National Laboratory operated by

Battelle Energy Alliance, Idaho Falls, Idaho
\end{abstract}

October 2014

\author{
Idaho National Laboratory \\ Idaho Falls, Idaho 83415
}

http://avt.inl.gov

Prepared for the

U.S. Department of Energy

Office of Nuclear Energy

Under DOE Idaho Operations Office

Contract DE-AC07-05ID14517 


\section{DISCLAIMER}

This information was prepared as an account of work sponsored by an agency of the U.S. Government. Neither the U.S. Government nor any agency thereof, nor any of their employees, makes any warranty, expressed or implied, or assumes any legal liability or responsibility for the accuracy, completeness, or usefulness, of any information, apparatus, product, or process disclosed, or represents that its use would not infringe privately owned rights. References herein to any specific commercial product, process, or service by trade name, trade mark, manufacturer, or otherwise, does not necessarily constitute or imply its endorsement, recommendation, or favoring by the U.S. Government or any agency thereof. The views and opinions of authors expressed herein do not necessarily state or reflect those of the U.S. Government or any agency thereof. 


\section{ABSTRACT}

Battelle Energy Alliance, LLC, managing and operating contractor for the U.S. Department of Energy's Idaho National Laboratory, is the lead laboratory for U.S. Department of Energy Advanced Vehicle Testing. Battelle Energy Alliance, LLC contracted with Intertek Testing Services, North America (Intertek) to collect and evaluate data on federal fleet operations as part of the Advanced Vehicle Testing Activity's Federal Fleet Vehicle Data Logging and Characterization Study. The Advanced Vehicle Testing Activity study seeks to collect and evaluate data to validate the utilization of advanced plug-in electric vehicle (PEV) transportation.

This report focuses on the Department of Veterans Affairs, James J. Peters VA Medical Center (VA - Bronx) fleet to identify daily operational characteristics of select vehicles and report findings on vehicle and mission characterizations to support the successful introduction of PEVs into the agencies' fleets.

Individual observations of these selected vehicles provide the basis for recommendations related to electric vehicle adoption and whether a battery electric vehicle or plug-in hybrid electric vehicle (collectively referred to as PEVs) can fulfill the mission requirements.

Intertek acknowledges the support of Idaho National Laboratory and VA Bronx personnel for participation in the study. 


\section{EXECUTIVE SUMMARY}

Federal agencies are mandated to purchase alternative-fuel vehicles, increase consumption of alternative fuels, and reduce petroleum consumption. Available plug-in electric vehicles (PEVs) provide an attractive option in the selection of alternative fuel vehicles. PEVs, which consist of both battery electric vehicles (BEVs) and plug-in hybrid electric vehicles (PHEVs), have significant advantages over internal combustion engine (ICE) vehicles in terms of energy efficiency, reduced petroleum consumption, reduced production of greenhouse gas (GHG) emissions, and they provide performance benefits with quieter, smoother operation. This study is intended to evaluate the extent to which the Department of Veterans Affairs, James J. Peters VA Medical Center (VA Bronx) could convert part or all of their fleet of vehicles from petroleum-fueled vehicles to PEVs.

It is likely that more fuel-efficient ICE vehicles, including hybrid electric vehicles, exist that may provide improvements for the current fleet; however, this study's focus is on replacing ICE vehicles with suitable PEVs.

BEVs provide the greatest benefit when it comes to fuel and emissions savings because all motive power is provided by the energy stored in the onboard battery pack. These vehicles use no petroleum and emit no pollutants at their point of use. PHEVs provide similar savings when their battery provides the motive power; however, they also have the ability to extend their operating range with an onboard ICE. Because a PHEV can meet all transportation range needs, the adoption of a PHEV will be dependent on its ability to meet other transportation needs such as cargo or passenger carrying. Operation of PHEVs in battery-only mode can be increased with opportunity charging at available charging stations; it should be noted, however, that not all PHEVs have a mode in which the battery provides all motive power at all speeds. This study focuses on the mission requirements of the fleet of vehicles with the objective of identifying vehicles that may be replaced with PEVs, with emphasis on BEVs that provide maximum benefit.

The VA - Bronx, located at 130 West Kingsbridge Road in Bronx, New York, is a part of the U.S. Department of Veterans Affairs. It is a tertiary care facility classified as a Clinical Referral Level 1 Facility. It is a teaching hospital that provides a full range of patient care services, with state-of-the-art technology and education and research. Comprehensive health care is provided through primary care, tertiary care, and long-term care in areas of medicine, surgery, psychiatry, physical medicine and rehabilitation, neurology, oncology, dentistry, geriatrics, and extended care. The James J. Peters VAMC is a part of VA Network 3, which includes facilities in Brooklyn, Castle Point, Manhattan, Montrose, Northport, St. Albans (Queens), New York and East Orange and Lyons, New Jersey. ${ }^{\text {a }}$

VA - Bronx has 50 vehicles in its fleet, with nine vehicles being identified as representative of the fleet and instrumented for data collection and analysis. Fleet vehicle mission categories are defined in Section 4. While the VA - Bronx vehicles conduct many different missions, two (i.e., pool and bus/shuttle

\footnotetext{
${ }^{a}$ http://www.bronx.va.gov/about/index.asp [accessed October 11, 2014].
} 
missions) were selected by agency management to be part of this fleet evaluation. These two mission categories accounted for 35 of the 50 total fleet vehicles. The remaining vehicles were specialty, enforcement, support, and transport vehicles.

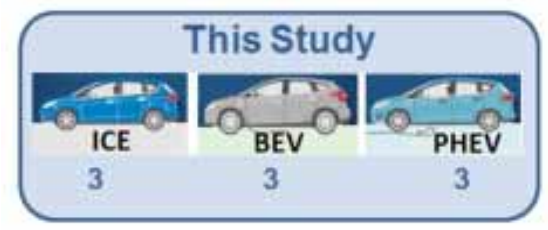

While there are no current PEV types available to replace the passenger vans in the bus/shuttle mission category, the usage of these vehicles was studied and reported herein. No extrapolation to the larger fleet was possible; however, VA - Bronx may wish to evaluate this fleet of vehicles to determine whether minivans or sport utility vehicles may be used in this mission category. PEV types do currently exist for these vehicle types.

This report observes that a mix of BEVs and PHEVs are capable of performing the pool mission and of providing alternative vehicles because, while some vehicles travel long distances, the group could support some

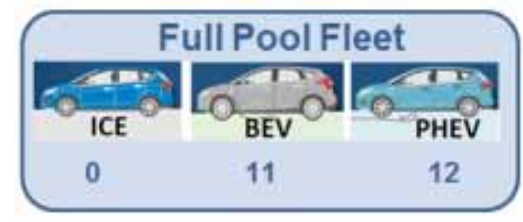
BEVs for the short trips and PHEVs for the longer trips. The recommended mix of vehicles will provide sufficient range for individual trips and time is available each day for charging to accommodate multiple trips per day. These charging

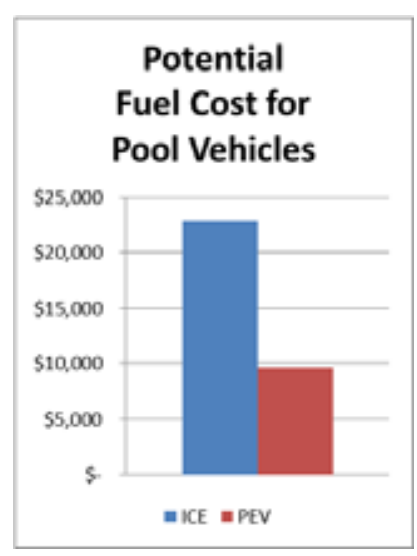
events could occur at the vehicle's home base. Replacement of vehicles in the current fleet would result in significant reductions in the emission of GHGs and in petroleum use, as well as reduced fleet operating costs.

Based on data collected for the monitored vehicles, the nine-vehicle fleet subset could possibly consist of three ICE shuttles, three BEVs, and three PHEVs. The replacement of these six ICE vehicles with PEVs could result in an annual GHG savings over $14,613 \mathrm{lbs}-\mathrm{CO}_{2} \mathrm{e}(40 \%$ reduction) and an annual fuel cost savings of $\$ 3,796$ (60\% reduction).

Based on data collected from the monitored vehicles and extrapolating to the 23 vehicles with pool mission, a fleet consisting of $11 \mathrm{BEVs}$ and 12 PHEVs may meet the VA's needs. Replacement of the 23 ICE vehicles with PEVs could result in an annual GHG savings over 48,300 lbs- $\mathrm{CO}_{2} \mathrm{e}(36 \%$ reduction) and an annual fuel cost savings of over $\$ 13,200$ (58\% reduction).

PEV charging stations could be located in various locations of the VA - Bronx and could benefit employees and those in the visiting public that own PEVs.

Intertek suggests that VA - Bronx may wish to move forward in the near future with replacement of pool

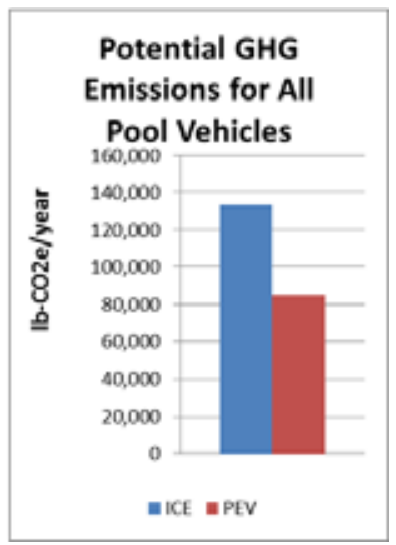
vehicles with PEVs as current budget and vehicle replacement schedules allow. Certainly, the vehicle types studied in this report may be candidates for immediate replacement. 


\section{CONTENTS}

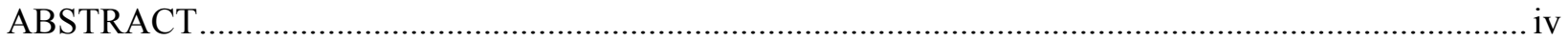

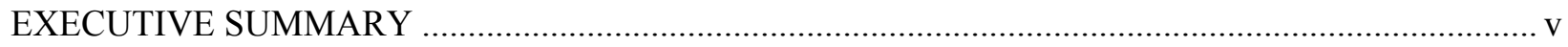

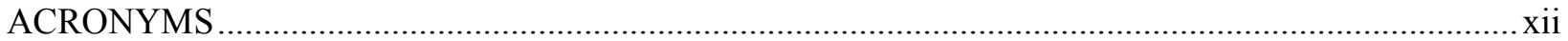

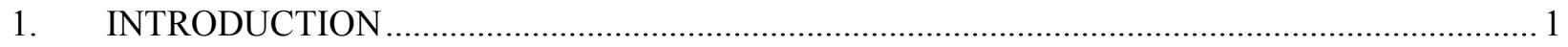

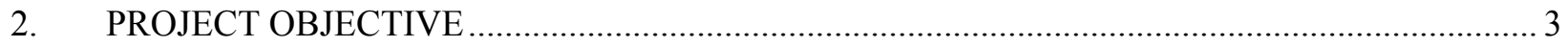

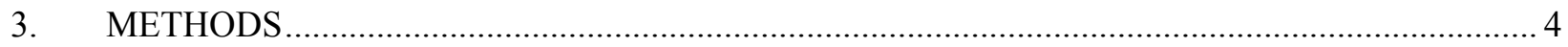

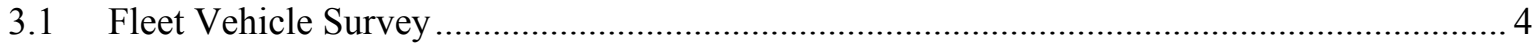

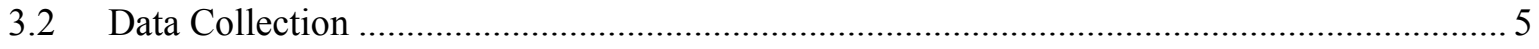

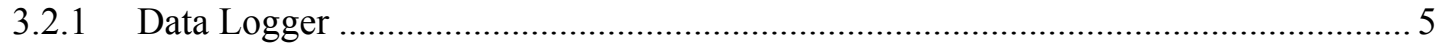

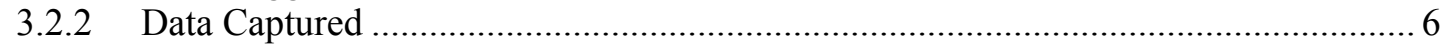

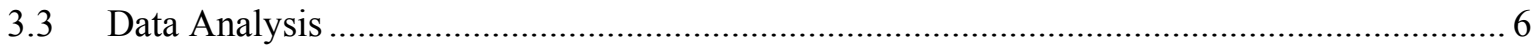

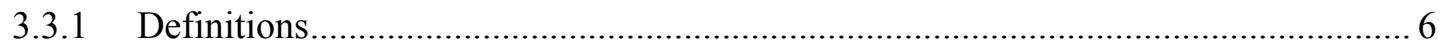

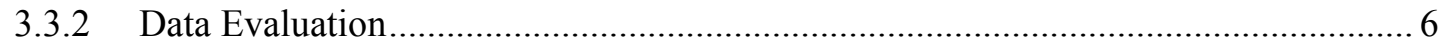

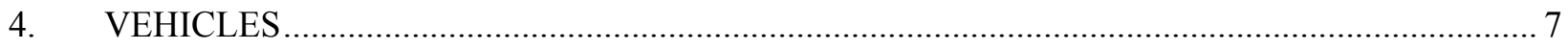

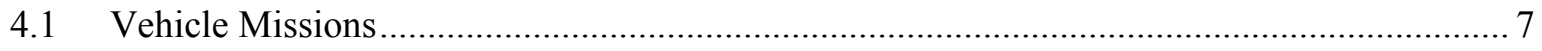

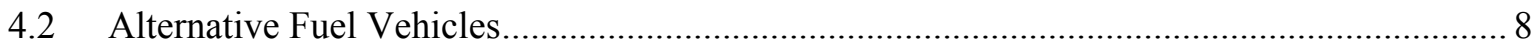

4.3 Battery Electric Vehicle and Plug-In Hybrid Electric Vehicle Benefits/Challenges .............. 9

4.3.1 Battery Electric Vehicle Benefits/Challenges ...................................................... 9

4.3.2 Plug-in Hybrid Electric Vehicle Benefits/Challenges............................................ 9

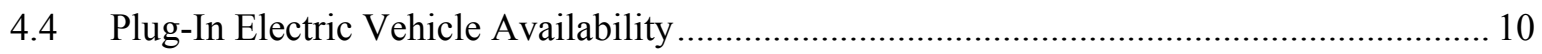

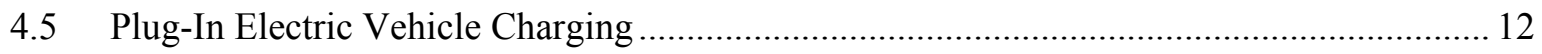

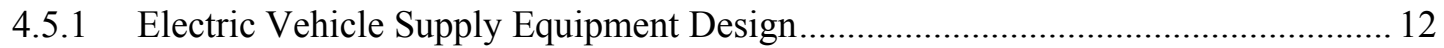

4.5.2 Electric Vehicle Supply Equipment Stations ........................................................ 15

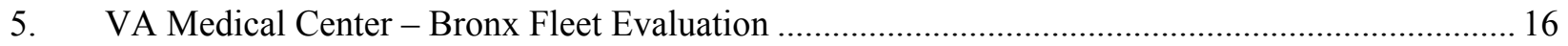

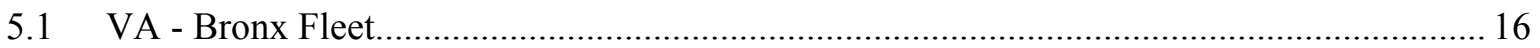

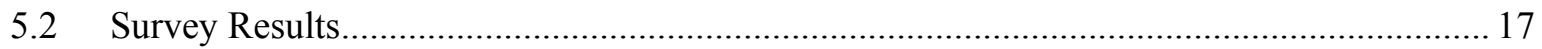

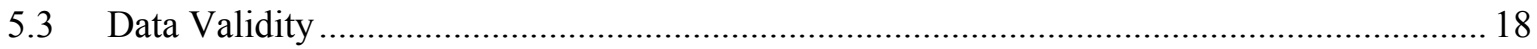




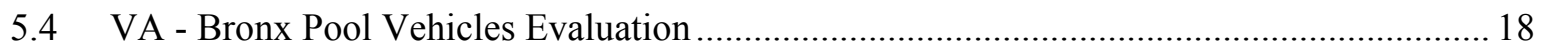

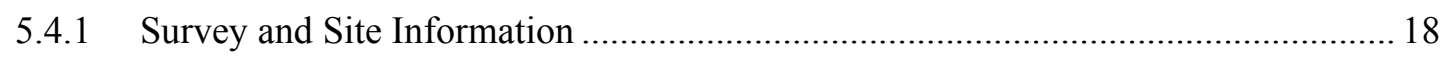

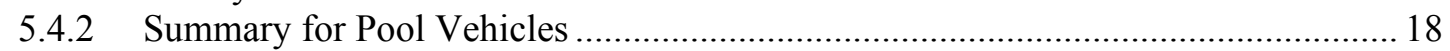

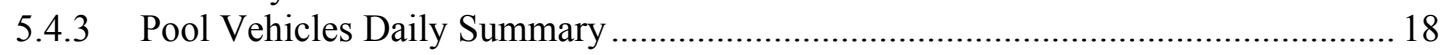

5.4.4 VA - Bronx Pool Vehicle Observations/Summary ................................................ 21

5.4.5 VA - Bronx Pool Vehicle Charging Needs ................................................................... 22

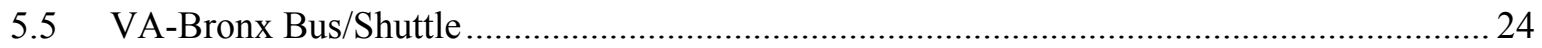

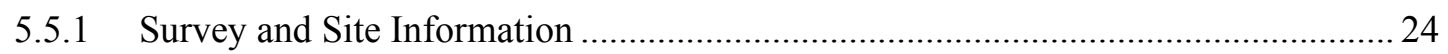

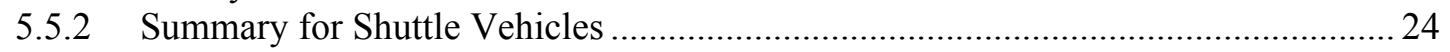

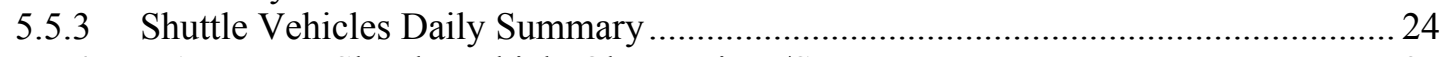

5.5.4 VA - Bronx Shuttle Vehicle Observations/Summary ............................................. 27

5.6 Balance of Fleet Vehicles ......................................................................................... 27

\section{GREENHOUSE GAS EMISSIONS AVOIDED AND FUEL COST REDUCTION}

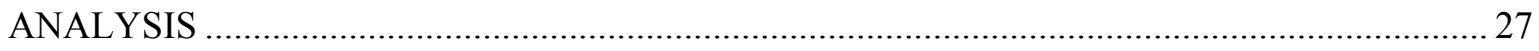

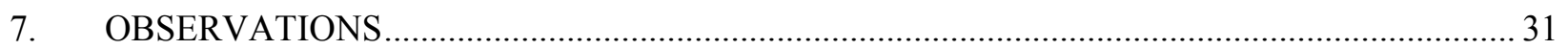

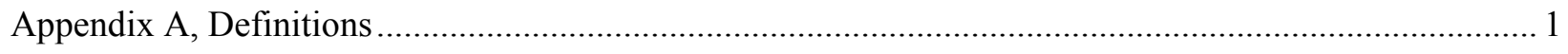

Appendix B, VA - Bronx Vehicle Data Sheets.................................................................................... 1

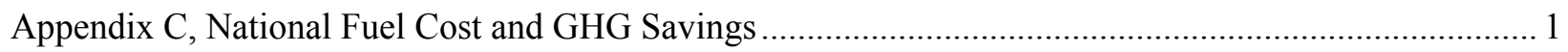

\section{FIGURES}

1. VA - Bronx facilities graphical representation .............................................................. 2

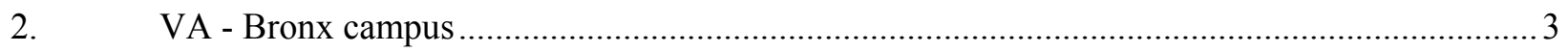

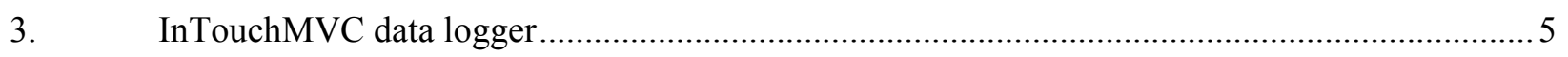

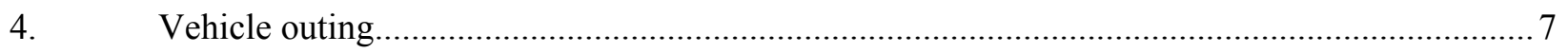

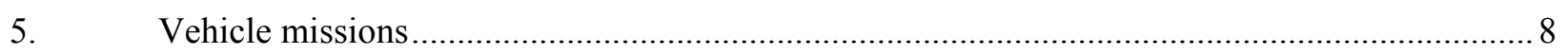

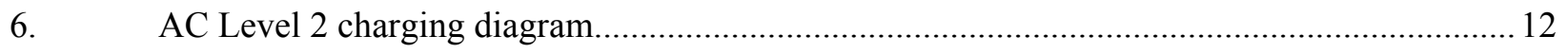

7. Society of Automotive Engineers charging configurations and ratings terminology ................ 13

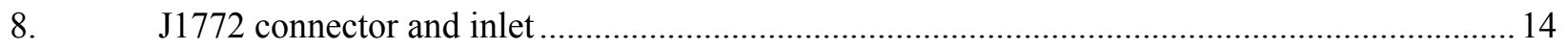

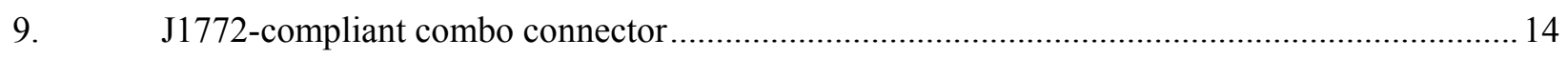

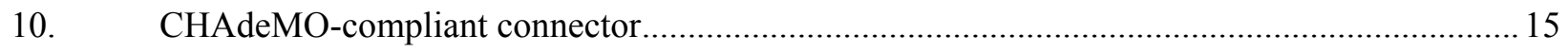




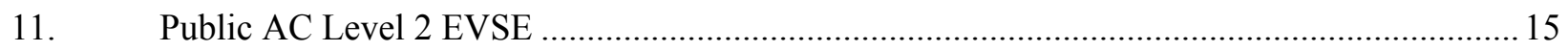

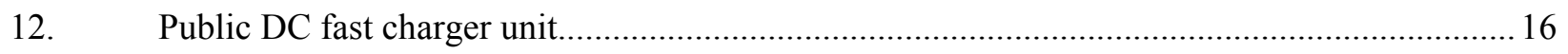

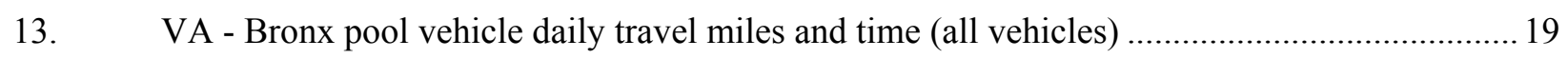

14. VA - Bronx pool vehicle daily travel history (all vehicles) .................................................. 19

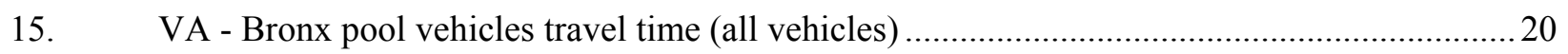

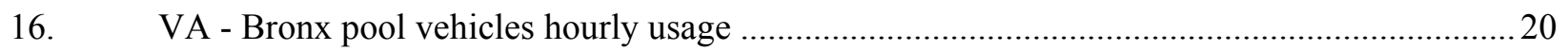

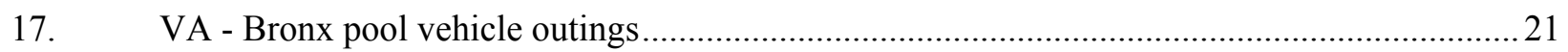

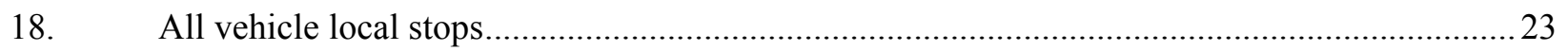

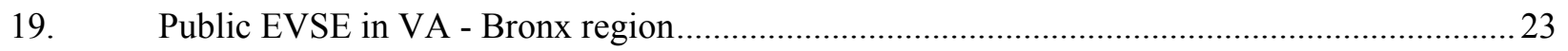

20. VA - Bronx shuttle vehicle daily travel miles and time (all vehicles) ...................................22

21. VA - Bronx shuttle vehicle daily travel history (all vehicles) ................................................25

22. VA - Bronx shuttle vehicles travel time (all vehicles) .........................................................25

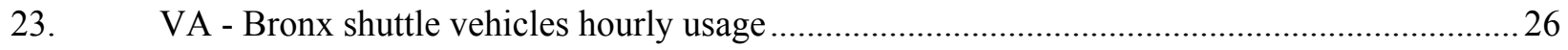

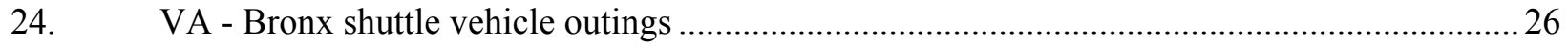

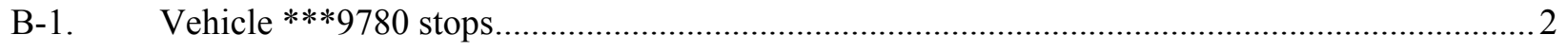

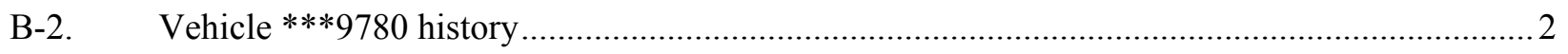

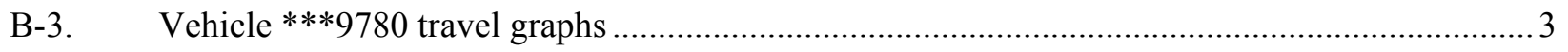

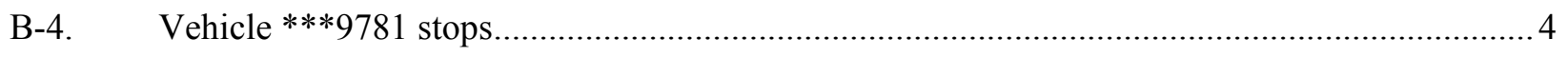

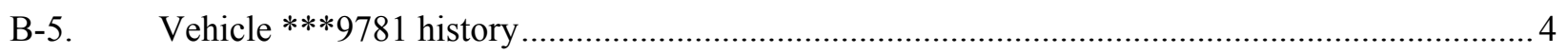

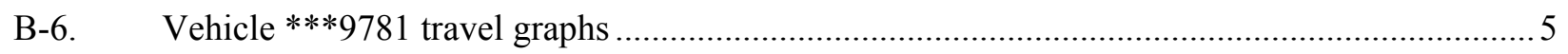

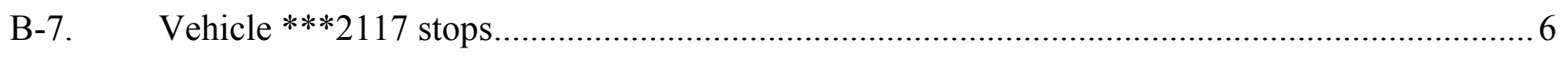

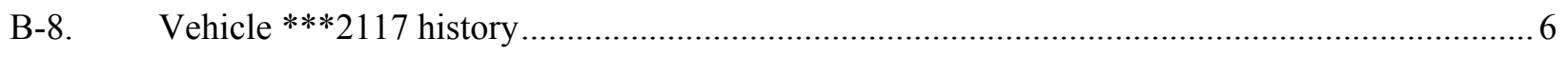

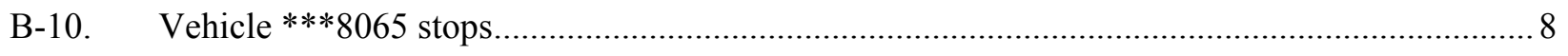

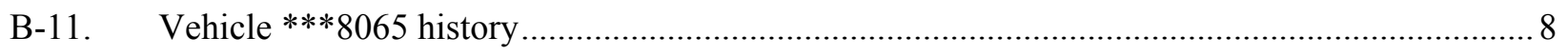

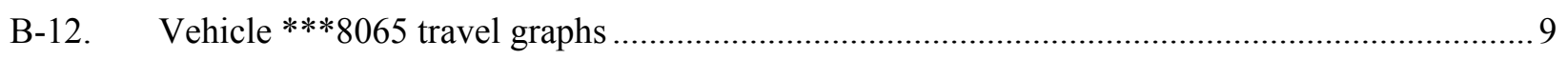

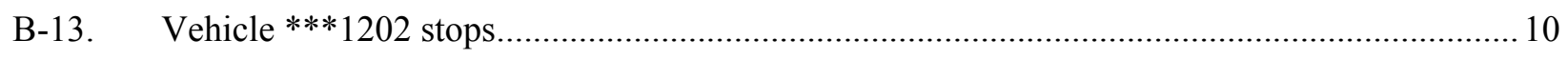




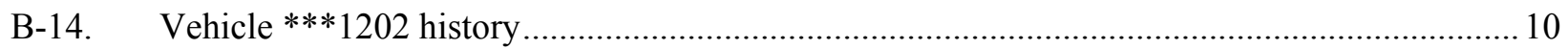

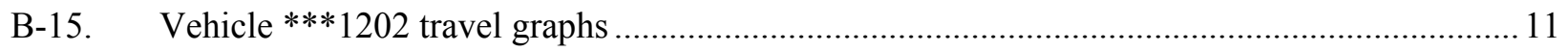

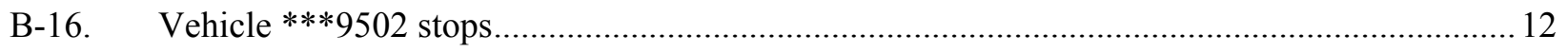

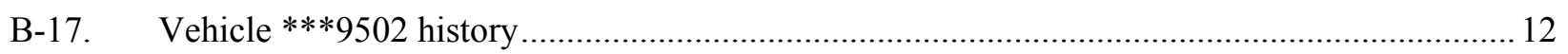

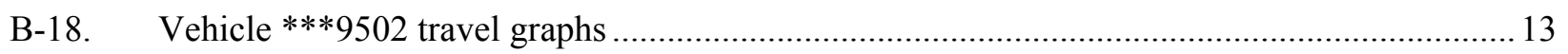

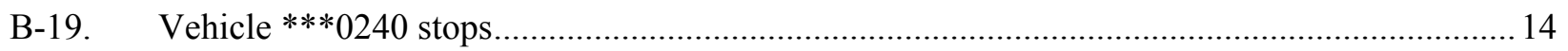

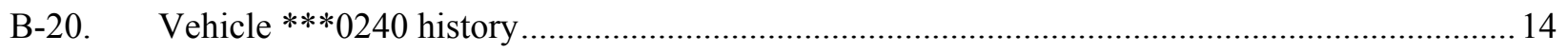

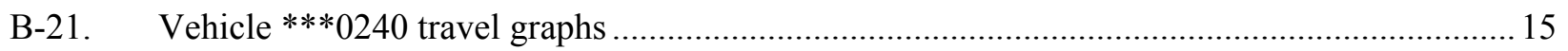

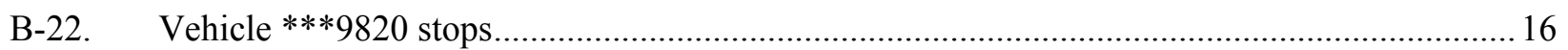

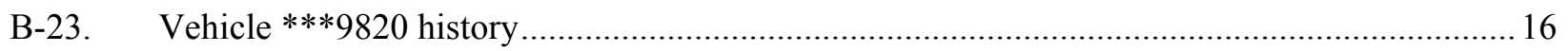

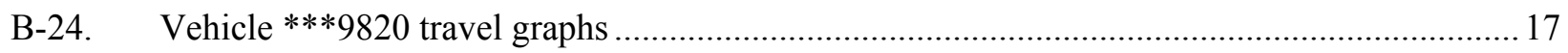

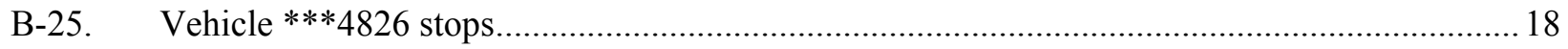

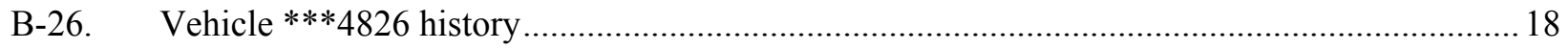

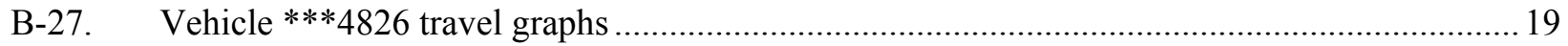

\section{TABLES}

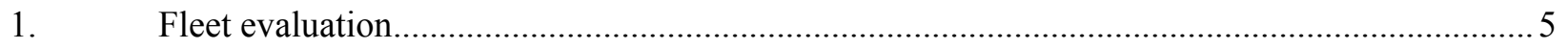

2. General Services Administration vehicle replacement requirements ...................................... 8

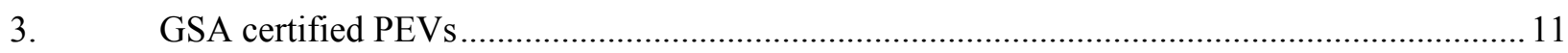

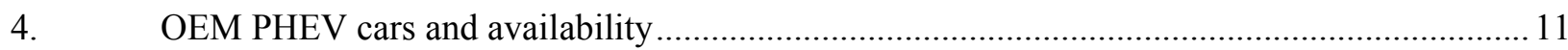

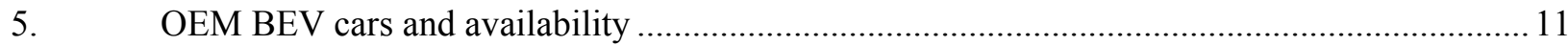

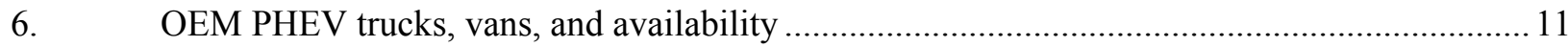

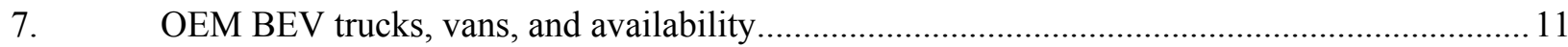

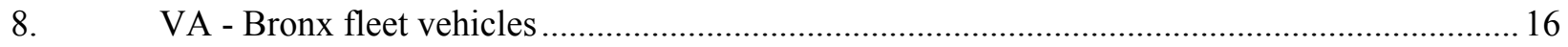

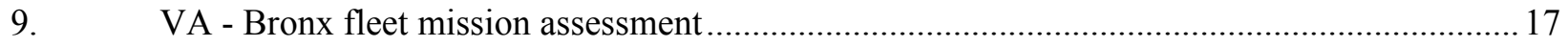

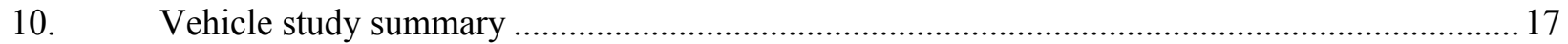




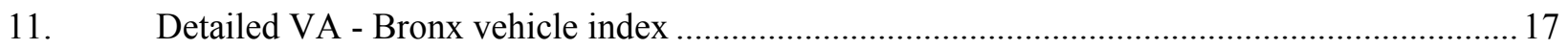

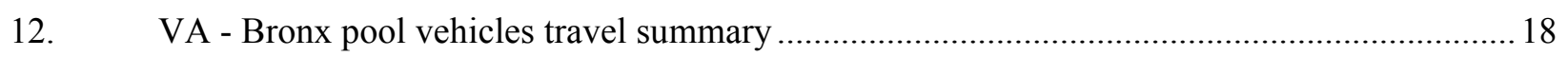

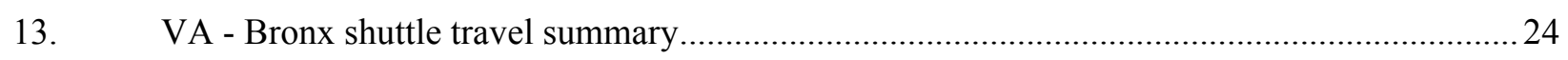

14. U.S. EPA fuel economy ratings of current fleet vehicles ......................................................2 28

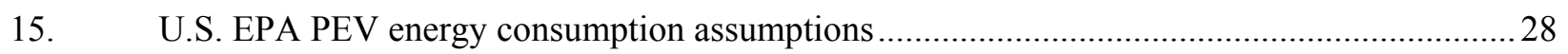

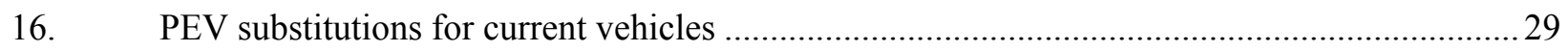

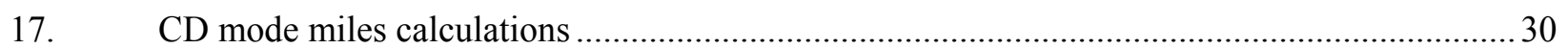

18. GHG emissions avoidance and fuel cost reduction analysis summary..................................... 31

19. Extrapolated greenhouse gas emissions avoided and fuel cost savings for the entire fleet ........31

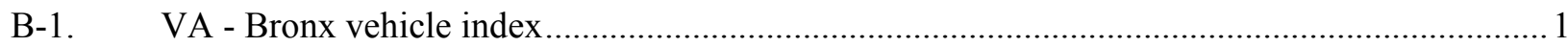

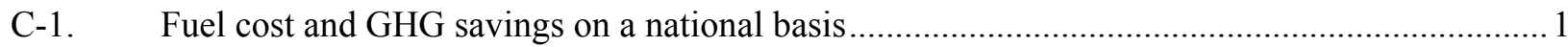

C-2. Extrapolated GHG emissions avoided and fuel cost savings for the entire fleet........................ 1 


\section{ACRONYMS}

AC alternating current

BEV battery electric vehicle

CD charge depleting

CS charge sustaining

DC direct current

EPA U.S. Environmental Protection Agency

EVSE electric vehicle supply equipment

GHG greenhouse gas emissions

GSA General Services Administration

ICE internal combustion engine

Intertek Intertek Testing Services, North America

OEM original equipment manufacturers

PEV plug-in electric vehicle (includes BEVs and PHEVs, but not hybrid electric vehicles)

PHEV plug-in hybrid electric vehicle

SAE Society of Automotive Engineers

SUV sport utility vehicle

VIN vehicle identification number 


\section{INTRODUCTION}

Federal agencies are mandated by the Energy Policy Act of $1992,{ }^{2}$ Energy Policy Act of $2005,{ }^{3}$ Executive Order 13423 (President Bush 2007), ${ }^{4}$ Executive Order 13514 (President Obama), ${ }^{5}$ and the Energy Independence and Security Act of $2007^{6}$ to purchase alternative-fuel vehicles, increase consumption of alternative fuels, reduce petroleum consumption, and reduce greenhouse gas (GHG) emissions.

Battelle Energy Alliance, LLC, managing and operating contractor for Idaho National Laboratory, is the lead laboratory for the U.S. Department of Energy's advanced vehicle testing and manages the Advanced Vehicle Testing Activity Federal Fleet Vehicle Data Logging and Characterization Study, which promotes utilization of advanced electric drive vehicle transportation technologies. The Advanced Vehicle Testing Activity focuses its testing activities on emerging and newly commercialized plug-in electric vehicle (PEV) technologies, because of the high-energy efficiencies and reduced consumption of petroleum through use of electric-drive vehicles. Battelle Energy Alliance, LLC selected Intertek Testing Services, North America (Intertek) to collect data on federal fleet operations and report the findings on vehicle and mission characterizations to support successful introduction of PEVs into federal fleets.

It is likely that more fuel efficient internal combustion engine (ICE) vehicles, including hybrid electric vehicles, exist that may provide improvements for the current fleet; however, they are not the focus of this study.

Because of the large number of vehicles in federal fleets in the United States, these fleets provide a substantial opportunity for the introduction of battery electric vehicles (BEVs) and plug-in hybrid electric vehicles (PHEVs) (collectively referred to as PEVs). However, to assess the scale of this opportunity, additional data are required to characterize the various missions performed by each fleet and to determine which existing vehicles are most suitable for replacement by a PEV.

The James J. Peters VA Medical Center (VA - Bronx) located in Bronx, New York is a part of the U.S. Department of Veterans Affairs. It is a tertiary care facility classified as a Clinical Referral Level 1 Facility. It is a teaching hospital that provides a full range of patient care services, with state-of-the-art technology and education and research. The VA-Bronx center is a modern, full-service medical facility, comprised of a 311-bed hospital and a 120-bed extended care facility. The medical center offers an integrated team approach to inpatient and outpatient care. The services available cover a wide range of acute medical, surgical, psychiatric, and rehabilitative services, as well as specialty practices in virtually every medical discipline. ${ }^{7}$ In 2012, the center employed approximately 1,700 full time medical care employee equivalents and served a catchment area with approximately 1.6 million veterans. ${ }^{8}$

VA - Bronx is an excellent site for fleet evaluation because of its size, location, and travel between this site and other local destinations (Figures 1 and 2). VA - Bronx has an opportunity to be a leader in the

\footnotetext{
${ }^{2}$ http://thomas.loc.gov/cgi-bin/query/z?c102:h.r.776.enr [accessed January 10, 2014].

${ }^{3}$ http://www.gpo.gov/fdsys/pkg/BILLS-109hr6enr/pdf/BILLS-109hr6enr.pdf [accessed January 10, 2014].

${ }^{4}$ http://www.gsa.gov/portal/content/102452 [accessed January 10, 2014].

${ }^{5}$ https://www.fedcenter.gov/programs/eo13514/ [accessed September 1, 2014].

${ }^{6} \mathrm{http} / /$ www.gpo.gov/fdsys/pkg/PLAW-110publ140/pdf/PLAW-110publ140.pdf [accessed January 10, 2014].

${ }^{7}$ http://www.bronx.va.gov/docs/BronxPtHandbook.pdf [accessed October 11, 2014].

${ }^{8}$ http://www.va.gov/oig/pubs/VAOIG-11-04566-163.pdf [accessed October 11, 2014].
} 
adoption of BEVs and PHEVs for its fleet. In addition, electric vehicle charging stations that may be installed at VA - Bronx may be generally available for use by employees and visitors.

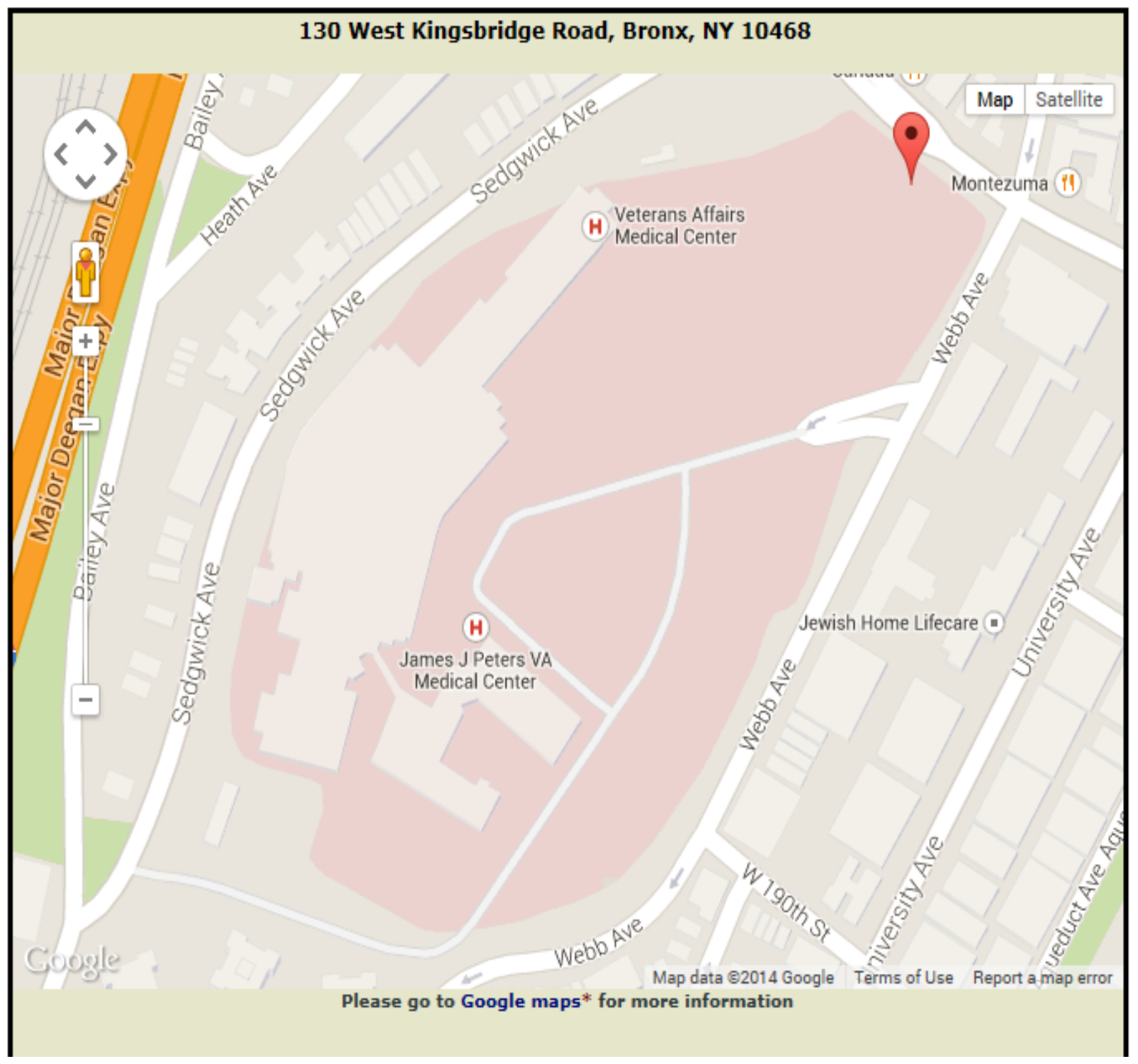

Figure 1. VA - Bronx facilities graphical representation. ${ }^{9}$

\footnotetext{
${ }^{9}$ http://www2.va.gov/directory/guide/viewmap.cfm?mapID=3\&id=205 [accessed October 5, 2014].
} 


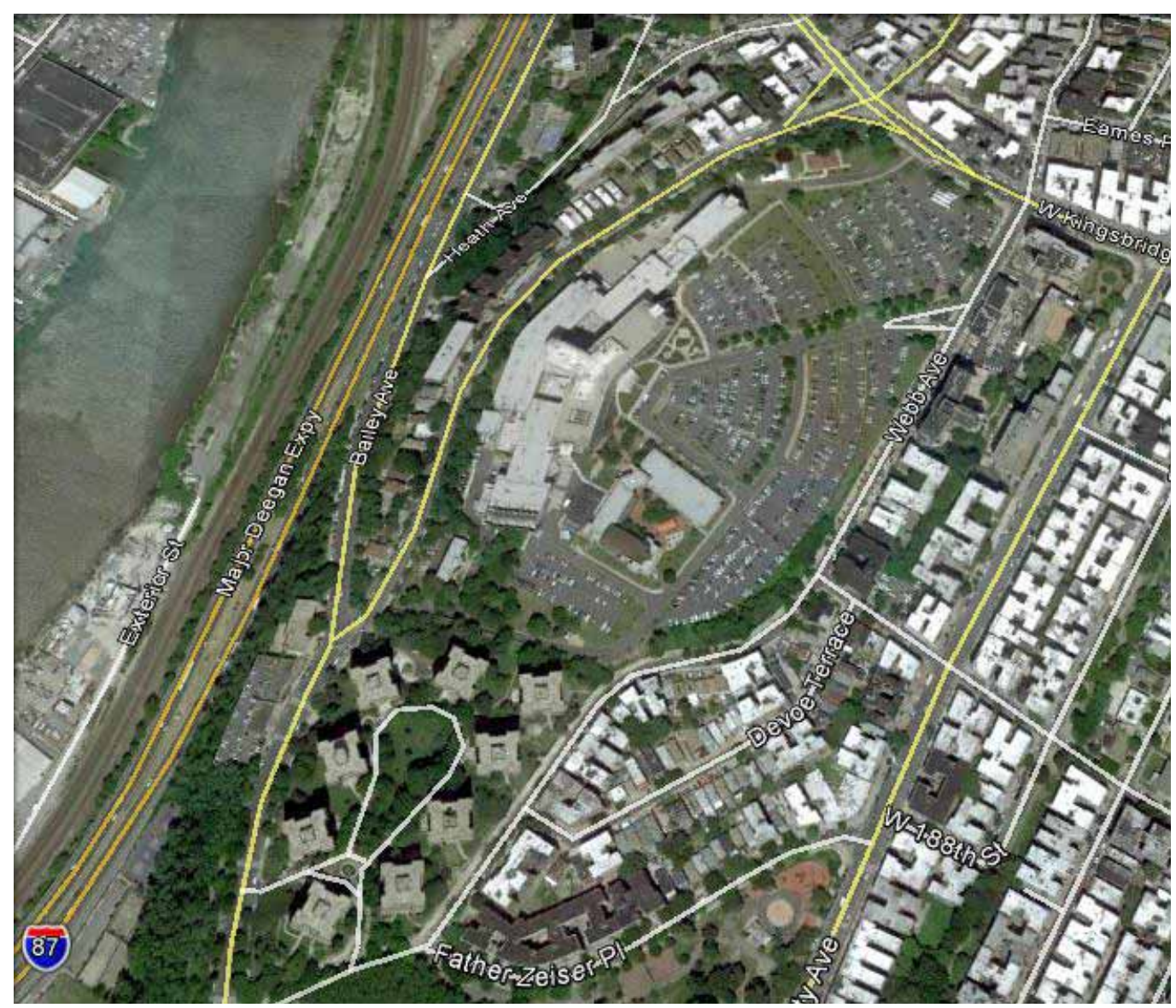

Figure 2. VA - Bronx campus. ${ }^{10}$

\section{PROJECT OBJECTIVE}

This study explores federal fleet vehicles and their usage characteristics, with a primary goal of supporting the goals of Presidential Executive Order 13514, which includes the following:

- Pursuing opportunities with vendors and contractors to address and incentivize GHG emission reductions and petroleum use reductions

- Implementing strategies and accommodations for transit, travel, training, and conferences that actively reduce carbon emissions associated with commuting and travel by agency staff

- Meeting GHG emissions reductions associated with other federal government sustainability goals

- Implementing innovative policies and practices that address agency-specific Scope 3 GHG emissions. ${ }^{11}$

Because of the large number of vehicles in the federal fleets, there is a substantial opportunity for PHEV and BEV adoption. Federal fleets offer an opportunity as a first market replacement for alternative fuels due to their scale, refueling patterns, and regular vehicle turnover. ${ }^{12}$

\footnotetext{
${ }^{10}$ Google earth [accessed October 2, 2014].

${ }^{11} \mathrm{http}: / /$ energy.gov/sites/prod/files/2013/10/f3/eo13514.pdf [accessed February 5, 2014].
} 
This project has the following four defined tasks:

1. Data collection: Coordinate with the fleet manager to collect data on agency fleet vehicles. This includes collecting information on the fleet vehicle and installing data loggers on a representative sample of the fleet vehicles to characterize their missions.

2. Data analysis and review: Examine the data collected by the loggers and fleet vehicle characteristics to describe typical fleet activity. Incorporate fleet manager's input on introducing PEVs to the agency's fleet.

3. PEV implementation feedback: Provide feedback to fleet personnel and Battelle Energy Alliance, LLC on the selection criteria for replacement PEVs in their specific fleet vehicle missions.

4. Observations and recommendations: Provide actionable information to introduce PEVs into agency fleet operations and assess any related impacts for the facility.

Data collected from vehicles include trip distance, idle time, time between uses, and stop locations. Data collection continues for 30 to 60 days using a non-intrusive data logger, which gathers and transmits information using global positioning satellites and cellular service. The loggers collect data at 1-minute intervals and transmit when an active signal is present.

Extrapolating the results of this analysis to the larger fleet provides estimates of potential savings in gasoline consumption and GHG emissions. This report also provides recommendations relating to fleet management of BEVs and PHEVs for additional consideration.

Fleet managers may use the information supplied in this report to help them identify which vehicles are candidates for replacement by BEVs or PHEVs based on their use. BEVs are preferred because of the greater potential reduction of GHG emissions, fuel cost and petroleum usage, but they are not likely to be suitable for all vehicle missions.

The information in this report supports a final report to Battelle Energy Alliance, LLC/Idaho National Laboratory and the U.S. Department of Energy. The aggregated results for all agencies' fleets will provide an overview of federal fleets, vehicle missions, vehicle uses, and agencies' needs to plan and establish a more systematic method for the adoption of BEVs and PHEVs.

\section{METHODS}

\subsection{Fleet Vehicle Survey}

Agency fleet managers selected fleet vehicles for this study and provided basic information for each vehicle, including its managing agency, home base for the vehicle, contact information, primary vehicle mission, vehicle ownership, fuel type, and odometer reading.

VA - Bronx identified 50 fleet vehicles in their fleet, with vehicle missions provided by VA (Table 1). (Note that Section 4 provides descriptions of the vehicle mission types.) Intertek coordinated with the VA - Bronx fleet manager to identify the specific vehicles for data collection for inclusion in the study. The fleet manager assessed their wide range of vehicles and made selections of high-interest, representative vehicles based on vehicle missions and vehicle type/class. Selection also favored vehicles used at least twice a week. Because data loggers rely on the vehicle's battery power, non-use of the vehicle can result in the vehicle having a depleted battery. Intertek received no reports of depleted batteries during the study at VA - Bronx.

\footnotetext{
${ }^{12}$ Fleet Purchase Behavior: Decision Processes and Implications for New Vehicle Technologies and Fuel, Nesbitt, Sperling, University of California, Davis 2001.
} 
Table 1. Fleet evaluation.

\begin{tabular}{cccc}
\hline Vehicle Mission & Study Vehicles & $\begin{array}{c}\text { Total Fleet } \\
\text { Reported }\end{array}$ & $\begin{array}{c}\text { Percentage } \\
\text { Studied }\end{array}$ \\
\hline Pool Vehicles & 6 & 23 & $26 \%$ \\
Support Vehicles & & 2 & \\
Enforcement Vehicles & & 5 & \\
Transport & & 3 & \\
Specialty Vehicles & 3 & 5 & \\
Bus & 9 & 12 & $25 \%$ \\
Total Fleet Vehicles & 9 & 50 & $18 \%$ \\
\hline
\end{tabular}

\subsection{Data Collection}

Individual privacy concerns exist when monitoring vehicle movement with data loggers. Data collection occurs by vehicle identification as identified by Intertek, data logger number, and vehicle identification number (VIN) or agency-assigned vehicle number. Intertek receives no information related to the vehicle operator and provides no raw data to the fleet managers. In this manner, Intertek does not collect, analyze, or report on individual driving habits.

\subsubsection{Data Logger}

Non-intrusive data loggers, produced by InTouchMVC ${ }^{13}$ and depicted in Figure 3, were inserted into the vehicle's onboard diagnostic port to collect and transmit the relevant data. Installation of the data logger and the manual recording of information about the vehicle that ties the logger and vehicle together in the data, typically takes less than 5 minutes. Once installed and activated (during vehicle use), the data loggers collect vehicle information once every minute during vehicle operation and transmit by cellular communication to the data center.

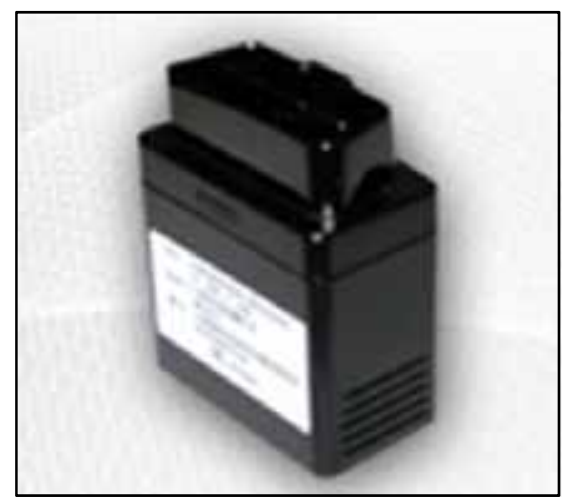

Figure 3. InTouchMVC data logger.

Intertek maintains the data logger's connectivity and verifies data transmission weekly. Missing data (reported as "null" values) are frequently the result of lost global positioning system reception, logger device removal, or extended periods in regions with insufficient cellular reception. Intertek filters the vehicle and data logger information if these null values present a significant impact on the data collected and no resolution is possible. This report also identifies the statistics on this validation process.

\footnotetext{
${ }^{13}$ www.intouchmvc.com [accessed January 10, 2014].
} 
VA - Bronx requested and installed ten data loggers into the selected fleet vehicles. The agency removed and shipped the data loggers to Intertek at the conclusion of the data collection period.

\subsubsection{Data Captured}

Data consist of key-on events, key-off events, and position updates logged every minute while the vehicle is keyed-on. InTouchMVC converted these data points into records of trip events, stop events, and idle events.

From these data points, the following information was available for evaluation:

- Trip start and stop time and location

- Trip distance and duration

- Idle start time, location, and duration

- Stop start time, location, and duration.

\subsection{Data Analysis}

\subsubsection{Definitions}

Figure 4Figure illustrates a vehicle outing, which is comprised of trips, stops, and idle events, that may occur during one day or over several days. The following list provides a definition of these terms:

1. Outing: An outing is the combination of trips and stops that begin at the home base and includes all travel until the vehicle returns home.

2. Trip: A trip begins with a key-on event and ends with the next key-off event.

3. Vehicle stop: A vehicle stop includes a key-off/key-on event pair.

4. Idle time: Idle time is the amount of time a vehicle spends stationary after a key-on event when the vehicle is not moving for a period of 3 minutes or longer.

5. Trip travel time: Trip travel time is the amount of time required to complete a trip, excluding stops, but including idle time.

Definitions of additional analysis and survey terms are as follows:

1. Operating shift: Fleet manager-defined period worked.

2. Study days: Days during which the data loggers are connected.

3. Vehicle days: Study days during which a vehicle is used.

4. Null values: Data record unusable for analysis for various reasons.

\subsubsection{Data Evaluation}

Processing the data involves removal of null values and aggregation by different spatial and temporal scales. Aggregation was by day, by trip, and by outing to produce figures showing the patterns of use. Aggregation by vehicle mission followed to characterize use for the agency fleet. Section 5 presents these results. Data were extrapolated to provide the overall fleet usage and benefit analysis when fleet information was provided. Section 6 presents these benefits. Intertek observations are included in Section 7.

Statistical data analysis uses Microsoft ${ }^{\circledR}$ Excel and Tableau ${ }^{\circledR}$ software. Frequency distributions summarize travel behavior of each vehicle and vehicle mission during the study period. Rounding of the tables and figures are to three significant digits. 


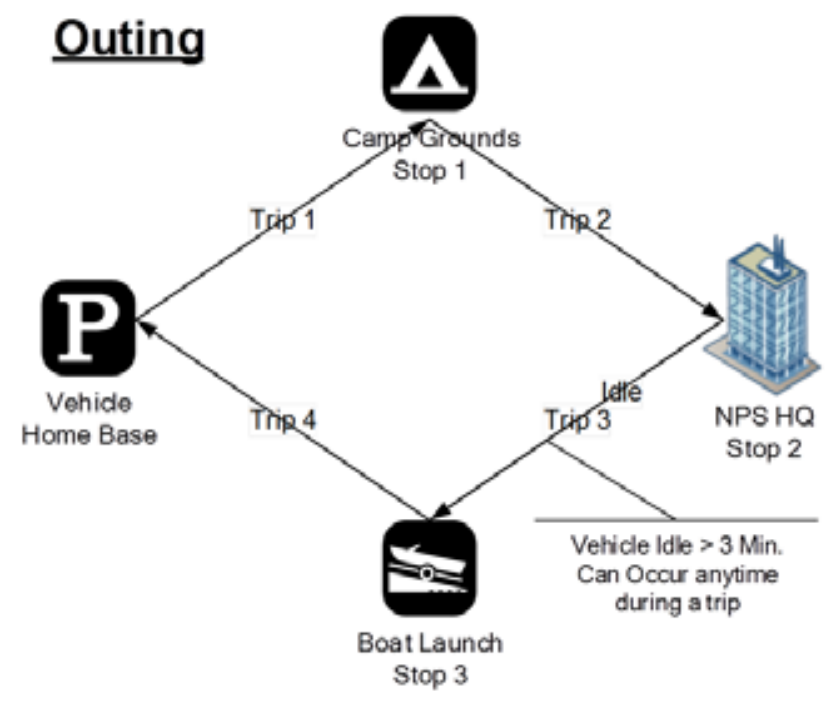

Figure 4. Vehicle outing.

\section{VEHICLES}

\subsection{Vehicle Missions}

The vehicle mission is an important characteristic in the fleet study. Information used to define the vehicle mission includes the vehicle's configuration, vehicle use, classification per 40 CFR Part 600.31582 and the Environmental Protection Agency (EPA), the participating agency use, and generally assumed vehicle use. Based on fleet information gathered, Intertek has established the following seven mission/vehicle categories for analysis (Figure 5):

1. Pool vehicles: A pool vehicle is any automobile (other than the low-speed vehicles identified below) manufactured primarily for use in passenger transportation, with not more than 10 passengers.

2. Enforcement vehicles: Vehicles specifically approved in an agency's appropriation act for use in apprehension, surveillance, police, or other law enforcement work. This category also includes site security vehicles, parking enforcement, and general use, but the vehicles are capable of requirements to support enforcement activities. Appendix A provides further definition.

3. Support vehicles: Vehicles assigned to a specific work function or group to support the mission of that group. Vehicles are generally passenger vehicles or light-duty pickup trucks and may contain after-market modifications to support the mission.

4. Transport vehicles: Light, medium, or heavy-duty trucks used to transport an operator and tools or equipment of a non-specific design or nature. The vehicle's uses include repair, maintenance, or delivery.

5. Specialty vehicles: Vehicles designed to accommodate a specific purpose or mission (such as ambulances, mobile cranes, and handicap controls).

6. Shuttles/buses: Vehicles designed to carry more than 12 passengers and further outlined in 49 CFR 532.2.

7. Low-speed vehicle: Vehicles that are legally limited to roads with posted speed limits up to $45 \mathrm{mph}$ and that have a limited load-carrying capability. 


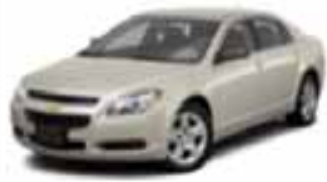

Pool Vehicle

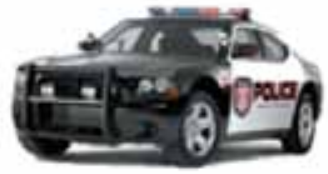

Enforcement Vehicle

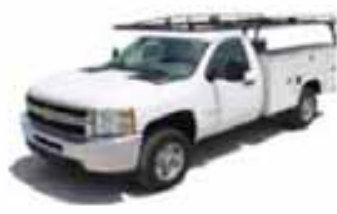

Support Vehicle

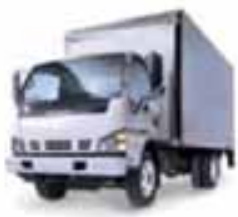

Transport Vehicle

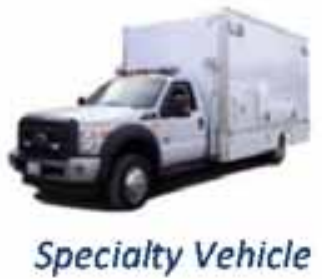

Specialty Vehicle

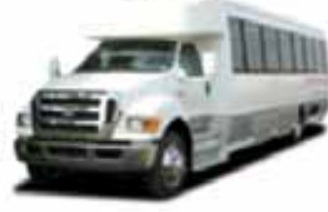

Shuttle / Bus

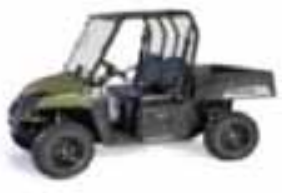

Low Speed

Vehicles

Figure 5. Vehicle missions.

\subsection{Alternative Fuel Vehicles}

As the operating agency, VA - Bronx has a unique opportunity to plan for the adoption of BEVs and PHEVs, along with planning for the supporting infrastructure. The adoption of PHEVs and BEVs is a primary goal of the General Services Administration (GSA) and supports the directives previously referenced.

As GSA increases its certification of PHEVs and BEVs, agencies can plan for vehicle replacement through GSA for passenger vehicles and trucks. Table 2 presents the replacement requirements for fleet vehicles. Note that both the age and mileage requirements need to be met in order for the vehicle to qualify for replacement, except where noted as "or."

Table 2. General Services Administration vehicle replacement requirements.

\begin{tabular}{cccc}
\hline & GSA Vehicle Replacement Requirements & \\
& Fuel Type & Years & Miles \\
\hline Passenger vehicles & Gasoline or & 3 & 36,000 \\
& Alternative Fuel & 4 & 24,000 \\
& Vehicle & 5 & Any mileage \\
& & Any age & 75,000 \\
Hight trucks 4 x 2 & Howid & 5 & Any miles \\
& Non-Diesel & 6 & Any miles \\
& Diesel & 7 & 65,000 \\
Light trucks 4 x 4 & Hybrid & 8 or & 150,000 \\
& Non-Diesel & 7 & Any mileage \\
& Diesel & 7 or & 60,000 \\
& Hybrid & 8 or & 150,000 \\
& & 7 & Any mileage \\
\hline
\end{tabular}

${ }^{14}$ http://www.gsa.gov/graphics/fas/VehicleReplacementStandardsJune2011Redux.pdf [accessed January 10, 2014]. 


\subsection{Battery Electric Vehicle and Plug-In Hybrid Electric Vehicle Benefits/Challenges}

BEVs are fully powered by the battery energy storage system available onboard the vehicle. The Nissan Leaf is an example of a BEV. Because the BEV has no other energy source for propulsion, the range, power requirements, and mission of the needed vehicle factor greatly in purchasing decisions. Maximizing BEV capabilities typically requires batteries more than an order of magnitude larger in capacity than the batteries in hybrid electric vehicles.

PHEVs obtain their power from at least two energy sources. The typical PHEV configuration uses a battery and an ICE, powered by either gasoline or diesel. PHEV designs differ between manufacturers. All have a charge-depleting (CD) mode, in which the battery is depleted of its stored energy to propel the vehicle, and a charge-sustaining (CS) mode (or extended range mode), which is entered after CD mode is complete and where the battery and the ICE work together to provide propulsion, while the state of charge of the battery is maintained between set limits. Some PHEVs' operation in CD modes is purely electric, while others employ the engine to supplement battery power during the initial battery depletion to a set state of charge (usually below 50\%).

\subsubsection{Battery Electric Vehicle Benefits/Challenges}

EPA identifies the following benefits of BEVs: ${ }^{15}$

- Energy efficient: Electric vehicles convert about 59 to $62 \%$ of the electrical energy from the grid to power at the wheels, whereas conventional gasoline vehicles only convert about 17 to $21 \%$ of the energy stored in gasoline to power at the wheels.

- Environmentally friendly: PEVs emit no tailpipe pollutants, although the power plant producing the electricity may emit them. Electricity from nuclear, hydro, solar, or wind-powered plants causes no air pollutants.

- Performance benefits: Electric motors provide quiet, smooth operation and exhibit maximum torque at zero and low speeds, while also requiring less maintenance than ICEs.

- Reduce energy dependence: Electricity is a domestic energy source.

The EPA also identifies challenges associated with BEVs, including the following:

- Driving range: Most BEVs can only travel about 100 to 200 miles (or less) before recharging, whereas gasoline vehicles can often travel over 300 miles before refueling and some much further.

- Recharge time: Fully recharging the battery pack can take 4 to 8 hours. With a high-power direct current (DC) fast charger, restoration from a depleted state to $80 \%$ capacity can take approximately 30 minutes.

- Battery cost: The large battery packs are expensive and may need to be replaced one or more times.

- Bulk and weight: Battery packs are heavy and take up considerable vehicle space.

\subsubsection{Plug-in Hybrid Electric Vehicle Benefits/Challenges}

EPA identifies the following benefits of PHEVs: ${ }^{16}$

\footnotetext{
${ }^{15}$ http://www.fueleconomy.gov/feg/evtech.shtml [accessed December 27, 2013].

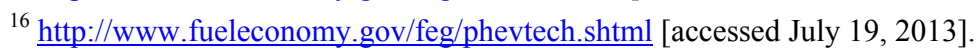


- Less petroleum use: PHEVs are expected to use about 40 to $60 \%$ less petroleum than conventional vehicles. Because electricity is produced primarily from domestic resources, PHEVs reduce dependence on oil.

- Fewer emissions: PHEVs are expected to emit fewer GHG emissions than conventional vehicles; however, as with BEVs, the difference depends largely on the type of power plant supplying the electricity.

- Higher vehicle costs, lower fuel costs: PHEVs will likely cost $\$ 1,000$ to $\$ 7,000$ more than comparable non-PHEVs. Fuel will cost less because electricity is much cheaper than gasoline, but the fuel savings depends on how much of the driving is done on the off-board electrical energy.

- Recharging takes time: Recharging the battery typically takes several hours. However, PHEVs do not have to be plugged in to be driven. They can be fueled solely with gasoline, but will not achieve maximum range, fuel economy, or fuel savings without charging.

- Measuring fuel economy: Because a PHEV can operate on electricity alone, gasoline alone, or a mixture of the two, EPA provides a fuel economy estimate for gasoline-only operation (CS mode), electric-only operation (all-electric CD mode), or combined gasoline and electric operation (blended CD mode).

In most cases, the PEV retail cost is higher than a non-PEV model. This incremental purchase cost may be a fleet budget challenge; however, many original equipment manufacturers (OEMs) have offered incentives to encourage the use and adoption of BEVs and PHEVs. Some OEMs have recently reduced the vehicle cost, while also increasing vehicle range. Additionally, federal and state incentives have increased the attractiveness of purchasing a PEV. A common assumption is that increasing PEV sales will result in a reduction in this incremental purchase cost and a positive feedback loop will ensue.

\subsection{Plug-In Electric Vehicle Availability}

GSA provides a summary of light and medium-duty passenger vehicles available for lease or purchase through the GSA portal, ${ }^{17}$ although not all BEVs and PHEVs currently on the market are 'certified' to be GSA replacements. Vehicles not on the GSA list of 'certified' vehicles require an agency to self-certify a functional need or provide alternative measures for exemptions. Table 3 summarizes the vehicles that may be suitable replacements and are certified replacements through GSA. Note that the "CD/CS" column provides the EPA fuel economy values for CD and CS modes. The fuel economy of CD mode is provided in units of miles-per-gallon-of-gasoline-equivalent (MPGe). This metric allows for the electricity consumption during CD mode to be compared with fuel consumption during CS mode (or against conventional vehicles). The Nissan Leaf and Mitsubishi i-MiEV are not included in the alternative fuel guide for 2014, but they have appeared in previous guides.

Replacement is dependent on vehicle configuration characteristics and the vehicle mission. Further evaluation related to vehicle purpose and mission follows in Section 5.

Tables 4 through 7 provide summaries of PHEVs and BEVs either currently available or near commercialization in both passenger cars and pickup trucks, but do not appear on the GSA 'certified' vehicle list. These vehicles may qualify for use by the agency through demonstrating a functional need.

Note that EPA differs in vehicle class. EPA identifies the Volt as a compact, the C_MAX Energi as a midsize, the Fusion Energi as a midsize, and the Focus as a compact. ${ }^{18}$

\footnotetext{
${ }^{17}$ http://www.gsa.gov/portal/content/104224 [accessed March 6, 2014].

${ }^{18} \mathrm{http}: / /$ www.fueleconomy.gov/feg/Find.do?action=sbs\&id=34130 [accessed August 1, 2014].
} 
Table 3. GSA certified PEVs.

\begin{tabular}{lcccc}
\multicolumn{1}{c}{ Make/Model } & GSA Class & Type & CD/CS & GSA Incremental Price \\
\hline Chevrolet Volt & Sedan, Subcompact & PHEV & $98 \mathrm{MPGe} / 37 \mathrm{mpg}$ & $\$ 17,087.18$ \\
Ford C-MAX Energi & Sedan, Subcompact & PHEV & $100 \mathrm{MPGe} / 38 \mathrm{mpg}$ & $\$ 14,899.52$ \\
Ford Focus Electric & Sedan, Subcompact & BEV & $110 \mathrm{MPGe} / 99 \mathrm{mpg}$ & $\$ 16,573.09$ \\
Ford Fusion Energi & Sedan, Compact & PHEV & $100 \mathrm{MPGe} / 38 \mathrm{mpg}$ & $\$ 19,289.99$ \\
\hline
\end{tabular}

Table 4. OEM PHEV cars and availability.

\begin{tabular}{llc}
\multicolumn{1}{c}{ Make } & \multicolumn{1}{c}{ Model } & Model Year \\
\hline Audi & A3 eTron PHEV & 2015 (estimate) \\
Chevrolet & Volt & 2011 \\
Honda & Accord PHEV & 2014 \\
Toyota & Prius PHEV & 2012 \\
Volvo & V60 Plug-in & 2016 (estimate) \\
BMW & i3 with range extender & 2014 \\
\hline
\end{tabular}

Table 5. OEM BEV cars and availability.

\begin{tabular}{llc}
\multicolumn{1}{c}{ Make } & \multicolumn{1}{c}{ Model } & Model Year \\
\hline BMW & i3 & 2014 \\
Chevrolet & Spark EV & 2014 \\
Fiat & 500e & 2013(California only) \\
Ford & Focus Electric & 2012 \\
Honda & Fit EV & 2013 \\
Kia & Soul EV & 2014 (estimate) \\
Mercedes-Benz & B-Class ED & 2015 (estimate) \\
Nissan & Leaf & 2011 \\
smart & ED & 2014 \\
Tesla & Model S & 2012 \\
Tesla & Model X & 2015 (estimate) \\
Volkswagen & Golf & 2015 (estimate) \\
Volvo & C30 Electric & 2016 (estimate) \\
\hline
\end{tabular}

Table 6. OEM PHEV trucks, vans, and availability.

\begin{tabular}{llc}
\multicolumn{1}{c}{ Make } & \multicolumn{1}{c}{ Model } & Model Year \\
\hline Land Rover & Range Rover Sport & 2016 (estimate) \\
Mitsubishi & Outlander PHEV & 2015 (estimate) \\
Via & VTRUX VR300 & 2013 \\
\hline
\end{tabular}

Table 7. OEM BEV trucks, vans, and availability.

\begin{tabular}{clc} 
Make & \multicolumn{1}{c}{ Model } & Model Year \\
\hline Nissan & eNV200 & 2015 (estimate) \\
Toyota & RAV4 EV & 2013 (California only - elsewhere 2015 estimate) \\
\hline
\end{tabular}


As further indication of the expanding market for PEVs, companies are offering after-market vehicle upgrades involving the addition of plug-in capabilities to OEM vehicles. For example, Echo Automotive headquartered in Scottsdale, Arizona offers a "...low-cost, bolt-on, plug-in hybrid system that can quickly be installed on new or existing fleet vehicles to increase fuel efficiency and decrease operating costs - all without affecting the OEM power train or requiring costly infrastructure." ${ }^{, 19}$ Options such as this company's conversions might be of benefit to the VA - Bronx fleet vehicles for which no replacement PEV is currently available.

\subsection{Plug-In Electric Vehicle Charging}

Refueling electric vehicles presents some challenges and some opportunities not encountered when refueling petroleum-fueled vehicles. Recharging the battery of a PHEV follows the same methodology as that for BEVs. This section provides basic information on recharging PEVs.

\subsubsection{Electric Vehicle Supply Equipment Design}

4.5.1.1 Charging Components. Electric vehicle supply equipment (EVSE) stations deliver electric power from the utility to the applicable charge port on the vehicle. Figure 6 illustrates the primary components of a typical alternating current (AC) Level 2 EVSE unit (Figure 6).

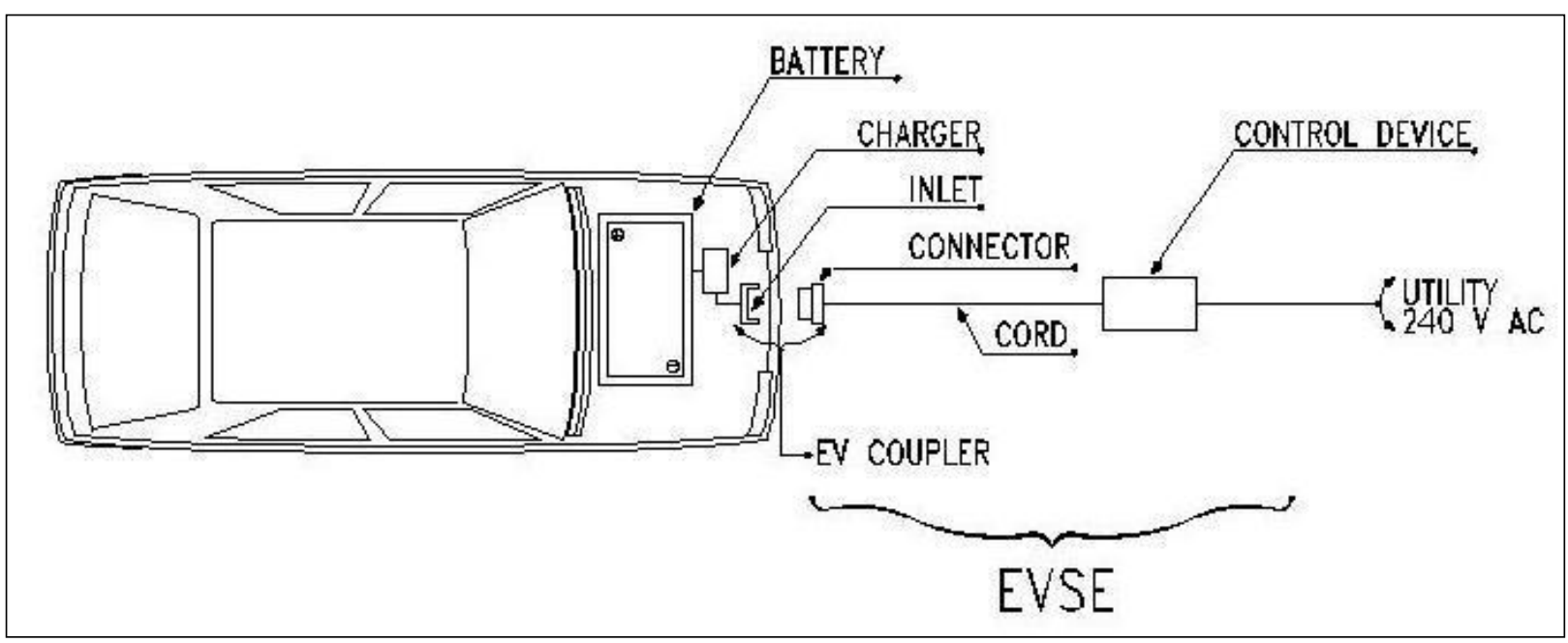

Figure 6. AC Level 2 charging diagram. ${ }^{20}$

The electric utility delivers AC current to the charging location. The conversion from AC to direct current (DC) electricity necessary for battery charging can occur either on or off board the vehicle. Section 4.5.1.2 provides further explanation of the different EVSE configurations. For onboard conversion, AC current flows through the PEV inlet to the onboard charger. The charger converts AC to the DC current required to charge the battery. A connector attached to the EVSE inserts into a PEV inlet to establish an electrical connection to the PEV for charging and information/data exchange. Off-board conversion, also known as DC charging, proceeds in a similar manner except that the AC to DC conversion occurs in a charger that is off board the vehicle and, thus, bypasses any onboard charger. For both AC and DC charging, the PEV's battery management system on board the vehicle controls the battery rate of charge, among other functions. All current PEVs have an onboard charger; some BEVs (but no PHEVs currently) accommodate DC charging.

\footnotetext{
${ }^{19} \mathrm{http}: / /$ www.echoautomotive.com/index.php?option=com_content\&view=article\&id=8 [accessed July 14, 2014].

${ }^{20} \mathrm{http}$ //www.theevproject.com/downloads/documents/Electric\%20Vehicle\%20Charging\%20Infrastructure $\% 20$ Deployment $\% 20$ Guidelines\%20for\%20the\%20Greater\%20Phoenix\%20Area\%20Ver\%203.2.pdf [accessed January 15, 2014].
} 
4.5.1.2 Charging Configurations and Ratings. The Society of Automotive Engineers standardized the requirements, configurations, and equipment followed by most PEV suppliers in the United States in the J1772 Standard. Figure 7 summarizes these attributes and the estimated recharge times. Actual recharge times depend on the onboard equipment, including the charger, battery, and battery management system.

\begin{tabular}{|c|c|c|c|}
\hline \multicolumn{4}{|c|}{ SAE Charging Configurations and Ratings Terminology } \\
\hline \multirow{5}{*}{$\begin{array}{l}\text { AC level } 1 \\
\text { (SAE J1772 }\end{array}$} & PEV includes on-board charger & \multirow[t]{5}{*}{ *DC Level 1} & EVSE includes an off-board charger \\
\hline & $\begin{array}{l}120 \mathrm{~V}, 1.4 \mathrm{~kW} @ 12 \mathrm{amp} \\
120 \mathrm{~V}, 1.9 \mathrm{~kW} @ 16 \mathrm{amp}\end{array}$ & & $200-450 \mathrm{~V} \mathrm{DC}$, up to $36 \mathrm{~kW}(80 \mathrm{~A})$ \\
\hline & Est. charge time: & & Est. charge time ( $20 \mathrm{~kW}$ off-board charger): \\
\hline & PHEV: 7 hrs (SOC* $-0 \%$ to full) & & PHEV: $22 \mathrm{~min}$. (SOC* $-0 \%$ to $80 \%$ ) \\
\hline & BEV: $17 \mathrm{hrs}$ (SOC $-20 \%$ to full) & & BEV: 1.2 hrs. (SOC $-20 \%$ to $100 \%)$ \\
\hline \multirow[t]{11}{*}{$\begin{array}{l}\text { AC level } 2 \\
\text { (SAE J1772 }\end{array}$} & $\begin{array}{l}\text { PEV includes on-board charger (see below for different } \\
\text { types) }\end{array}$ & \multirow[t]{6}{*}{ *DC Level 2} & EVSE includes an off-board charger \\
\hline & $240 \mathrm{~V}$, up to $19.2 \mathrm{~kW}(80 \mathrm{~A})$ & & $200-450 \mathrm{~V} \mathrm{DC}$, up to $90 \mathrm{~kW}(200 \mathrm{~A})$ \\
\hline & Est. charge time for $3.3 \mathrm{~kW}$ on-board charger & & Est. charge time ( $45 \mathrm{~kW}$ off-board charger): \\
\hline & PEV: 3 hrs (SOC* $-0 \%$ to full) & & PHEV: $10 \mathrm{~min}$. (SOC* $-0 \%$ to $80 \%$ ) \\
\hline & BEV: 7 hrs (SOC $-20 \%$ to full) & & BEV: $20 \mathrm{~min}$. (SOC $-20 \%$ to $80 \%)$ \\
\hline & Est. charge time for $7 \mathrm{~kW}$ on-board charger & & \\
\hline & PEV: 1.5 hrs (SOC* $-0 \%$ to full) & \multirow[t]{6}{*}{ *DC Level 3 (TBD) } & EVSE includes an off-board charger \\
\hline & BEV: 3.5 hrs (SOC $-20 \%$ to full) & & $200-600 \mathrm{~V} \mathrm{DC}$ (proposed) up to $240 \mathrm{~kW}(400 \mathrm{~A})$ \\
\hline & Est. charge time for $20 \mathrm{~kW}$ on-board charger & & Est. charge time ( $45 \mathrm{~kW}$ off-board charger): \\
\hline & PEV: $22 \mathrm{~min}$. (SOC* $-0 \%$ to full) & & BEV (only): $<10 \mathrm{~min}$. (SOC* $-0 \%$ to $80 \%$ ) \\
\hline & BEV: $1.2 \mathrm{hrs}$ (SOC $-20 \%$ to full) & & \\
\hline -AC Level 3 (TBD) & $>20 \mathrm{~kW}$, single phase and 3 phase & & \\
\hline \multicolumn{4}{|c|}{$\begin{array}{l}\text { "Not finalized } \\
\text { Voltages are nominal configuration voltages, not coupler ratings } \\
\text { Rated Power is at nominal configuration operating voltage and coupler rated current } \\
\text { Ideal charge times assume } 90 \% \text { efficient chargers, } 150 \mathrm{~W} \text { to } 12 \mathrm{~V} \text { loads and no balancing of Traction Battery Pack }\end{array}$} \\
\hline \multicolumn{4}{|c|}{$100 \%$} \\
\hline
\end{tabular}

Figure 7. Society of Automotive Engineers charging configurations and ratings terminology. ${ }^{21}$

Most PEV manufacturers supply an AC Level 1 cord-set with the vehicle, which provides sufficient capabilities for some drivers, but often provides an emergency backup capability because of the long recharge times. AC recharging capabilities found in the public arena more typically are AC Level 2. Figure 8 depicts a typical J1772-compliant inlet and connector for both AC Levels 1 and 2.

The J1772 standard also identifies requirements for DC charging. For PEVs that accept both AC and DC inputs, the Society of Automotive Engineers approved a single connector and inlet design. Figure 9 shows this connector, which is colloquially known as the J1772 "combo connector."

Some BEVs introduced in the United States prior to approval of the $\mathrm{J} 1772$ standard for DC charging employ the CHAdeMO (designed in Japan) standard for connector and inlet design. Figure 10 shows this connector. EVSE units that are either J1772-compliant or CHAdeMO-compliant are both known as DC fast chargers.

\footnotetext{
${ }^{21}$ http://www.sae.org/smartgrid/chargingspeeds.pdf [accessed January 15, 2014].
} 


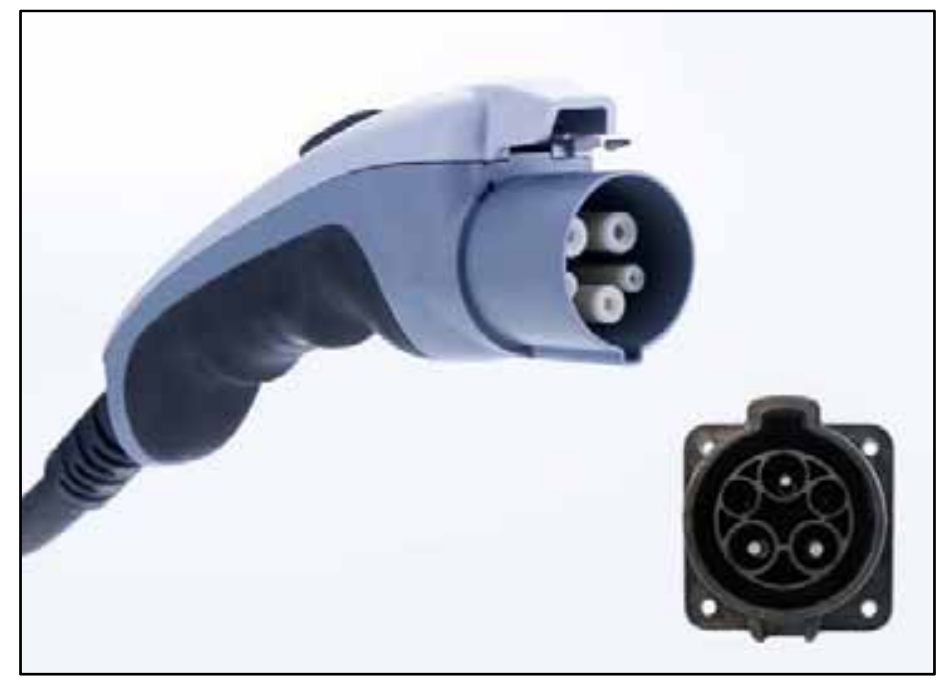

Figure 8. J1772 connector and inlet. ${ }^{22}$
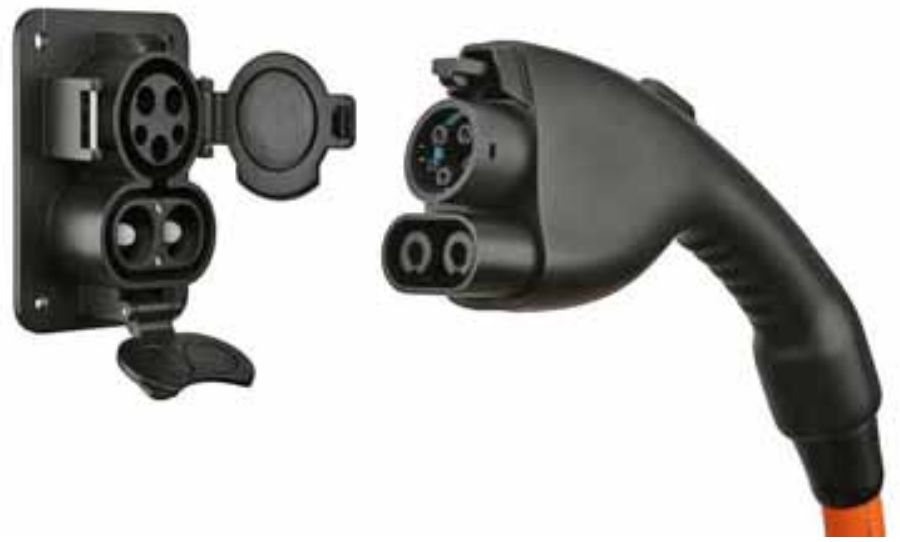

Figure 9. J1772-compliant combo connector. ${ }^{23}$

The presence of the two separate standards for DC charging presents challenges for vehicle owners to ensure the EVSE accessed provides the appropriate connector for their vehicle inlet. Not all PEV suppliers include DC charging options. BEV suppliers have provided DC inlets, where PHEV suppliers have not, because rapid recharging provides opportunities for expanded vehicle range with minimal operator wait times. PHEV operators can rely on the gasoline drive in the event they deplete the vehicle's battery; at present, no PHEV on the market or near commercialization has DC charging capability (although the Mitsubishi Outlander PHEV is rumored to be offering DC charging capability as an option). It is noted that DC Level 1 and DC Level 2 charging are commonly combined and labeled "DC fast charging."

Because the battery of a BEV is typically much larger than that of a PHEV, recharge times are longer (see Figure 7). BEVs that see daily mileage near the limits of the advertised range do better when

\footnotetext{
${ }^{22} \mathrm{http://carstations.com/types/j09} \mathrm{[accessed} \mathrm{January} \mathrm{15,} \mathrm{2014].}$

${ }^{23} \mathrm{http}$ ://www.zemotoring.com/news/2012/10/sae-standardizes-j1772-fast-dc-charging-up-to-100-kw [accessed January 15, 2014].
} 
recharged using AC Level 2 EVSE or DC fast charging, because AC Level 1 recharge times are usually extensive. PHEVs, on the other hand, generally can use AC Level 1 EVSE for overnight charging to ensure a fully charged battery at the start of daily use. AC Level 2 EVSE units provide greater range in the shortest amount of time when intermediate or opportunity charging. DC fast charging provides the fastest recharge capability for those vehicles equipped with DC fast charge inlets.

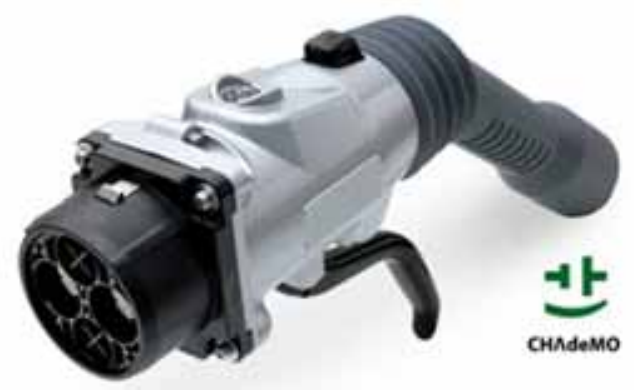

Figure 10. CHAdeMO-compliant connector. ${ }^{24}$

\subsubsection{Electric Vehicle Supply Equipment Stations}

AC Level 2 charging is the predominant rating of publicly accessible EVSE because of its wide acceptance by auto manufacturers and recharge times that are faster than AC Level 1 charging. Purchase and installation costs are more manageable than DC fast chargers and less space is required. There are several manufacturers of AC Level 2 equipment and the agency should review brands for comparison purposes. Figure 11 provides an example of a public AC Level 2 EVSE unit ${ }^{25}$.

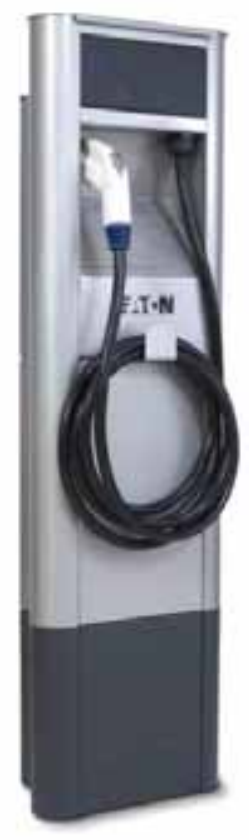

Figure 11. Public AC Level 2 EVSE.

\footnotetext{
${ }^{24} \mathrm{https://radio.azpm.org/p/azspot/2012/5/10/1632-electric-cars/} \mathrm{[accessed} \mathrm{January} \mathrm{15,} \mathrm{2014].}$

${ }^{25}$ www.eaton.com/ [accessed January 29, 2014].
} 
DC fast chargers also are available from several manufacturers. Figure 12 illustrates one such charger. ${ }^{26}$ This particular charger uses the CHAdeMO connector standard.

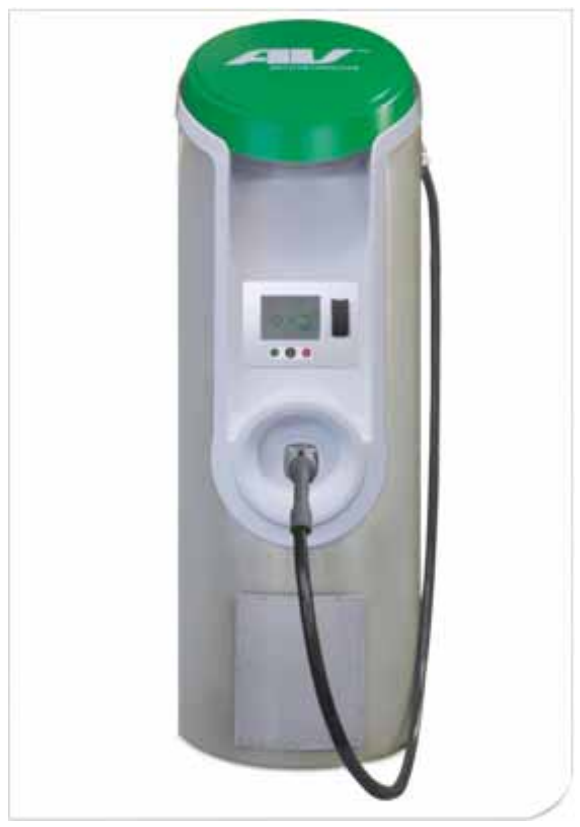

Figure 12. Public DC fast charger unit.

In general, installation costs are higher for the DC fast charger because of the higher voltage requirements and the inclusion of the AC to DC converter and other safety and design features. Costs for both types are highly dependent on site characteristics such as distance to the nearest power source, asphalt or concrete cutting and repair, conduit requirements, and payment systems, if any.

Payment and equipment control systems included by some suppliers provide the potential for use by privately owned vehicles for a fee, but can allow agency fleet vehicle use without direct payment. These systems also allow for accurate record keeping of vehicle charging requirements.

\section{VA Medical Center - Bronx Fleet Evaluation \\ 5.1 VA - Bronx Fleet}

VA - Bronx reports 50 Interior and GSA vehicles in their complete fleet. Table 8 shows the breakdown of EPA vehicle class.

Table 8. VA - Bronx fleet vehicles.

\begin{tabular}{|c|c|c|c|c|c|c|c|c|c|c|c|c|}
\hline & $\begin{array}{c}\text { Sedan } \\
\text { Compact }\end{array}$ & $\begin{array}{l}\text { Sedan } \\
\text { Midsiz } \\
\text { e }\end{array}$ & $\begin{array}{l}\text { Sedan } \\
\text { Large }\end{array}$ & SUV & $\begin{array}{l}\text { Mini } \\
\text {-van }\end{array}$ & $\begin{array}{c}\text { Cargo } \\
\text { Van }\end{array}$ & $\begin{array}{l}\text { Pass } \\
\text { Van }\end{array}$ & $\begin{array}{l}\text { Pickup } \\
\text { or LD } \\
\text { Truck }\end{array}$ & $\begin{array}{c}\text { MD } \\
\text { HD } \\
\text { Truck }\end{array}$ & Bus & Specialty & Total \\
\hline Total Fleet & 9 & 5 & 10 & 3 & 2 & 3 & 9 & 1 & 3 & 3 & 2 & 50 \\
\hline
\end{tabular}

Based on VA - Bronx input on fleet vehicles, an assessment of mission by vehicle type was completed. Table 9 shows the results of that assessment.

${ }^{26}$ http://evsolutions.avinc.com/products/public_charging/public_charging_b [accessed April 16, 2014]. 
Table 9. VA - Bronx fleet mission assessment.

\begin{tabular}{|c|c|c|c|c|c|c|c|c|c|c|c|c|}
\hline Mission & $\begin{array}{c}\text { Sedan } \\
\text { Compact }\end{array}$ & $\begin{array}{c}\text { Sedan } \\
\text { Midsize }\end{array}$ & $\begin{array}{l}\text { Sedan } \\
\text { Large } \\
\end{array}$ & SUV & $\begin{array}{c}\text { Mini- } \\
\text { van }\end{array}$ & $\begin{array}{c}\text { Cargo } \\
\text { Van } \\
\end{array}$ & $\begin{array}{l}\text { Pass } \\
\text { Van }\end{array}$ & $\begin{array}{c}\text { Pickup } \\
\text { or LD } \\
\text { Truck } \\
\end{array}$ & $\begin{array}{c}\text { Heavy- } \\
\text { Duty } \\
\text { Truck }\end{array}$ & Bus & Specialty & Total \\
\hline Pool & 9 & 5 & 6 & 1 & 2 & & & & & & & 23 \\
\hline Support & & & & & & & & 1 & 1 & & & 2 \\
\hline Law Enforce. & & & 3 & 2 & & & & & & & & 5 \\
\hline Transport & & & & & & 2 & & & 1 & & & 3 \\
\hline Specialty & & & 1 & & & 1 & & & 1 & & 2 & 5 \\
\hline Bus & & & & & & & 9 & & & 3 & & 12 \\
\hline Total & 9 & 5 & 10 & 3 & 2 & 3 & 9 & 1 & 3 & 3 & 2 & 50 \\
\hline
\end{tabular}

\subsection{Survey Results}

Nine vehicles were included in the study at VA - Bronx. Six vehicles have pool missions and three have bus/shuttle missions. Table 10 presents a summary of these vehicles and Table 11 provides details of the monitored vehicles.

Table 10 . Vehicle study summary.

\begin{tabular}{|c|c|c|c|c|c|c|c|c|c|c|c|}
\hline Mission & $\begin{array}{c}\text { Sedan } \\
\text { Compact } \\
\end{array}$ & $\begin{array}{c}\text { Sedan } \\
\text { Midsize } \\
\end{array}$ & $\begin{array}{l}\text { Sedan } \\
\text { Large } \\
\end{array}$ & SUV & $\begin{array}{c}\text { Mini- } \\
\text { van }\end{array}$ & $\begin{array}{l}\text { Pass } \\
\text { Van } \\
\end{array}$ & $\begin{array}{l}\text { Pickup or } \\
\text { LD Truck } \\
\end{array}$ & $\begin{array}{c}\text { MD HD } \\
\text { Truck }\end{array}$ & Bus & Specialty & Total \\
\hline Pool & 2 & 2 & 1 & & 1 & & & & & & 6 \\
\hline Support & & & & & & & & & & & \\
\hline Law Enforce. & & & & & & & & & & & \\
\hline Transport & & & & & & & & & & & \\
\hline Bus/shuttle & & & & & & 3 & & & & & 3 \\
\hline Specialty & & & & & & & & & & & \\
\hline Total & 2 & 2 & 1 & & 1 & 3 & & & & & 9 \\
\hline
\end{tabular}

Table 11. Detailed VA - Bronx vehicle index.

\begin{tabular}{ccccccc}
\hline Log & Fleet Vehicle Id & Make & Model & Year & EPA Class & Mission \\
\hline 23 & $* * * 9780$ & Ford & Fusion Hybrid & 2010 & Sedan - Midsize & Pool \\
24 & $* * * 9781$ & Ford & Fusion Hybrid & 2010 & Sedan - Midsize & Pool \\
25 & $* * * 2117$ & Ford & Focus & 2009 & Sedan - Compact & Pool \\
26 & $* * * 8065$ & Chevrolet & Impala & 2007 & Sedan - Large & Pool \\
27 & $* * * 1202$ & Ford & Focus & 2012 & Sedan - Compact & Pool \\
28 & $* * * 9502$ & Chevrolet & Venture & 2004 & Minivan & Pool \\
29 & $* * * 0240$ & Chevrolet & Express & 2011 & Van - Pass & Bus/shuttle \\
30 & $* * * 9820$ & Chevrolet & Express & 2010 & Van - Pass & Bus/shuttle \\
31 & $* * * 4826$ & Chevrolet & Express & 2008 & Van - Pass & Bus/shuttle \\
\hline
\end{tabular}

The vehicle ID is the last four digits of the VIN. Specific vehicle references may be made to the vehicle ID or logger ID in this report. 
Appendix B provides the analysis of each individual vehicle included in this study. Grouping the vehicles by mission creates an aggregated view of mission requirements to provide observations related to PEV replacement. The missions of these two categories vary considerably; therefore, these missions are evaluated separately.

\subsection{Data Validity}

VA - Bronx data collection took place from April through August 2012. Vehicle data sheets (presented in Appendix B) detail the collected data for each vehicle, including specific dates the logger provided data.

Of the data collected, validation occurred for $99.4 \%$, while null values exist for the balance.

\subsection{VA - Bronx Pool Vehicles Evaluation}

\subsubsection{Survey and Site Information}

Pool vehicles are typically light-duty motor vehicles for use in passenger transportation, with not more than 10 passengers. Pool missions can vary by agency, location, and jurisdiction; however, they typically utilize sedans, minivans, sport utility vehicles (SUVs), vans, or small pickup trucks and typically do not carry specific cargo or equipment. Table 11 identifies the six vehicles (i.e., one large sedan, two compact sedans, two midsize sedans, and one minivan).

Incorporation of BEVs and/or PHEVs into the pool mission is a definite possibility. Pool vehicles used for shorter trips or outings qualify for BEV or PHEV replacement, while other pool vehicle activities that are associated with longer trips may require PHEV capabilities.

\subsubsection{Summary for Pool Vehicles}

Appendix B provides the vehicle data sheets for each of the pool vehicles monitored. This section aggregates data for all pool vehicles for VA - Bronx. Table 12 summarizes pool travel during the study period for those days in which the vehicle was driven. Vehicle use occurred primarily between 0700 and 1700 hours daily. The vehicles were driven 13,965 miles, logged 738 hours of operation, and idled 171 hours during the study period.

Table 12. VA - Bronx pool vehicles travel summary.

\begin{tabular}{lcccc}
\hline & Pool Vehicles Travel Summary & & \\
& Per Day & Per Outing & Per Trip & \\
& Average/Peak & Average/Peak & Average/Peak & Total \\
\hline Travel Distance (Miles) & $44.2 / 296.3$ & $16.4 / 663.5$ & $5.3 / 260.4$ & 13,965 \\
Travel Time (Minutes) & $140.1 / 613.0$ & $51.9 / 724.0$ & $16.8 / 362.0$ & 44,283 \\
Idle Time (Minutes) & $32.6 / \mathrm{NA}$ & $12.1 / \mathrm{NA}$ & $3.9 / \mathrm{NA}$ & 10,287 \\
\hline
\end{tabular}

\subsubsection{Pool Vehicles Daily Summary}

Figure 13 identifies daily travel distance and time for all pool vehicles. The green line and bars indicate typical electric range on a single charge for a PHEV, while the blue line and bars (including the green bars) indicate the same for a BEV. Figures 14 and 15 show the composite history in distance and time traveled for the pool vehicles. In the stacked bar charts of Figures 14 and 15, the contribution of each vehicle is indicated by a different color.

Although all vehicles, except $* * * 8065$, show peak travel days of greater than 100 miles, Vehicles ***9780 and ***1202 experienced the longest travel days as shown in Figures 13 through 15 and in Appendix B. When driven, the average travel distance per day for pool vehicles was 44.2 miles. On $82 \%$ 
of these vehicle days, the daily travel was less than the 70 miles considered to be within the BEV safe range (i.e., while BEV range can vary based on several factors, most BEVs provide at least 70 miles of vehicle range on a single battery charge) and $18 \%$ of pool daily travel is greater than 70 miles. Further, $58 \%$ of vehicle travel days are less than the 40 miles considered to be within the CD range of a PHEV. Figures 14 and 15 show that the vehicles are not used every day, although there are many days when many of the vehicles are in use. Vehicles $* * * 8065$ and $* * * 1202$ had the highest percentage of use in travel days, while vehicles $* * * 9780$ and $* * * 9781$ had the least. Figure 16 displays the summary of use by time of day for all pool vehicles.
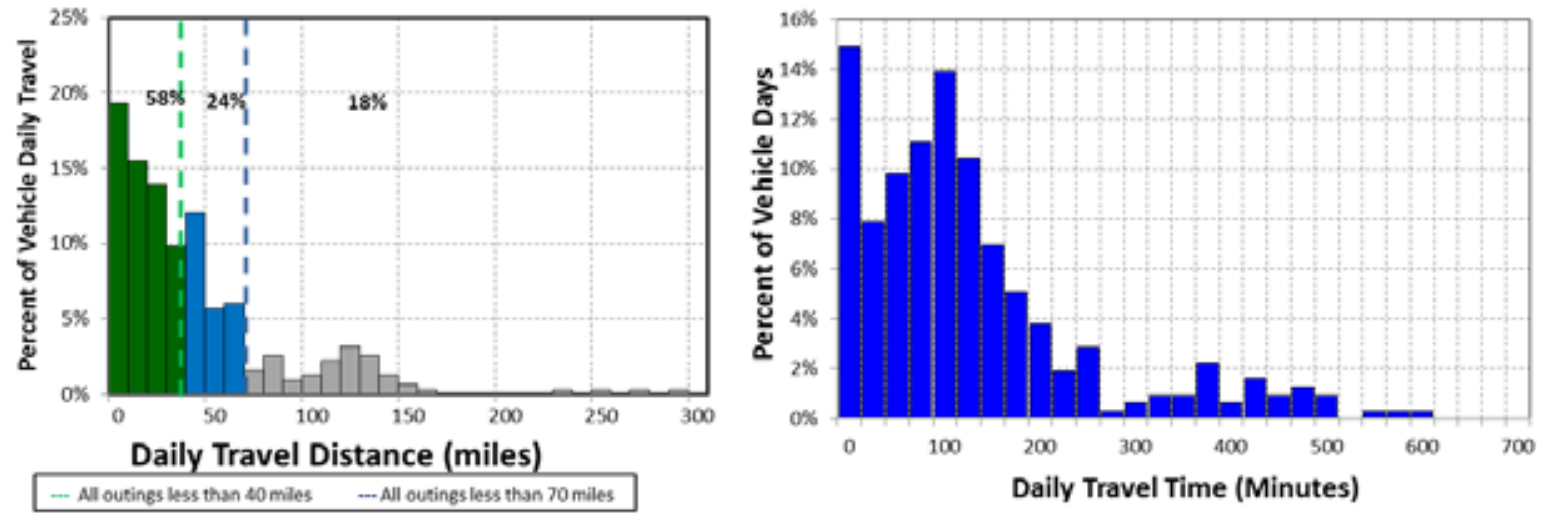

Figure 13. VA - Bronx pool vehicle daily travel miles and time (all vehicles).

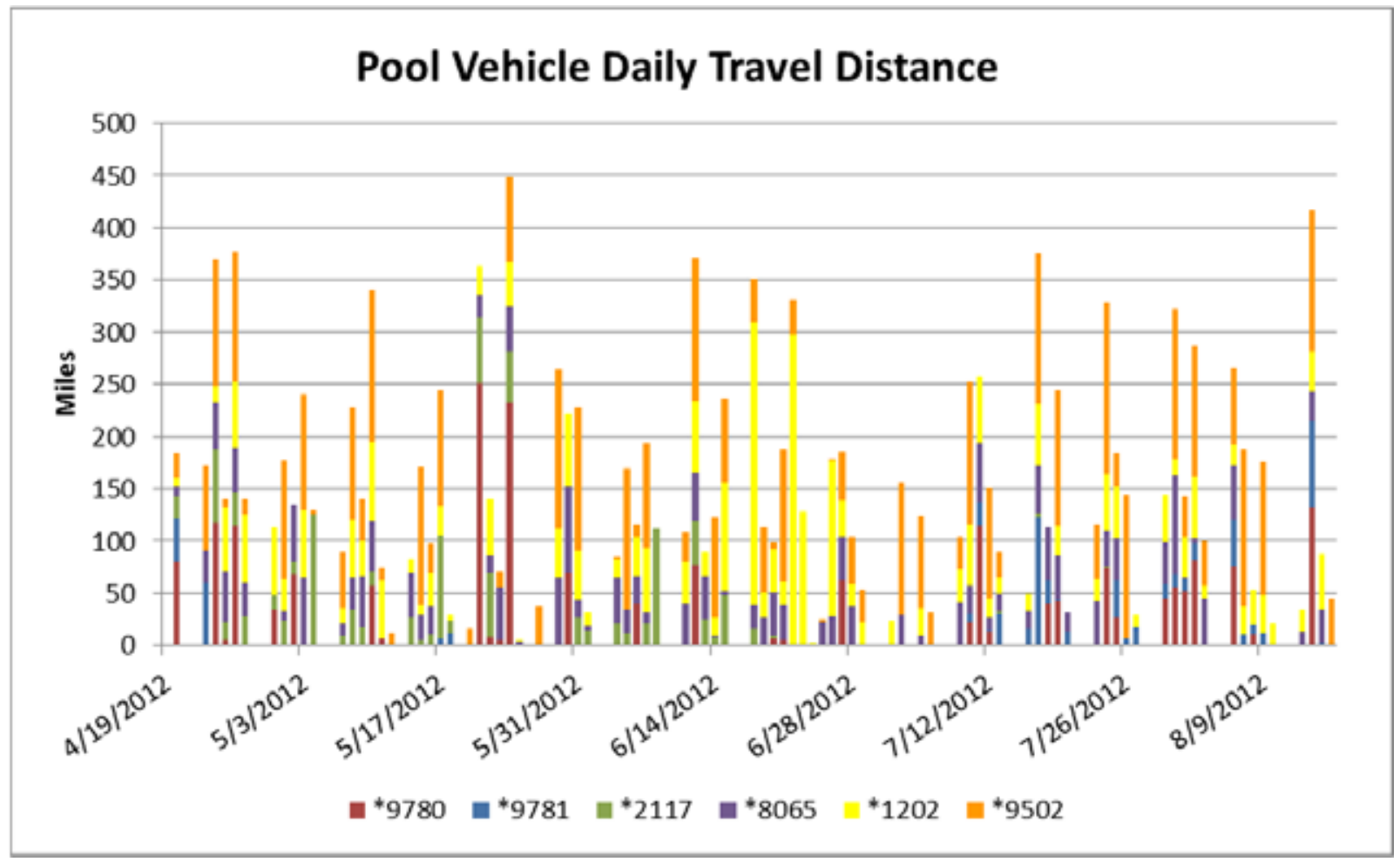

Figure 14. VA - Bronx pool vehicle daily travel history (all vehicles). 


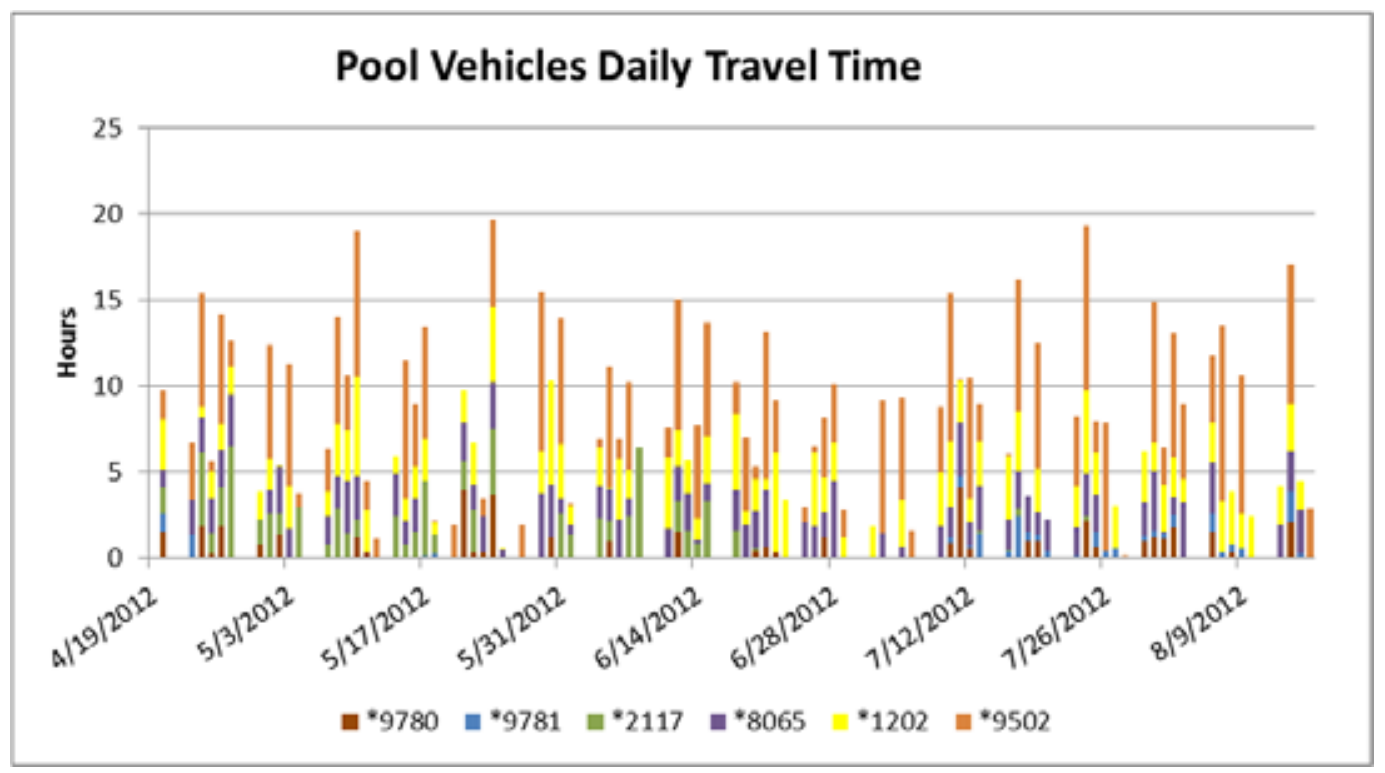

Figure 15. VA - Bronx pool vehicles travel time (all vehicles).

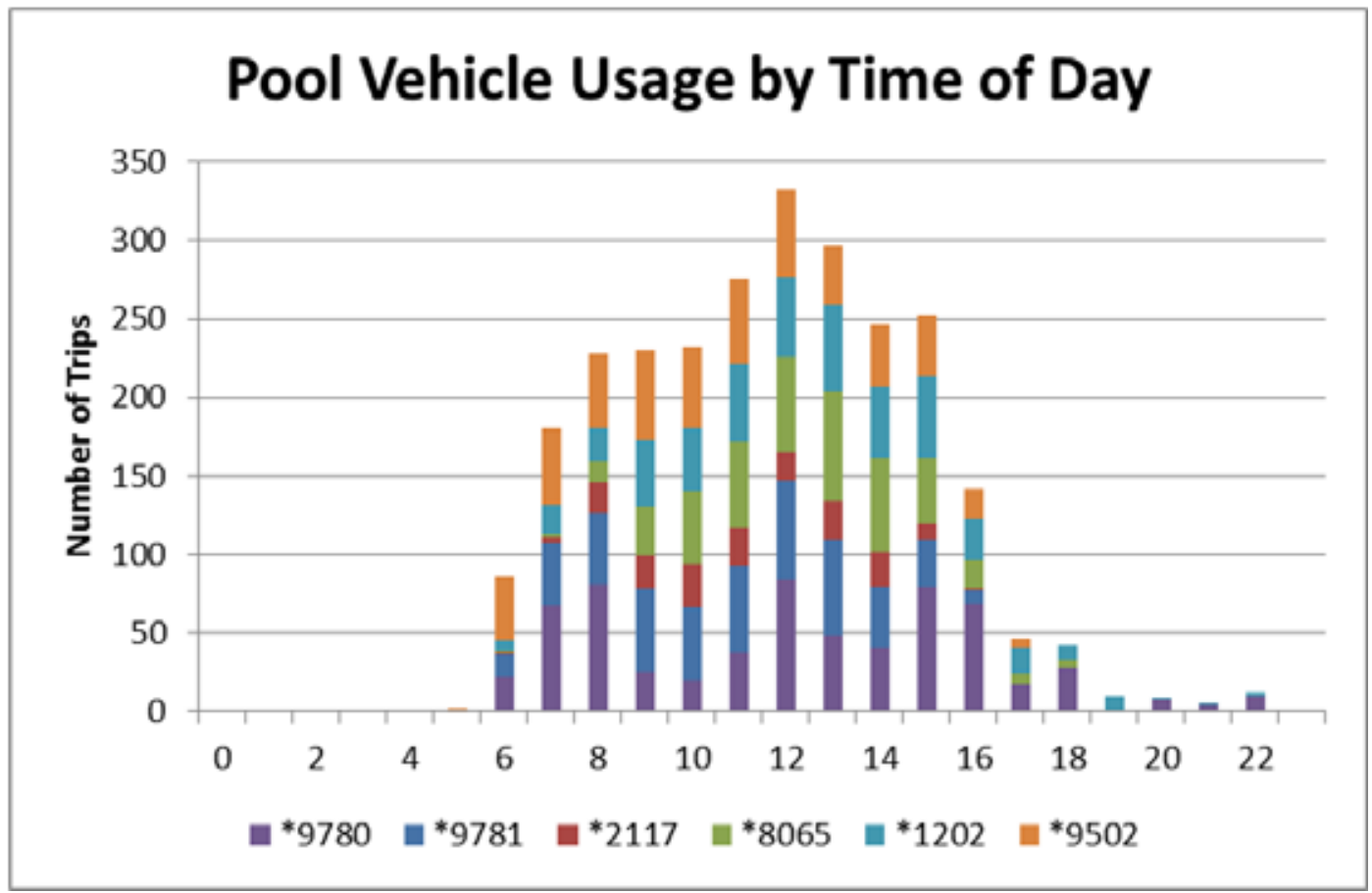

Figure 16. VA - Bronx pool vehicles hourly usage.

Figure 17 shows the outing distances traveled, including data for all pool vehicles. 


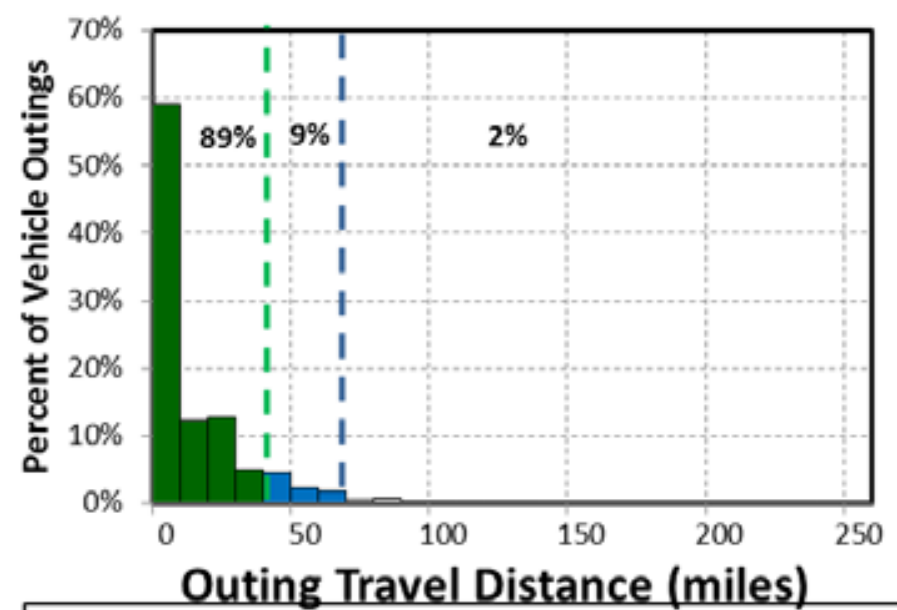

... All outings less than 40 miles .... All outings less than 70 miles

Figure 17. VA - Bronx pool vehicle outings (for clarity, the peak outings of 663.5 and 626.5 miles are not shown).

Appendix B provides the details of each of the pool vehicle's outing travel. The average travel outing for pool vehicles was 16.4 miles. On $98 \%$ of these vehicle outings, the distance traveled was less than the 70 miles considered to be within the BEV safe range. Only $2 \%$ percent of pool outing travel was greater than 70 miles. Further, $89 \%$ of vehicle travel outings were less than 40 miles considered to be within the $\mathrm{CD}$ range of a PHEV. In summary, these vehicles were used in many outings in a day of relatively short distance, but which add to significant mileage daily. There were a few days of extended travel lasting several days away from home. While the average outing was a low value, all vehicles experienced at least one outing that exceeded the range of a BEV.

\subsubsection{VA - Bronx Pool Vehicle Observations/Summary}

There appears to be three choices for VA - Bronx in implementing PEVs into the pool fleet. It should be noted that the objective would be to incorporate as many BEVs as possible to realize the advantages of reduced petroleum usage and reduced emissions of GHGs.

1. All BEV fleet: While some BEV manufacturers report vehicle range exceeding 70 miles, Intertek recommends careful evaluation of experienced range to ensure vehicle missions are accomplished. Nevertheless, assuming the 70-mile safe range for a BEV, an all-BEV fleet does not appear to be possible due to the length of the daily travel.

2. Mixed BEV/PHEV fleet: Certainly, PHEVs can accomplish the same mission as the current fleet when only considering travel times and distances, because the PHEV's gasoline engine can provide motive power when the battery has been depleted. Figure 13 shows that on $58 \%$ of all vehicle travel days, the total daily travel was less than 40 miles, which typically is the maximum distance a PHEV will travel in CD mode. This represents a significant operating cost savings opportunity, while retaining the ability to go longer distances when needed. In addition, $89 \%$ of the outings were less than 40 miles and could be completed in CD mode for certain PHEVs if the battery was fully charged prior to the outing.

Meanwhile, $98 \%$ of the outings were within the typical capability of a BEV; therefore, EVSE at the home base could provide recharge energy for another outing. A mixed fleet requires fleet manager attention to assign vehicles appropriately for the anticipated use on that day. 
Figure 13 also shows $82 \%$ of daily travel was within the typical range of a BEV. This would suggest that $18 \%$ of the fleet could be PHEVs to handle travel greater than 70 miles per day without requiring additional opportunity charging during daytime stops and $82 \%$ of the fleet could be BEVs. The fact that $98 \%$ of the outings were within the range capabilities of a BEV suggest that with additional charging between outings, the BEV could be able to handle more of the daily travel. The pool vehicles averaged 2.3 hours of use daily, suggesting that time is available for additional charging.

However, a fleet with $82 \%$ BEVs does not allow for use of several vehicles at the same time and would require a greater level of fleet management, with the daily assignment of vehicles based on anticipated driving distance. PEV models are currently available for potential replacement of these vehicle types. Allowing more conservatism in assigning vehicles for the six vehicles, three PHEVs and three BEVs could conservatively meet the demand.

3. All PHEV fleet: As noted above, PHEVs can accomplish the same mission as the current fleet when only considering travel times and distances. Replacing all current vehicles with PHEVs only requires an evaluation of the individual vehicle capabilities of currently available PHEVs to meet current pool requirements. All these vehicles have replacement PEVs available. Data show that for a significant number of days, the PHEV will operate in CD mode. The first 40 miles of longer travel days would also be powered by (at least mostly) electricity so that $58 \%$ of all pool vehicle travel would be (again, at least mostly) battery powered with only one charge per day. As above, this represents an opportunity for significant operating cost savings, while retaining the ability to go longer distances when needed. Intermediate charging opportunities provide additional benefit, enhancing CD mode. Data show significant charging opportunities throughout the day during stop times.

The vehicle summary shows sufficient time for charging at the base location during the course of the day and additional opportunities at intermediate charging stations are not required. These stations also provide charging opportunities for the visiting public, whose fees may assist in offsetting operating costs. Given the availability of daytime changing, with experience, VA - Bronx may find a greater fraction of BEVs within the pool vehicle fleet may meet their needs.

Considering a full complement of 23 pool vehicles in the total fleet, Intertek suggests that a mixed fleet may be possible. While the remaining vehicles were not monitored, using the same ratio as above, suggests a fleet of 11 BEVs and 12 PHEVs would conservatively meet vehicle travel requirements. Typically, additional EVSE at frequently visited locations provide recharging for both the BEV and PHEV that may be of benefit.

\subsubsection{VA - Bronx Pool Vehicle Charging Needs}

Upon review of these data, Intertek suggests replacement of six of the studied pool fleet with three BEVs and three PHEVs. No available PHEVs at this writing provide for DC fast charging nor do the data suggest that this would be a significant benefit for PHEVs in the pool fleet. A DC fast charger at the home base will provide a more rapid recharge for BEVs, but appears to be unnecessary, given that the data show that $98 \%$ of outings are less than a typical BEV's driving range.

As noted above, AC Level 2 overnight charging of BEVs is typical, whereas overnight charging of PHEVs can usually be accomplished with AC Level 1 charging.

Intertek's experience suggests that each vehicle should have an assigned charging parking space at its home base. Assigned stations require less management attention to ensure completion of overnight charging. BEVs and PHEVs not assigned to these stations also benefit during visits to the location as part of their normal operation. For the entire fleet of pool vehicles, the $11 \mathrm{BEVs}$ require $11 \mathrm{AC}$ Level $2 \mathrm{EVSE}$ units for overnight charging and the 12 PHEVs require $12 \mathrm{AC}$ Level 1 outlets at each vehicle's overnight parking location. Intertek recommends a minimum of two EVSE at each location to maximize charge capability without a significant increase in installation costs. The PHEVs can utilize the AC Level 2 EVSE at the home base during the day to increase the amount of vehicle miles traveled in CD mode. 
Figure 18 shows the stop locations of all monitored vehicles in the local area. Longer trips to other states are not shown. This represents the typical service area of these vehicles. This can be helpful in considering other local charge opportunities, because, at times, fleet vehicles obtain benefit from using public charging infrastructure.

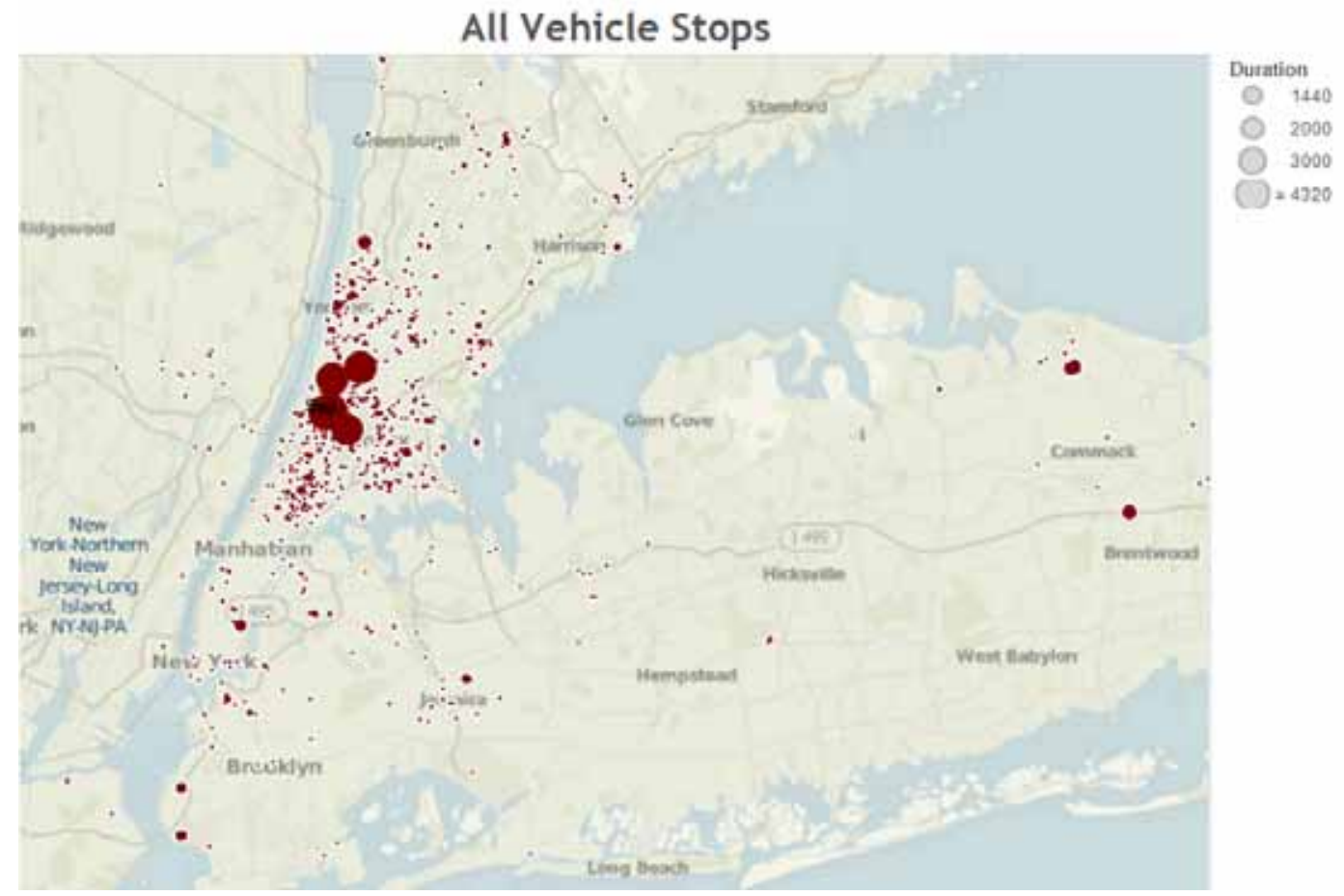

Figure 18. All vehicle local stops.

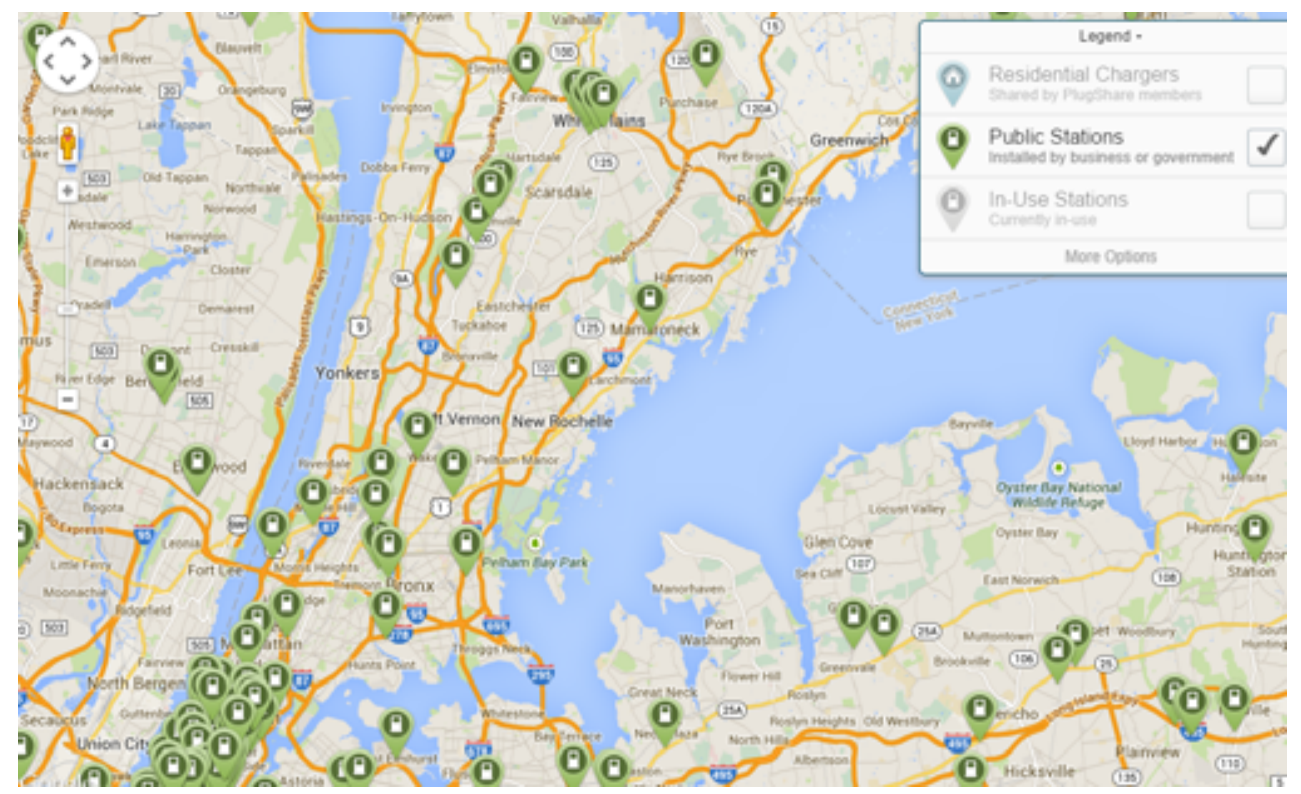

Figure 19. Public EVSE in VA - Bronx region. ${ }^{27}$

\footnotetext{
${ }^{27}$ http://www.plugshare.com/ [accessed October 13, 2014].
} 
Figure 19 displays the availability of public charging at the time of this writing for the VA - Bronx area. All indicated stations are available to the public and provide AC Level 2 or Level 1 EVSE. Some of these may be located along the traffic routes used by VA - Bronx vehicles.

\subsection{VA-Bronx Bus/Shuttle}

\subsubsection{Survey and Site Information}

Bus/shuttle vehicles are typically motor vehicles for use in passenger transportation with more than 10 passengers. While electric buses are available and in service, the charging needs are more typically unique and specific to the bus obtained. VA-Bronx monitored three passenger vans as part of this study. Replacement PEVs do not currently exist for these vehicles. However, VA-Bronx may wish to evaluate whether other vehicle types (i.e., minivans or SUVs) may be able to conduct the same mission. In that view, the following analysis is provided.

Incorporation of BEVs and/or PHEVs into the shuttle mission may be possible. Shuttles used for shorter trips or outings qualify for BEV or PHEV replacement, while other shuttle activities that are associated with longer trips may require PHEV capabilities.

\subsubsection{Summary for Shuttle Vehicles}

Appendix B provides the vehicle data sheets for each of the shuttles monitored. This section aggregates data for all these vehicles for VA - Bronx. Table 13 summarizes shuttle travel during the study period for those days in which the vehicle was driven. Vehicle use occurred primarily between 0600 and 1700 hours daily. The vehicles were driven 8,314 miles, logged 543 hours of operation, and idled 178 hours during the study period.

Table 13. VA - Bronx shuttle travel summary.

\begin{tabular}{lcccc}
\hline \multicolumn{4}{c}{ Shuttle Travel Summary } & \\
& $\begin{array}{c}\text { Per Day } \\
\text { Average/Peak }\end{array}$ & $\begin{array}{c}\text { Per Outing } \\
\text { Average/Peak }\end{array}$ & $\begin{array}{c}\text { Per Trip } \\
\text { Average/Peak }\end{array}$ & Total \\
\hline Travel Distance (Miles) & $56.2 / 360.8$ & $8.8 / 913.0$ & $6.5 / 199.3$ & 8,314 \\
Travel Time (Minutes) & $220.2 / 513.0$ & $34.4 / 1,726$ & $25.6 / 242.0$ & 32,587 \\
Idle Time (Minutes) & $72.1 / \mathrm{NA}$ & $11.3 / \mathrm{NA}$ & $8.4 / \mathrm{NA}$ & 10,673 \\
\hline
\end{tabular}

\subsubsection{Shuttle Vehicles Daily Summary}

Figure 20 identifies daily travel distance and time for all shuttle vehicles. The green line and bars indicate the typical electric range on a single charge for a PHEV, while the blue line and bars (including the green bars) indicate the same for a BEV. Figures 21 and 22 show the composite history in distance and time traveled for the shuttle vehicles. In the stacked bar charts of Figures 21 and 22, the contribution of each vehicle is indicated by a different color.

All vehicles experienced at least 1 day of travel greater than the range of a PEV. When driven, the average travel distance per day for shuttle vehicles was 56.2 miles. On $67 \%$ of these vehicle days, the daily travel was less than the 70 miles considered to be within the BEV safe range (i.e., while BEV range can vary based on several factors, most BEVs provide at least 70 miles of vehicle range on a single battery charge) and $33 \%$ of shuttle daily travel was greater than 70 miles. Further, $43 \%$ of vehicle travel days are less than the 40 miles considered to be within the CD range of a PHEV. Figures 21 and 22 show that the vehicles were not used every day, although all were used between 58 and $64 \%$ of the study days. Figure 23 displays the summary of use by time of day for all shuttle vehicles. 

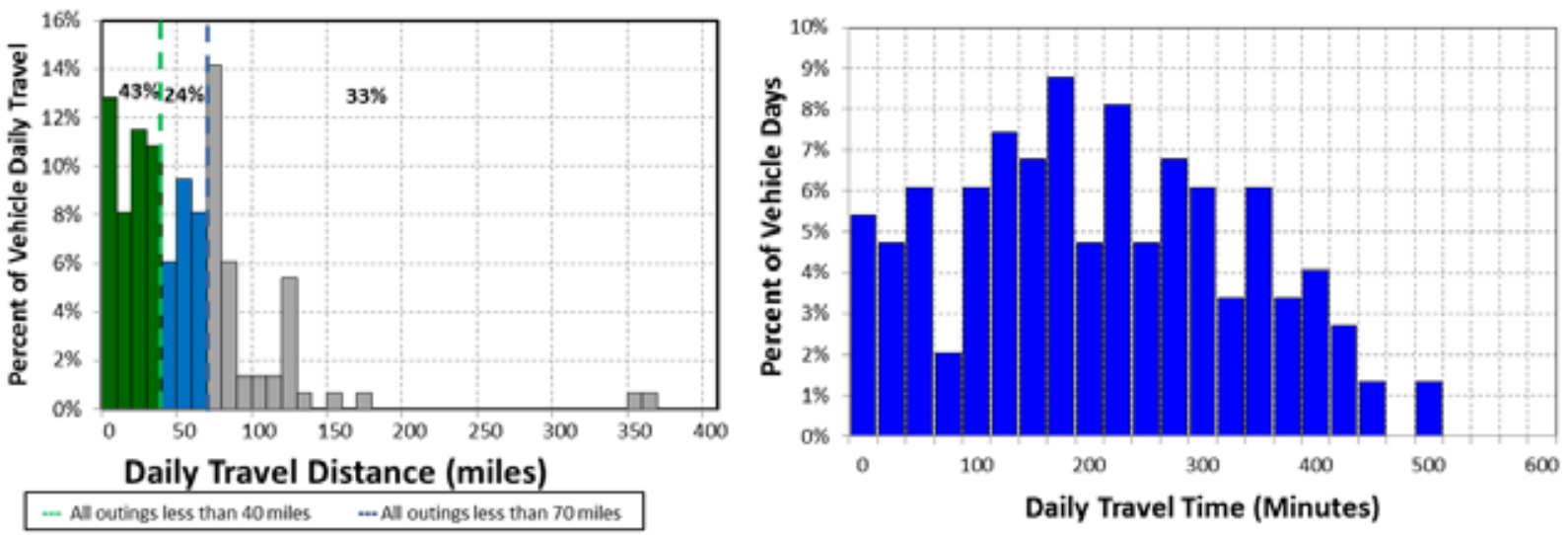

Figure 20. VA - Bronx shuttle vehicle daily travel miles and time (all vehicles).

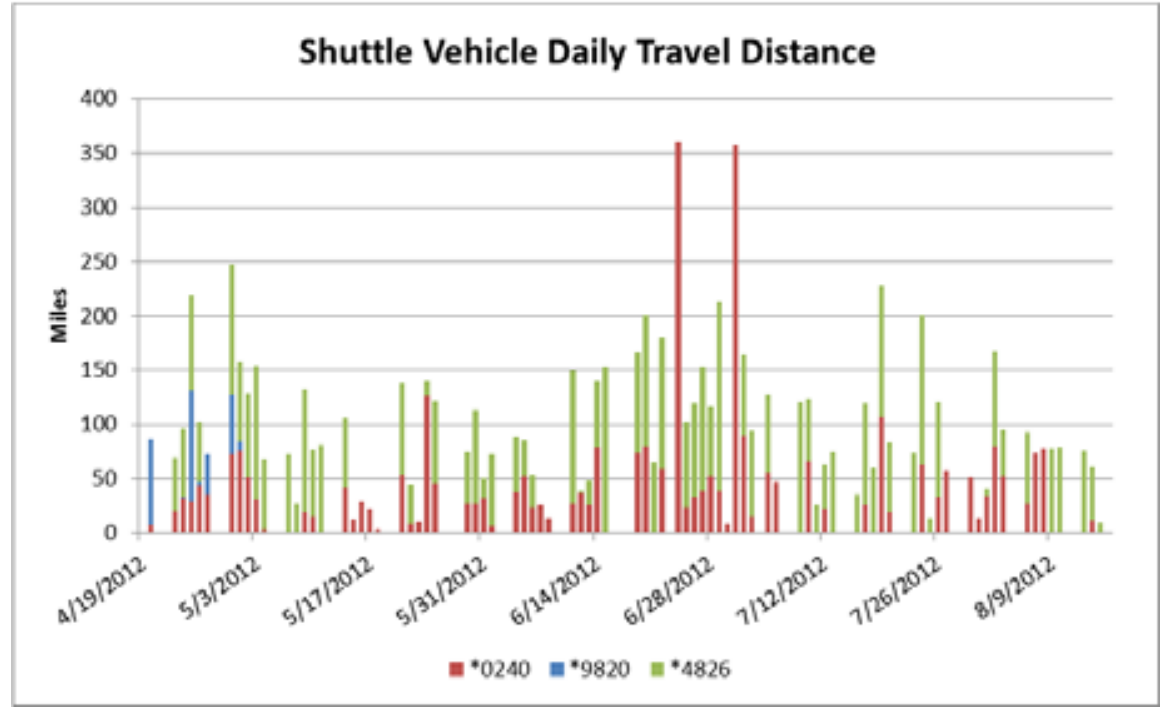

Figure 21. VA - Bronx shuttle vehicle daily travel history (all vehicles).

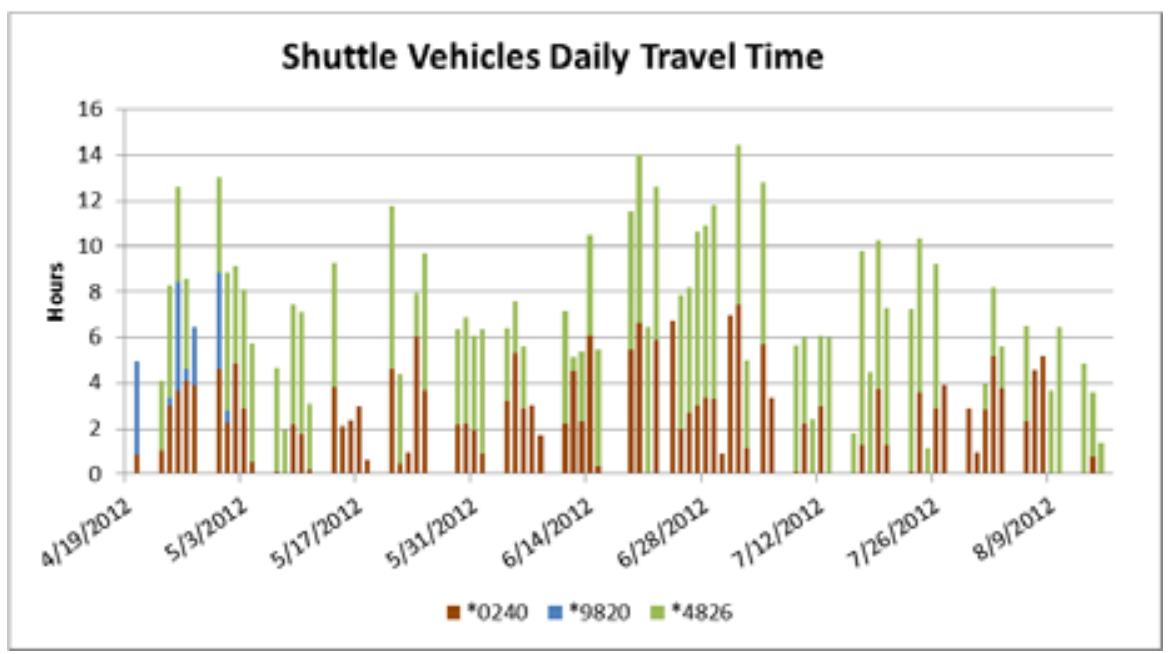

Figure 22. VA - Bronx shuttle vehicles travel time (all vehicles). 


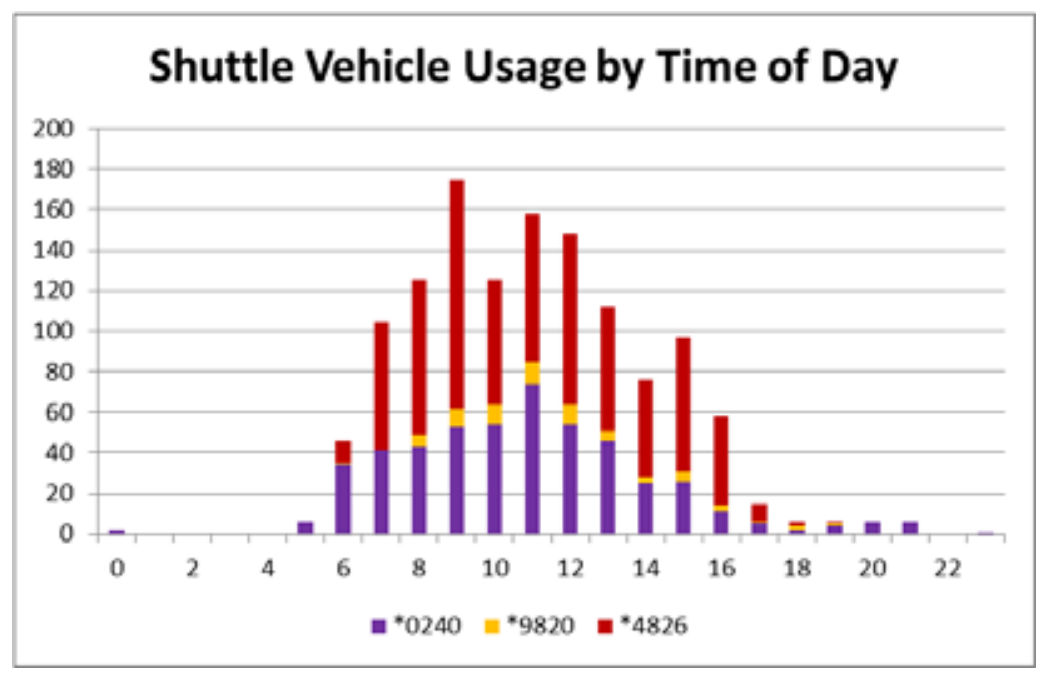

Figure 23. VA - Bronx shuttle vehicles hourly usage.

Figure 24 shows the outing distances traveled, including data for all shuttle vehicles.

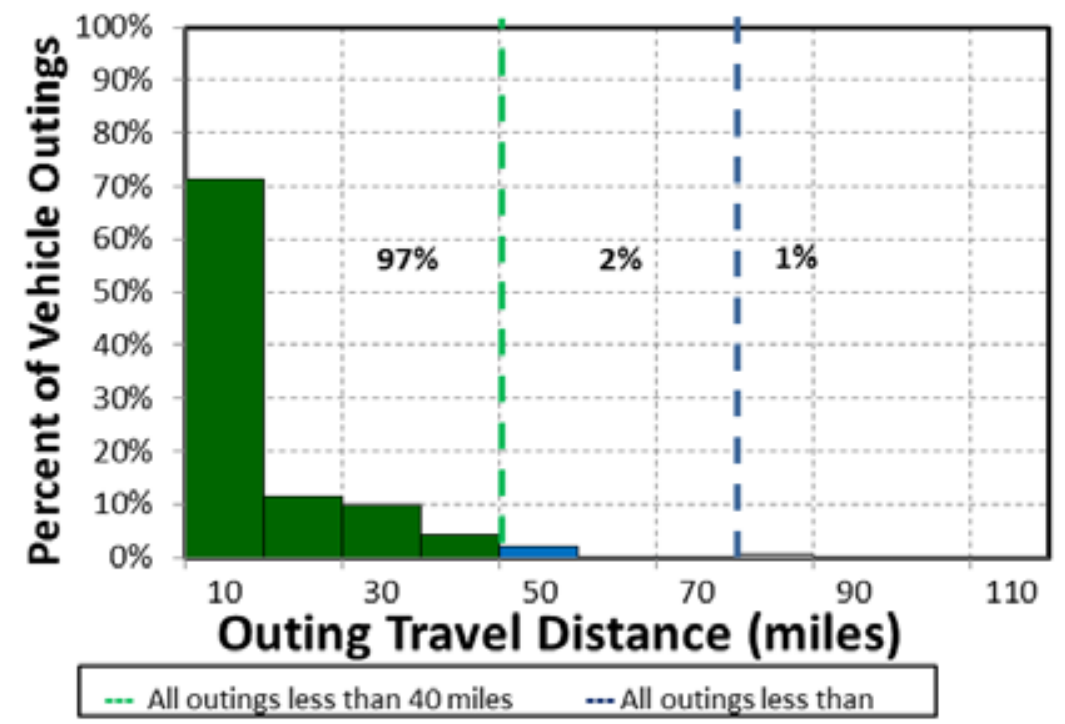

Figure 24. VA - Bronx shuttle vehicle outings (note: the maximum outing of 913 miles was not shown for clarity of scale).

The longest single outing of 913 miles was experienced by vehicle ***0240 as noted in Appendix B.

The average travel outing for shuttle vehicles is 8.8 miles. On $99 \%$ of these vehicle outings, the distance traveled was less than the 70 miles considered to be within the BEV safe range. Only $1 \%$ percent of shuttle outing travel was greater than 70 miles. Further, $97 \%$ of vehicle travel outings were less than 40 miles considered to be within the CD range of a PHEV. In summary, these vehicles were used in many outings in a day of relatively short distance, but which adds to significant mileage daily. There were a few days of extended travel. While the average outing is a low value, only ***9820 did not experience at least one outing exceeding the range of a BEV. 


\subsubsection{VA - Bronx Shuttle Vehicle Observations/Summary}

As noted above, there are no PEVs currently available as replacements for passenger vans. Should VA-Bronx consider other vehicles as potential replacements for these passenger vans (such as minivans or SUVs), these PEV types do exist and could be considered for replacement vehicles. As seen above, a majority of these vehicles could be BEVs.

\subsection{Balance of Fleet Vehicles}

The balance of the VA - Bronx fleet of vehicles consists of enforcement, specialty, buses, support, and transport vehicles. The five enforcement vehicles do have PEV replacement vehicle types and should be considered for replacement. Certainly, PHEVs can support the enforcement mission and BEVs may also be considered based on the specific mission of the replaced vehicle. The pickup truck used in the support mission also has potential PEV replacement, specifically the Via Motors VTRUX PHEV. Certain select PEVs are being demonstrated for various specialty applications, but none is listed in the GSA schedule. Finally, the cargo vans with the transport mission also have potential PEV replacements, including the Nissan eNV200 and the Via Motors VTRUX van. VA - Bronx may wish to review the balance of their fleet vehicles for potential replacements.

\section{GREENHOUSE GAS EMISSIONS AVOIDED AND FUEL COST REDUCTION ANALYSIS}

PEV substitution for an existing conventional vehicle avoids GHG emissions and reduces fuel costs. The GHG emissions avoided occur due to the difference in emissions associated with power plant electricity generation versus fuel combustion that occurs in the engine of a conventional vehicle. This analysis does not account for life-cycle emissions that occur outside of the electricity generation and fuel combustion phases (i.e., materials and resource extraction, production supply-chains, and decommissioning are not accounted for). These phases are beyond the scope of this report due to the significant effort required to conduct an accurate environmental life-cycle assessment for a transportation system in a very specific setting. The analysis used is known as a "tank-to-wheel" analysis rather than a "well-to-wheel" analysis that would include the aforementioned phases. Cost reduction also occurs because the cost of electricity is comparable to the cost of gasoline on a unit of energy basis; however, PEVs are more efficient than conventional ICE vehicles. Because fuel logs were not kept, the mileage accumulated by each vehicle and extrapolation to annual miles provide one source of annual miles estimates. VA - Bronx also provided information related to anticipated annual miles. These were compared to that calculated during the study to identify the source of fuel consumption estimates for the study vehicles.

In order to perform the analysis, EPA fuel economy ratings are used. ${ }^{28}$ Tables 14 and 15 provide these ratings. Ratings for the PHEVs in Table 15 include CD operation. Because these data are estimates, assumptions include the following:

1. PHEVs operate in CD mode only for the percentage of travel less than 40 miles per day. This is reasonable for most daily operations, as described in Section 5. This is conservative because there exists additional charge time between most outings. It is also conservative because the replacement PEV typically will have greater fuel economy when operating in CS mode. BEVs operate in electric mode for $100 \%$ of travel.

2. The energy consumption for the Mitsubishi Outlander is assigned the same value as the RAV4 EV because EPA has not yet created ratings for this vehicle.

\footnotetext{
${ }^{28}$ http://www.fueleconomy.gov/feg/Find.do?action=sbs\&id=33558 [accessed August 27, 2014]
} 
3. Figure 15 suggests the PEVs that can replace the existing monitored vehicles. See Section 4.4 for vehicle availability.

Annual miles were calculated from the actual miles identified in the study and extrapolated to a full 365-day year. This was compared to the annual miles reported by VA - Bronx for information. The VA Bronx annual miles were used for the reduction calculations if available. Miles in CD mode were the VA - Bronx annual miles times the percent of daily travel less than 40 miles for the PHEV replacement and full annual miles for the BEV replacement. Table 16 provides a pictorial view of potential replacement PEVs.

Table 14. U.S. EPA fuel economy ratings of current fleet vehicles.

\begin{tabular}{cccccc}
\hline Vehicle & Logger & Mission & Make and Model & Model Year & $\begin{array}{c}\text { Fuel Economy-Combined } \\
\text { (miles/gallon) }\end{array}$ \\
\hline$* * * 9780$ & 23 & Pool & Ford Fusion Hybrid & 2010 & 39 \\
$* * * 9781$ & 24 & Pool & Ford Fusion Hybrid & 2010 & 39 \\
$* * * 2117$ & 25 & Pool & Ford Focus & 2009 & 27 \\
$* * * 8065$ & 26 & Pool & Chevrolet Impala & 2007 & 22 \\
$* * * 1202$ & 27 & Pool & Ford Focus & 2012 & 31 \\
$* * * 9502$ & 28 & Pool & Chevrolet Venture & 2004 & 20 \\
$* * * 0240$ & 29 & Bus/shuttle & Chevrolet Express & 2011 & 14 \\
$* * * 9820$ & 30 & Bus/shuttle & Chevrolet Express & 2010 & 14 \\
$* * * 4826$ & 31 & Bus/shuttle & Chevrolet Express & 2008 & 14 \\
\hline
\end{tabular}

Table 15. U.S. EPA PEV energy consumption assumptions.

\begin{tabular}{cccc}
\hline Vehicle & Mission & Replacement PEV & Wh/mile \\
\hline$* * * 9780$ & Pool & Ford Fusion & 370 \\
$* * * 9781$ & Pool & Nissan Leaf & 300 \\
$* * * 2117$ & Pool & Ford Focus & 310 \\
$* * * 8065$ & Pool & Nissan Leaf & 300 \\
$* * * 1202$ & Pool & Chevrolet Volt & 350 \\
$* * * 9502$ & Pool & Mitsubishi Outlander & 440 \\
$* * * 0240$ & Bus/shuttle & NA & NA \\
$* * * 9820$ & Bus/shuttle & NA & NA \\
$* * * 4826$ & Bus/shuttle & NA & NA \\
\hline
\end{tabular}

Calculations provided for GHG emissions and fuel savings include both a total U.S. perspective and for the local area. The electricity generation mix of power plants for the total United States is different from the local mix of generation in the VA - Bronx area. Likewise, the national average cost for petroleum fuel is different from the local cost for fuel. This analysis includes both approaches in order to allow for local evaluation and to provide the potential benefit for fleet vehicles in other locations of the United States that may be of interest. The final report summarizing results from all sites studied across the United States from Intertek to Idaho National Laboratory primarily will consider the national figures. For clarity, only the local figures are shown here. The national figures are included in Appendix C. 
Table 16. PEV substitutions for current vehicles.

\begin{tabular}{|c|c|c|c|}
\hline Vehicle Class & $\begin{array}{c}\text { Current Vehicle } \\
\text { Example }\end{array}$ & Replacement PHEV & Replacement BEV \\
\hline \multicolumn{4}{|c|}{ Sedan - Midsize/Large } \\
\hline & Chevrolet Impala & $\begin{array}{l}\text { Ford Fusion Energi } \\
370 \mathrm{Wh} / \mathrm{mi}\end{array}$ & Nissan Leaf $300 \mathrm{Wh} / \mathrm{mi}$ \\
\hline \multicolumn{4}{|l|}{ Sedan - Compact } \\
\hline & Ford Focus Hybrid & $\begin{array}{l}\text { Chevrolet Volt } \\
350 \mathrm{Wh} / \mathrm{mi}\end{array}$ & $\begin{array}{l}\text { Ford Focus BEV } \\
310 \mathrm{Wh} / \mathrm{mi}\end{array}$ \\
\hline \multicolumn{4}{|l|}{ SUV and Minivan } \\
\hline & Chevrolet Venture & $\begin{array}{l}\text { Mitsubishi Outlander } \\
440 \mathrm{wh} / \mathrm{mi}\end{array}$ & $\begin{array}{l}\text { Toyota RAV4 EV } \\
440 \mathrm{wh} / \mathrm{mi}\end{array}$ \\
\hline
\end{tabular}

For the GHG emissions avoided portion of the analysis, the GHG emissions (in pounds of carbon dioxide equivalent (which also accounts for other GHGs such as methane and nitrous oxide), $l b-\mathrm{CO}_{2} e$ from combustion of gasoline is $20.1 \mathrm{lb}-\mathrm{CO}_{2} \mathrm{e} /$ gallon. ${ }^{29}$ The United States averages for GHG emissions for the production of electricity is $1.53 \mathrm{lb}-\mathrm{CO}_{2} \mathrm{e} / \mathrm{kWh}{ }^{30}$

Consolidated Edison Company provides power to the VA-Bronx area. It operates oil and gas plants in the New York area and reports the addition of solar plants in recent years. ${ }^{31}$ Consolidated Edison reports emissions to EPA and EPA reports GHG emissions from all plants in the production of electricity. The annual report is available in the Emissions and Generation Resource Integrated Database. The most recent publication is for $2010 .^{32}$ Using the information provided for Consolidated Edison plants, emissions for 2010 for the production of electricity were $1.3431 \mathrm{lb}-\mathrm{CO}_{2} \mathrm{e} / \mathrm{kWh}$.

GHG emissions avoided are the GHGs emitted by the current vehicle (total annual gallons gasoline $\times$ GHG emissions/gallon) minus the annual GHG emitted by the replacement PEV (total annual $\mathrm{kWh} \times$ GHG emissions/kWh). For PHEVs, the percentages of outings less than 40 miles are counted for the annual miles saved in $\mathrm{CD}$ mode, with the balance of the miles accounted as fueled with gasoline.

\footnotetext{
${ }^{29} \mathrm{http}: / /$ www.theevproject.com/cms-assets/documents/106077-891082.ghg.pdf [accessed 19 July 2013].

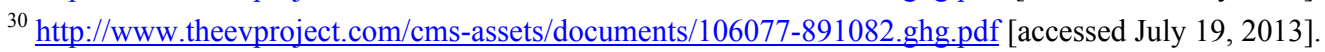

${ }^{31} \mathrm{http}: / / w w w . c o n e d i s o n . c o m / e h s / 2011$ annualreport/environmental-stewardship/reducing-greenhouse-gases.html [accessed October 13, 2014].

${ }^{32}$ http://www.epa.gov/cleanenergy/energy-resources/egrid// [accessed September 20, 2014].
} 
Table 17 shows the calculation of annual miles based on the recorded and extrapolated miles in this study. The VA - Bronx reported annual miles are also shown for comparison. A replacement vehicle is identified for each vehicle. It is important to note that the analysis conducted above suggests replacement vehicles for the fleet of vehicles rather than necessarily replacing the exact vehicle monitored. The percent of miles in CD mode is 100\% for BEVs because all travel is battery powered. The percent of miles in CD mode for PHEVs is obtained from the daily travel shown in Appendix B. Miles in CD mode is the percentage of VA - Bronx reported annual miles.

Table 17. CD mode miles calculations.

\begin{tabular}{cccccc}
\hline & & $\begin{array}{c}\text { Study } \\
\text { Calculated } \\
\text { Vehnicle }\end{array}$ & $\begin{array}{c}\text { VA - Bronx } \\
\text { Reported Annual } \\
\text { Miles }\end{array}$ & $\begin{array}{c}\text { Percent of } \\
\text { Miles CD } \\
\text { Mode }\end{array}$ & $\begin{array}{c}\text { CD Mode } \\
\text { Miles }\end{array}$ \\
\hline Fusion Hybrid & Ford Fusion & 6,337 & 10,000 & $43 \%$ & 4,300 \\
Fusion Hybrid & Nissan Leaf & 2,000 & 10,000 & $100 \%$ & 10,000 \\
Focus & Ford Focus & 3,480 & 12,000 & $100 \%$ & 12,000 \\
Impala & Nissan Leaf & 8,019 & 12,000 & $100 \%$ & 12,000 \\
Focus & Chevrolet Volt & 10,156 & 12,000 & $61 \%$ & 7,320 \\
Venture & Mitsubishi Outlander & 14,600 & 12,000 & $41 \%$ & 4,920 \\
Express & NA & 10,415 & 12,000 & NA & NA \\
Express & NA & 8,787 & 12,000 & NA & NA \\
Express & NA & 15,005 & 12,000 & NA & NA \\
\hline
\end{tabular}

For the cost-avoided piece of the analysis, fuel cost assumptions are \$3.186/gallon of regular gasoline for the United States and \$3.440 gallon in Bronx, NY. ${ }^{33}$ Electrical costs are $0.0984 \$ / \mathrm{kWh}$ for the United States and $0.152 \$ / \mathrm{kWh}$ in New York. ${ }^{34}$ Therefore, fuel costs savings are the current vehicle's calculated annual gasoline cost (total annual gallons gasoline $\times$ cost/gallon) minus the electricity cost (total annual $\mathrm{kWh} \times \operatorname{cost} / \mathrm{kWh}$ ) of the replacement PEV traveling the same distance.

The miles calculated above for CD mode yield estimates for yearly GHG emissions avoided and fuel cost reductions. The results of this analysis (shown in Table ) demonstrate that the substitution of a conventional ICE vehicle with a PEV can reduce the GHG emissions and fuel costs dramatically. The table also shows the percentage reduction in GHG emissions and fuel costs for ease of comparison. For example, if the Chevrolet Volt replaces the Ford Focus pool vehicle ***1202, a 28\% reduction in GHG emissions in New York occurs. The Focus traveling 7,320 miles per year produces 4,746 lb- $\mathrm{CO}_{2} \mathrm{e} / \mathrm{year}$, whereas the Volt produces 3,4411b- $\mathrm{CO}_{2} \mathrm{e} /$ year for that same distance for a reduction of $1,305 \mathrm{lb}-\mathrm{CO}_{2} \mathrm{e} /$ year.

Table shows the high potential benefit in reduction of GHG emissions in the local VA - Bronx area. In addition, the fuel cost reduction potential benefit is also significant due to the low cost of power.

As presented in Section 5, 11 BEVs and 12 PHEVs could replace the entire pool fleet of 23 vehicles. None of the other mission categories were studied to extrapolate results to the entire fleet. However, using an average savings per vehicle, Table 19 provides the avoided GHG and fuel cost savings should these replacements occur. The table also shows the percentage reduction in GHG emissions and fuel costs for ease of comparison. Only local New York savings are projected in this table, while national figures are presented in Appendix C.

\footnotetext{
${ }^{33}$ http://www.newyorkgasprices.com/Bronx/index.aspx [October 13, 2014].

${ }^{34} \mathrm{http}: / / w w w . e i a . g o v /$ electricity/state/ [Accessed October 3, 2014].
} 
Table 18. GHG emissions avoidance and fuel cost reduction analysis summary.

\begin{tabular}{cccccc}
\hline & & $\begin{array}{c}\text { Extrapolated } \\
\text { Local. Yearly }\end{array}$ & \multicolumn{3}{c}{$\begin{array}{c}\text { Extrapolated } \\
\text { Local Yearly }\end{array}$} \\
Mission & Replacement Model & $\begin{array}{c}\mathrm{CO}_{2} \mathrm{e} \text { Avoided } \\
\left({\left.\mathrm{lb}-\mathrm{CO}_{2} \mathrm{e} / \text { year }\right)}\right.\end{array}$ & $\begin{array}{c}\text { Fuel Cost } \\
\text { Reduction }\end{array}$ & \% reduction \\
\hline Pool & Ford Fusion & 79 & $4 \%$ & $\$ 137$ & $36 \%$ \\
Pool & Nissan Leaf & 1,125 & $22 \%$ & $\$ 426$ & $48 \%$ \\
Pool & Ford Focus & 3,937 & $44 \%$ & $\$ 963$ & $63 \%$ \\
Pool & Nissan Leaf & 6,129 & $56 \%$ & $\$ 1,329$ & $71 \%$ \\
Pool & Chevrolet Volt & 1,305 & $28 \%$ & $\$ 423$ & $52 \%$ \\
Pool & Mitsubishi Outlander & 2,037 & $41 \%$ & $\$ 517$ & $61 \%$ \\
Bus & NA & NA & NA & NA & NA \\
Bus & NA & NA & NA & NA & NA \\
Bus & NA & NA & NA & NA & NA \\
& Total & $\mathbf{1 4 , 6 1 3}$ & $\mathbf{4 0 \%}$ & $\mathbf{\$ 3 , 7 9 6}$ & $\mathbf{6 0 \%}$
\end{tabular}

Table 19. Extrapolated greenhouse gas emissions avoided and fuel cost savings for the entire fleet.

\begin{tabular}{ccccc}
\hline & $\begin{array}{c}\text { Extrapolated Local } \\
\text { Yearly } \mathrm{CO}_{2} \mathrm{e} \text { Avoided } \\
\left(\mathrm{lb}-\mathrm{CO}_{2} \mathrm{e} / \text { year }\right)\end{array}$ & $\%$ reduction & $\begin{array}{c}\text { Extrapolated Local } \\
\text { Yearly Fuel Cost } \\
\text { Reduction }(\$ / \text { year }\end{array}$ & $\%$ reduction \\
\hline Pool & 48,361 & $36 \%$ & $\$ 13,205$ & $58 \%$ \\
\hline
\end{tabular}

\section{OBSERVATIONS}

Intertek appreciates the opportunity to present the results of this evaluation. Observations for possible follow-up action include the following:

\section{Observation \#1:}

Implementation: VA - Bronx can move forward in the near future with replacement of pool vehicles with PEVs as current budget and vehicle replacement schedules allow. Certainly, all pool vehicle types studied in this report are candidates for immediate replacement.

\section{Observation \#2:}

Fleet Inventory: A more thorough examination of the quantities and types of fleet vehicles within each usage category may be beneficial to quantify the potential for replacement by PEVs. While Intertek suggests a mix of BEVs and PHEVs, a more refined look may be possible. In addition, this study did not look at the other fleet vehicle categories, such as those with specialty, support, enforcement, or transport missions, in detail.

\section{Observation \#3:}

Vehicle Replacement Plan: The development of a detailed vehicle replacement plan could be beneficial. This plan would include the schedule for vehicle replacement and EVSE infrastructure installation. A more detailed survey and calculation of the use of the fleet vehicles (such as vehicle parking locations, age of vehicle, expected replacement time, expected replacement costs, GSA vehicle costs, EVSE cost, total life costs, and EVSE installation costs) provide support to this replacement plan. A more refined estimate for reduced GHG emissions, petroleum usage reduction, and fuel cost savings flow from this detailed plan. 


\section{Observation \#4:}

Infrastructure Planning: In conjunction with the replacement plan, evaluation of the VA - Bronx sites for placement of PEV charging infrastructure could be beneficial. Intertek has significant experience in this area and such plans will consider not only fleet vehicle charging needs, but also the convenience that charging infrastructure provides employees and visitors. This planning also considers the existing facility electrical distribution system. Vehicle home base considerations factor into the ratio of PEVs to EVSE units to maintain all vehicles at operational readiness.

Charging stations at VA - Bronx may also provide an opportunity for charging by employees and the public. 


\section{Appendix A Definitions}

Alternative fuel

City fuel economy (MPG)

Conventional fuel

Daily travel

Diesel fuel

E85

Electric vehicle

Ethanol-fueled vehicle

Federal vehicle standards

Government motor vehicle

Gross vehicle weight rating

GSA fleet
An alternative fuel means any fuel other than gasoline and diesel fuels, such as methanol, ethanol, and gaseous fuels (40 CFR 86.1803-01). A fuel type other than petroleum-based gasoline or diesel as defined by the Energy Policy Act (examples include ethanol, methanol, compressed natural gas, propane, and electrical energy).

City fuel economy means the city fuel economy determined by operating a vehicle (or vehicles) over the driving schedule in the federal emission test procedure or determined according to the vehicle-specific 5-cycle or derived 5-cycle procedures (40 CFR 600.001).

A petroleum-based fuel (examples include gasoline and diesel fuel).

The sum of daily trips and stops in one day.

Diesel means a type of engine with operating characteristics significantly similar to the theoretical diesel combustion cycle. The non-use of a throttle during normal operation is indicative of a diesel engine (49 CFR 86-1803).

Ethanol fuel blend of up to $85 \%$ denatured ethanol fuel and gasoline or other hydrocarbons by volume.

Electric vehicle means a motor vehicle that is powered solely by an electric motor drawing current from a rechargeable energy storage system, such as from storage batteries or other portable electrical energy storage devices, including hydrogen fuel cells, provided that

(1) The vehicle is capable of drawing recharge energy from a source off the vehicle, such as residential electric service

(2) The vehicle must be certified to the emission standards of Bin \#1 of Table S04-1 in § 86.1811-09(c)(6)

(3) The vehicle does not have an onboard combustion engine/generator system as a means of providing electrical energy (40 CFR 86-1803).

Ethanol-fueled vehicle-means any motor vehicle or motor vehicle engine that is engineered and designed to be operated using ethanol fuel (i.e., a fuel that contains at least $50 \%$ ethanol $\left(\mathrm{C}_{2} \mathrm{H}_{5} \mathrm{OH}\right)$ by volume) as fuel (40 CFR 86.1803-01).

The document that establishes classifications for various types and sizes of vehicles, general requirements, and equipment options. It is issued annually by the GSA Vehicle Acquisition and Leasing Service's Automotive Division.

Any motor vehicle that the government owns or leases. This includes motor vehicles obtained through purchase, excess, forfeiture, commercial lease, or GSA fleet lease.

Gross vehicle weight rating (GVWR) means the value specified by the vehicle manufacturer as the maximum design loaded weight of a single vehicle (e.g., vocational vehicle) (US Government Printing Office 2009)

GSA fleet lease means obtaining a motor vehicle from the General Services Administration fleet (GSA fleet) (41 CFR 102-34). 
Heavy light-duty truck

Highway fuel economy (Hwy MPG)

Hybrid electric vehicle

Idle time

Law enforcement

Light-duty motor vehicle Light-duty truck
Heavy light-duty truck means any light-duty truck rated greater than 6,000 lb GVWR. The light-duty truck 3 (LDT3) and LDT4 classifications comprise the heavy light-duty truck category (40 CFR 86.1803-01).

Highway fuel economy means the highway fuel economy determined either by operating a vehicle (or vehicles) over the driving schedule in the federal highway fuel economy test procedure or determined according to either the vehicle-specific, 5-cycle equation, or the derived 5-cycle equation for highway fuel economy (40 CFR 600.001).

Hybrid electric vehicle means a motor vehicle that draws propulsion energy from onboard sources of stored energy that are both an internal combustion engine or heat engine using consumable fuel and a rechargeable energy storage system (such as a battery, capacitor, hydraulic accumulator, or flywheel), where recharge energy for the energy storage system comes solely from sources on board the vehicle.

Idle time is logged whenever a vehicle idles with the engine running for 3 minutes or longer.

Law enforcement motor vehicle means a light-duty motor vehicle that is specifically approved in an agency-s appropriation act for use in apprehension, surveillance, police, or other law enforcement work or specifically designed for use in law enforcement. If not identified in an agency's appropriation language, a motor vehicle qualifies as a law enforcement motor vehicle only in the following cases:

(1) A passenger automobile having heavy-duty components for electrical, cooling, and suspension systems and at least the next higher cubic inch displacement or more powerful engine than is standard for the automobile concerned

(2) A light truck having emergency warning lights and identified with markings such as "police"

(3) An unmarked motor vehicle certified by the agency head as essential for the safe and efficient performance of intelligence, counterintelligence, protective, or other law enforcement duties

(4) A forfeited motor vehicle seized by a federal agency that subsequently is used for performing law enforcement activities (41 CFR Part 102-34.35).

Any motor vehicle with a GVWR of 8,500 pounds or less (41 CFR 102-34). Light-duty truck means any motor vehicle rated at 8,500 pounds GVWR or less, which has a curb weight of 6,000 pounds or less and, which has a basic vehicle frontal area of 45 square feet or less, which is as follows:

(1) Designed primarily for purposes of transportation of property or is a derivation of such a vehicle

(2) Designed primarily for transportation of persons and has a capacity of more than 12 persons

(3) Available with special features, enabling off-street or off-highway operation and use.

LDT1 means any light light-duty truck up through 3,750-lb loaded vehicle weight.

LDT2 means any light light-duty truck greater than 3,750-lb loaded vehicle weight. 


\section{Light-duty vehicle \\ Low-speed vehicle \\ Light-duty vehicle means a passenger car or passenger car derivative capable of seating 12 passengers or less. \\ Low-speed vehicle means a motor vehicle \\ (1) That is 4-wheeled \\ (2) Whose speed attainable in $1.6 \mathrm{~km}$ (1 mile) is more than 32 kilometers per hour (20 miles per hour) and not more than 40 kilometers per hour (25 miles per hour) on a paved level surface \\ (3) Whose GVWR is less than 1,361 kilograms (3,000 pounds) (49 CFR 571.3 - Definitions).}

Medium-duty passenger vehicle

Model year

$M P G$

$M P G e$

Non-passenger automobile
LDT3 means any heavy light-duty truck up through 5,750-lb adjusted loaded vehicle weight.

LDT4 means any heavy light-duty truck greater than 5,750-lb adjusted loaded vehicle weight (US Government Printing Office 2009)

Medium-duty passenger vehicle means any heavy-duty vehicle (as defined in this subpart) with a GVWR of less than 10,000 pounds that is designed primarily for transportation of persons. The medium-duty passenger vehicle definition does not include any vehicle which

(1) Is an "incomplete truck" as defined in this subpart

(2) Has a seating capacity of more than 12 persons

(3) Is designed for more than 9 persons in seating rearward of the driver's seat

(4) Is equipped with an open cargo area (for example, a pick-up truck box or bed) of 72.0 inches in interior length or more. A covered box not readily accessible from the passenger compartment will be considered an open cargo area for purposes of this definition (US Government Printing Office 2009)

Model year means the manufacturer's annual production period (as determined by the administrator), which includes January 1 of such calendar year; provided that if the manufacturer has no annual production period, the term "model year" shall mean the calendar year (40 CFR 86-1803.01).

"MPG" or "mpg" means miles per gallon. This generally may be used to describe fuel economy as a quantity or it may be used as the units associated with a particular value.

MPGe means miles per gallon equivalent. This generally is used to quantify a fuel economy value for vehicles that use a fuel other than gasoline. The value represents miles the vehicle can drive with the energy equivalent of one gallon of gasoline:

(c) SCF means standard cubic feet

(d) SUV means sport utility vehicle

(e) CREE means carbon-related exhaust emissions [76 FR 39527, July 6, 2011].

A non-passenger automobile means an automobile that is not a passenger automobile or a work truck and includes vehicles described in paragraphs (a) and (b) of 49 CFR 523.5. 
Owning agency

Passenger automobile

Pickup truck

Plug-in hybrid electric vehicle

Vehicle class

Vehicle configuration

Vehicle days

Vehicle home base

Vehicle study period
Owning agency means the executive agency that holds the vehicle title, manufacturer's Certificate of Origin or is the lessee of a commercial lease. This term does not apply to agencies that lease motor vehicles from the GSA fleet (41 CFR Part 102-34.35).

A passenger automobile is any automobile (other than an automobile capable of off-highway operation) manufactured primarily for use in the transportation of not more than 10 individuals (49 CFR 523.4 - Passenger automobile). A sedan or station wagon designed primarily to transport people (41 CFR 102-34).

Pickup truck means a non-passenger automobile, which has a passenger compartment and an open cargo bed (49 CFR 523.2).

PHEV means a hybrid electric vehicle that has the capability to charge the battery from an off-vehicle electric source, such that the off-vehicle source cannot be connected to the vehicle while the vehicle is in motion (40 CFR 86.1803).

The designation of motor vehicle types that include sedans, station wagons, ambulances, buses, and trucks, or different categories of vehicles according to Federal vehicle standards and further defined in 49 CFR 600.315-82.

Vehicle configuration means a unique combination of basic engine, engine code, inertia weight class, transmission configuration, and axle ratio.

The number of days a vehicle was driven or utilized during the (vehicle) study period.

The primary assigned outing beginning and ending parking location for the vehicle.

The time period the vehicle, within the study, has been equipped with a data logger. 


\section{Appendix B VA - Bronx Vehicle Data Sheets}

Table B-1. VA - Bronx vehicle index.

\begin{tabular}{ccccccc}
\hline Log & Fleet Vehicle Id & Make & Model & Year & EPA Class & Mission \\
\hline 23 & $* * * 9780$ & Ford & Fusion Hybrid & 2010 & Sedan - Midsize & Pool \\
24 & $* * * 9781$ & Ford & Fusion Hybrid & 2010 & Sedan - Midsize & Pool \\
25 & $* * * 2117$ & Ford & Focus & 2009 & Sedan - Compact & Pool \\
26 & $* * * 8065$ & Chevrolet & Impala & 2007 & Sedan - Large & Pool \\
27 & $* * * 1202$ & Ford & Focus & 2012 & Sedan - Compact & Pool \\
28 & $* * * 9502$ & Chevrolet & Venture & 2004 & Minivan & Pool \\
29 & $* * * 0240$ & Chevrolet & Express & 2011 & Van - Pass & Bus/shuttle \\
30 & $* * * 9820$ & Chevrolet & Express & 2010 & Van - Pass & Bus/shuttle \\
31 & $* * * 4826$ & Chevrolet & Express & 2008 & Van - Pass & Bus/shuttle \\
\hline
\end{tabular}




\begin{tabular}{|c|c|c|}
\hline & Make Model/Year & Ford Fusion Hybrid/2010 \\
\hline & EPA Class Size & Sedan - Midsize \\
\hline$m=$ & Mission & Pool \\
\hline & VIN & 3FADP0L3XBR129780 \\
\hline & Parking Location & Sedgwick Ave \\
\hline & Fleet Vehicle ID & $* * * 9780$ \\
\hline & Fuel Type & Gas \\
\hline & EPA Label/MPG (City/Hwy/Combined) & $41 / 36 / 39$ \\
\hline & EPA GHG Emissions (Grams $\mathrm{CO}_{2} / \mathrm{Mi}$ ) & 228 \\
\hline & Study Logger ID & 23 \\
\hline & Total Vehicle Days/Total Study Days & $35 / 117$ \\
\hline
\end{tabular}

\begin{tabular}{|l|c|c|c|c|}
\hline \multicolumn{5}{|c|}{ Vehicle***9780 Travel Summary } \\
& Per Day Average/Peak & $\begin{array}{c}\text { Per Outing } \\
\text { Average/Peak }\end{array}$ & $\begin{array}{c}\text { Per Trip } \\
\text { Average/Peak }\end{array}$ & Total \\
\hline Travel Distance (Miles) & $58.0 / 251.6$ & $50.8 / 663.5$ & $3.2 / 95.6$ & 2,031 \\
\hline Travel Time (Minutes) & $73.0 / 247.0$ & $64.1 / 701.0$ & $4.0 / 143.0$ & 2,564 \\
\hline Idle Time (Minutes) & $4.5 / \mathrm{NA}$ & $4.0 / \mathrm{NA}$ & $0.2 / \mathrm{NA}$ & 158 \\
\hline
\end{tabular}

\begin{tabular}{|c|c|c|c|c|}
\hline \multicolumn{2}{|c|}{ Total Stops } & \multicolumn{2}{c|}{ Stop Duration } \\
\hline $\begin{array}{c}\text { Distance From Home } \\
\text { Base (Miles) }\end{array}$ & Stops & Percentages & $\begin{array}{c}\text { Stop Duration } \\
\text { (Hours) }\end{array}$ & Stops \\
\hline Less than 10 & 105 & $53.8 \%$ & Less than 2 & 130 \\
\hline 10 to 20 & 30 & $15.4 \%$ & 2 to 4 & 14 \\
\hline 20 to 40 & 24 & $12.3 \%$ & 4 to 8 & 12 \\
\hline Greater than 40 & 36 & $18.4 \%$ & Greater than 8 & 39 \\
\hline
\end{tabular}

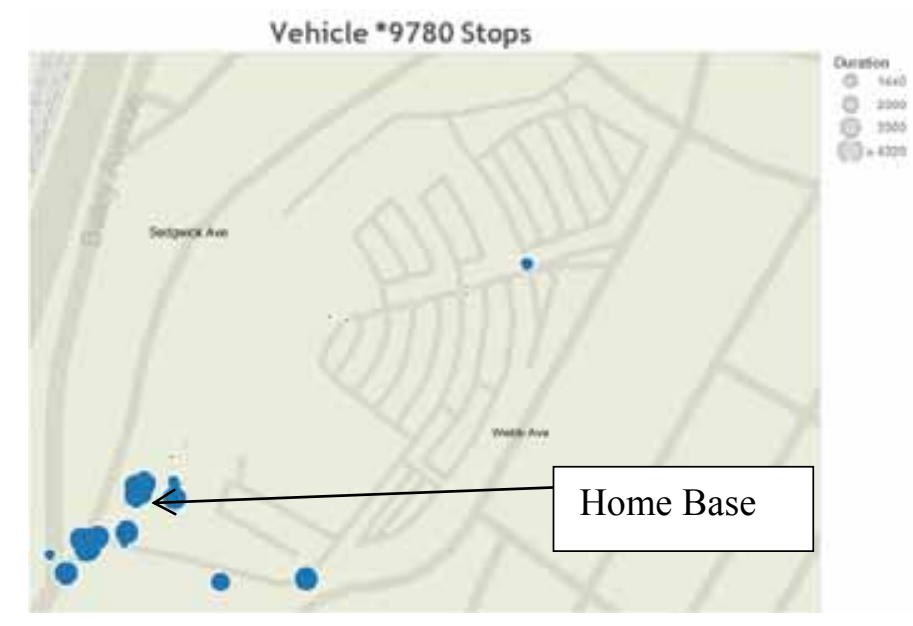

Figure B-1. Vehicle ***9780 stops.

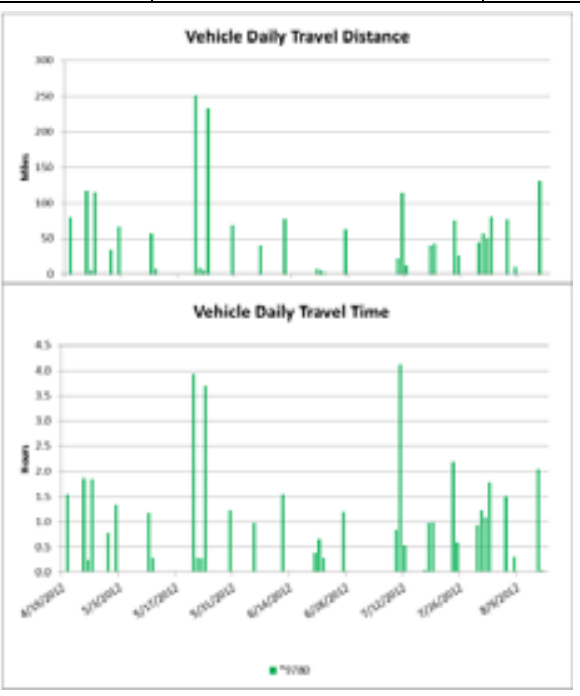

Figure B-2. Vehicle ***9780 history. 

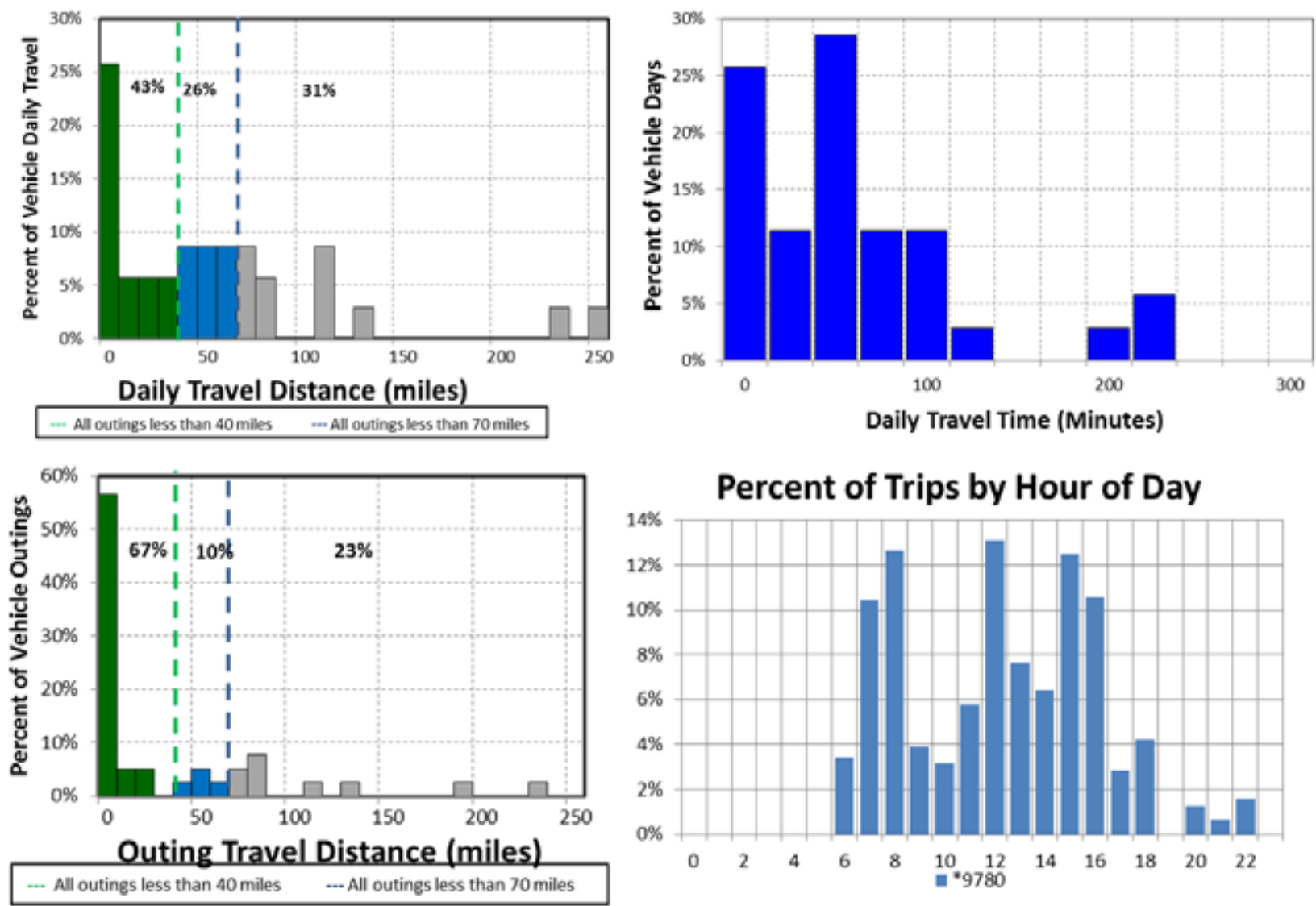

Figure B-1. Vehicle ***9780 travel graphs. Note: Outing graph does not include peak outing of 663.5 miles for clarity of scale.

\section{Vehicle ${ }^{* *} 9780$ Observations}

Logger 23 collected data on this vehicle for 35 days of the 117-day study period. Validation occurred on $98.9 \%$ of the input data. VA - Bronx reports that this vehicle has a pool mission for staff transport. This vehicle's data indicate it parks primarily on Sedgwick Avenue (Figure B-1and the Google Earth figure to the right).

VA - Bronx reports the vehicle odometer indicated 8,001 miles during the study and it traveled 10,000 miles per year. The vehicle was used on $30 \%$ of available days with an average daily usage of 1.2 hours and a peak daily usage of 4.1 hours on the days it was used. The vehicle was used primarily during dayshift hours.

Figure B-3 shows several days of travel exceeding the

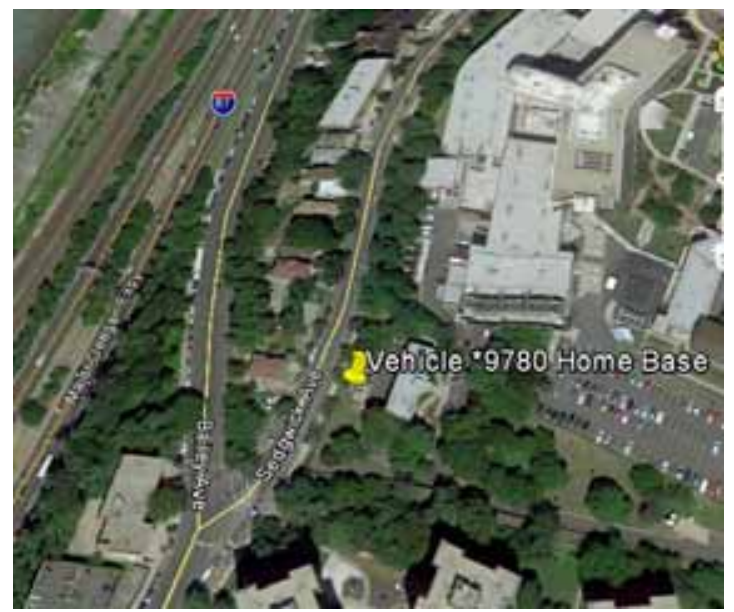
advertised range of a BEV of approximately 70 miles, with $69 \%$ of daily travel is within the BEV range. Seventy-seven percent of the outings are also within this range. Further, $43 \%$ of daily travel and $67 \%$ of outings are within the typically advertised CD mode of 40 miles for PHEVs. The peak outing of 663.5 miles occurred over a several day excursion to locations in Virginia and Maryland.

A BEV could not meet the daily travel, but a PHEV could provide benefits for a significant amount of travel that was local. Thus, a fleet of pool vehicles would likely contain a mix of BEVs and PHEVs. 


\section{Vehicle ${ }^{* *} 9781$}

\begin{tabular}{|c|c|c|}
\hline \multirow{11}{*}{ 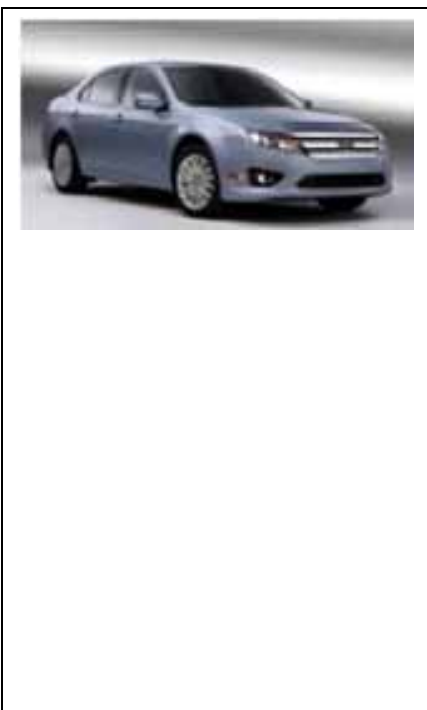 } & Make/Model/Year & Ford Fusion Hybrid/2010 \\
\hline & EPA Class Size & Sedan - Midsize \\
\hline & Mission & Pool \\
\hline & VIN & 3FADP0L31BR129781 \\
\hline & Parking Location & Sedgwick Ave \\
\hline & Fleet Vehicle ID & $* * * 9781$ \\
\hline & Fuel Type & Gas \\
\hline & EPA Label/MPG (City/Hwy/Combined) & $41 / 36 / 39$ \\
\hline & EPA GHG Emissions (Grams $\mathrm{CO}_{2} / \mathrm{Mi}$ ) & 228 \\
\hline & Study Logger ID & 24 \\
\hline & Total Vehicle Days/Total Study Days & $30 / 117$ \\
\hline
\end{tabular}

\begin{tabular}{|l|c|c|c|c|}
\hline \multicolumn{5}{|c|}{ Vehicle***9781 Travel Summary } \\
\hline & $\begin{array}{c}\text { Per Day } \\
\text { Average/Peak }\end{array}$ & $\begin{array}{c}\text { Per Outing } \\
\text { Average/Peak }\end{array}$ & $\begin{array}{c}\text { Per Trip } \\
\text { Average/Peak }\end{array}$ & Total \\
\hline Travel Distance (Miles) & $21.4 / 122.8$ & $13.6 / 139.2$ & $1.41 / 43.9$ & 641 \\
\hline Travel Time (Minutes) & $36.0 / 139.0$ & $22.8 / 163.0$ & $2.4 / 48.0$ & 1,072 \\
\hline Idle Time (Minutes) & $1.8 / \mathrm{NA}$ & $1.1 / \mathrm{NA}$ & $0.1 / \mathrm{NA}$ & 53 \\
\hline
\end{tabular}

\begin{tabular}{|c|c|c|c|c|}
\hline \multicolumn{2}{|c|}{ Total Stops } & \multicolumn{2}{c|}{ Stop Duration } \\
\hline $\begin{array}{c}\text { Distance From } \\
\text { Home Base (Miles) }\end{array}$ & Stops & Percentages & $\begin{array}{c}\text { Stop Duration } \\
\text { (Hours) }\end{array}$ & Stops \\
\hline Less than 10 & 181 & $86.2 \%$ & Less than 2 & 167 \\
\hline 10 to 20 & 17 & $8.1 \%$ & 2 to 4 & 10 \\
\hline 20 to 40 & 11 & $5.2 \%$ & 4 to 8 & 5 \\
\hline Greater than 40 & 1 & $0.5 \%$ & Greater than 8 & 28 \\
\hline
\end{tabular}

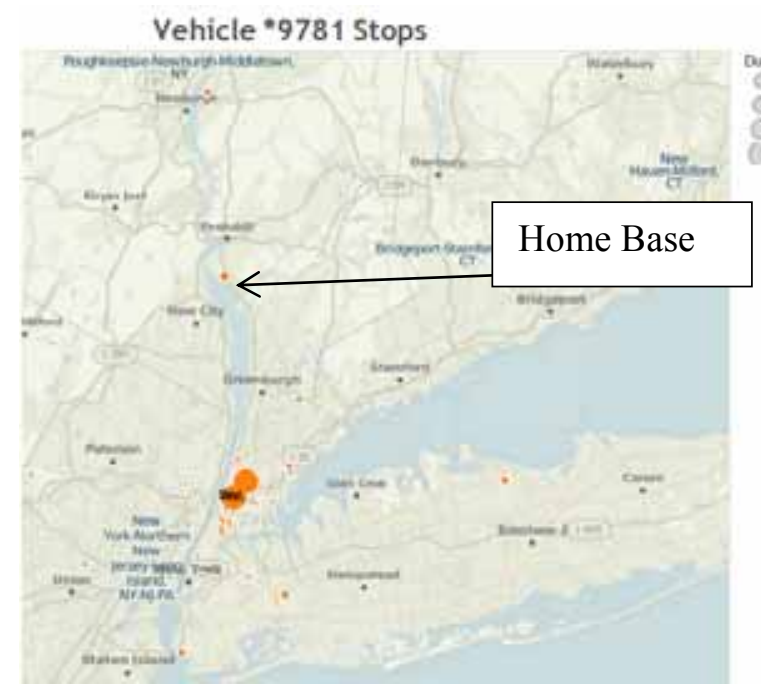

Figure B-4. Vehicle ***9781 stops.

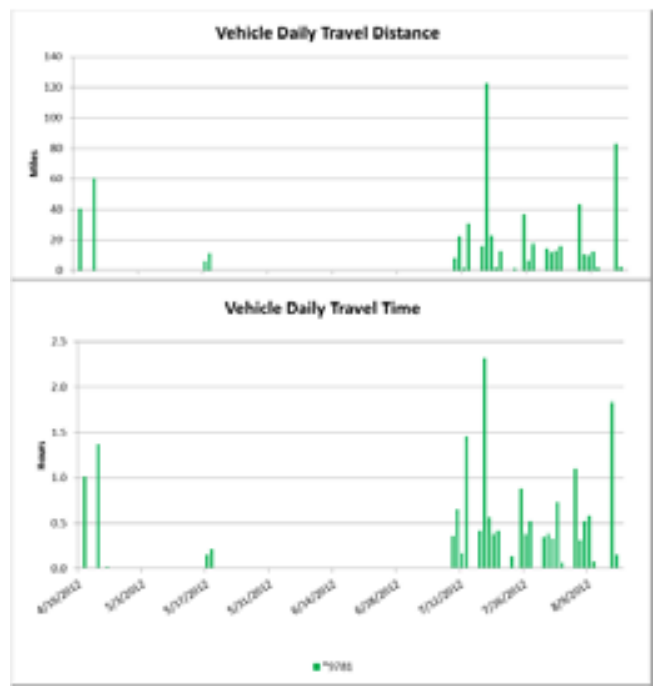

Figure B-5. Vehicle ***9781 history. 


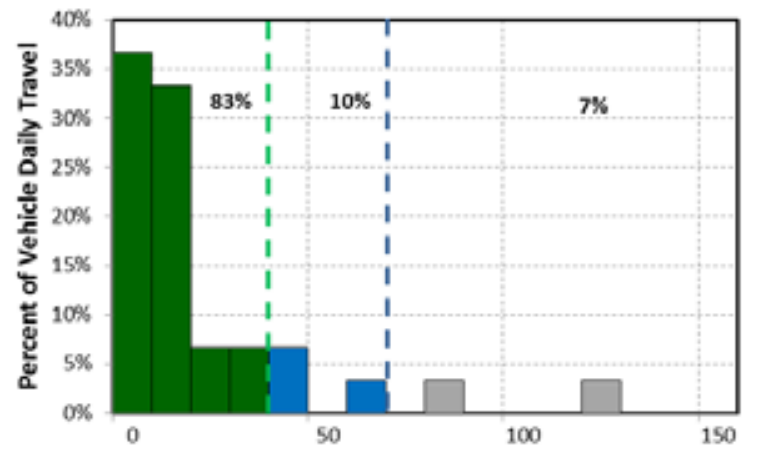

Daily Travel Distance (miles)

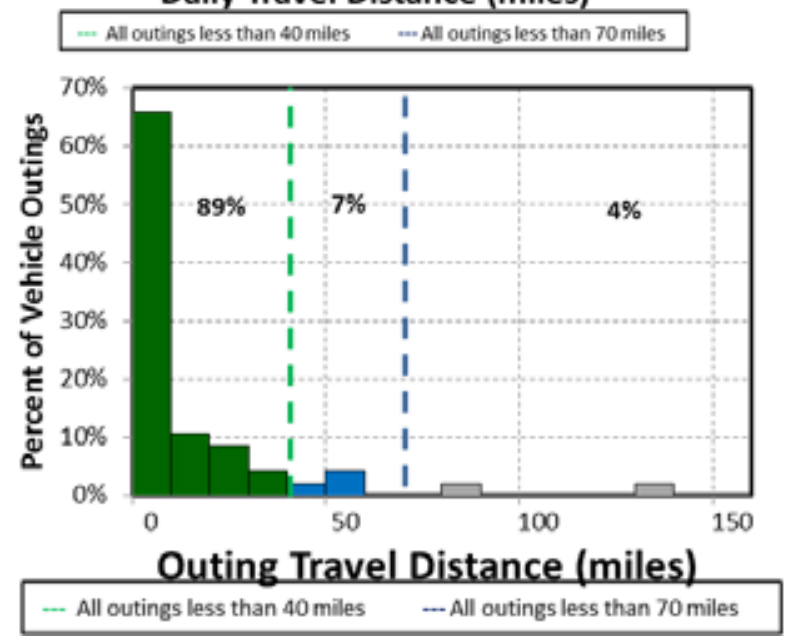

Figure B-2. Vehicle ***9781 travel graphs.
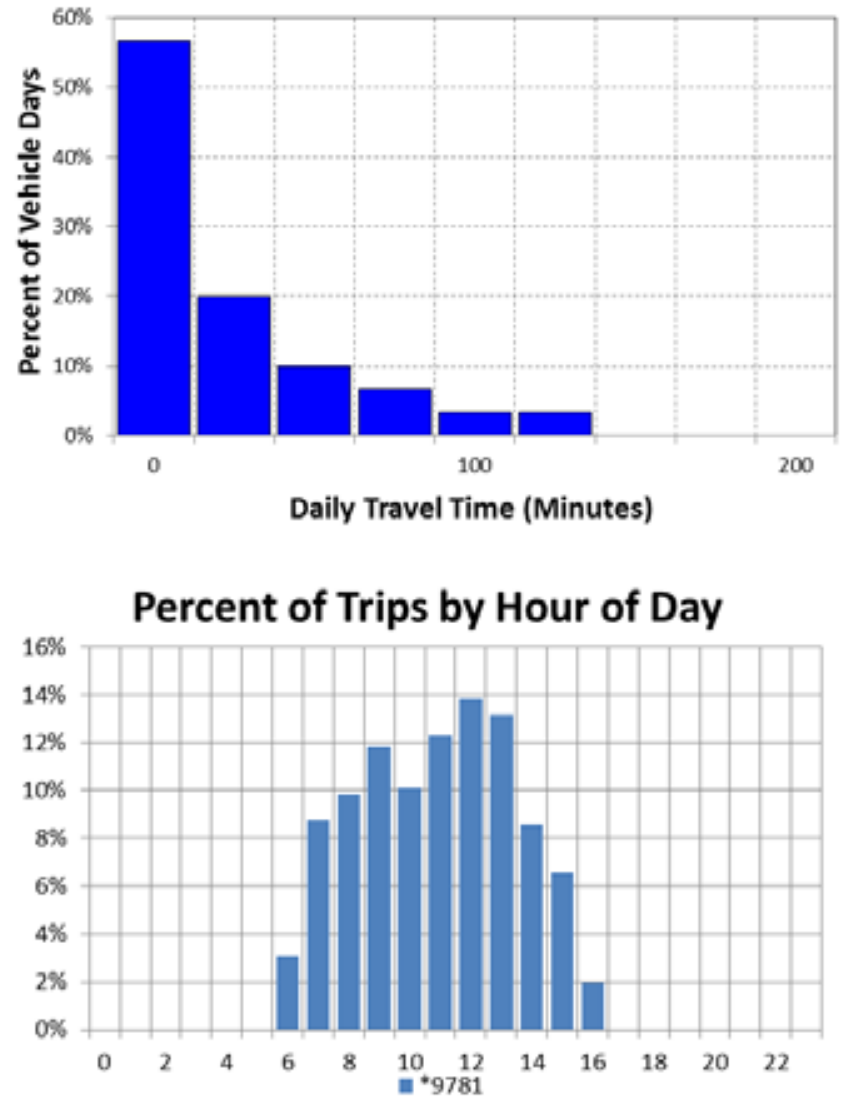

\section{Vehicle ***9781 Observations}

Logger 24 collected data on this vehicle for 30 days of the 117-day study period. Validation occurred on $99.3 \%$ of the input data. VA - Bronx reports this vehicle has a pool mission for staff transport. Data indicate it typically parks overnight on Sedgwick Ave (Figure B-4 and Google Earth figure to the right).

VA - Bronx reports the vehicle odometer indicated 11,353 miles during the study and it travels 10,000 miles per year. The vehicle was used on $26 \%$ of the available days with an average daily usage of 0.6 hours and a peak daily usage of 2.3 hours on the days it was used. The vehicle was used during day shift hours.

Figure B-6 shows $93 \%$ of the daily travel and $96 \%$ of the outings are within the typically advertised range of a BEV of approximately 70 miles. Further, $83 \%$ of daily travel and $89 \%$ of outings are within the typically advertised CD mode of 40 miles for PHEVs.

A BEV cannot meet all daily travel without additional charging opportunities. A PHEV could provide benefits for a significant amount of travel that was local. Thus, a fleet of pool vehicles would likely contain a mix

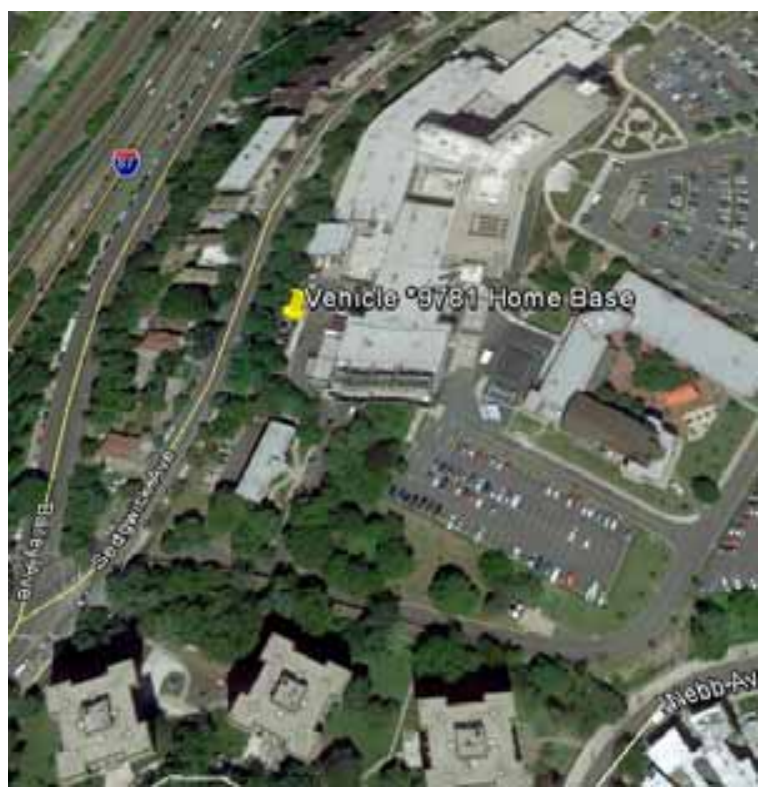
of BEVs and PHEVs. 


\begin{tabular}{|c|c|c|}
\hline & Make/Model/Year & Ford Focus/2009 \\
\hline & EPA Class Size & Sedan - Compact \\
\hline$=$ & Mission & Pool \\
\hline & VIN & 1FAHP35N59W222117 \\
\hline & Parking Location & Sedgwick Ave \\
\hline & Fleet Vehicle ID & $* * * 2117$ \\
\hline & Fuel Type & Gas \\
\hline & EPA Label/MPG (City/Hwy/Combined) & $24 / 33 / 27$ \\
\hline & EPA GHG Emissions (Grams $\mathrm{CO}_{2} / \mathrm{Mi}$ ) & 329 \\
\hline & Study Logger ID & 25 \\
\hline & Total Vehicle Days/Total Study Days & $42 / 115$ \\
\hline
\end{tabular}

\begin{tabular}{|l|c|c|c|c|}
\hline \multicolumn{5}{|c|}{ Vehicle***2117 Travel Summary } \\
\hline & Per Day Average/Peak & $\begin{array}{c}\text { Per Outing } \\
\text { Average/Peak }\end{array}$ & $\begin{array}{c}\text { Per Trip } \\
\text { Average/Peak }\end{array}$ & Total \\
\hline Travel Distance (Miles) & $26.1 / 125.1$ & $10.3 / 124.6$ & $6.3 / 75.2$ & 1,097 \\
\hline Travel Time (Minutes) & $107.0 / 393.0$ & $42.5 / 386.0$ & $26.0 / 362.0$ & 4,501 \\
\hline Idle Time (Minutes) & $30.4 / \mathrm{NA}$ & $12.1 / \mathrm{NA}$ & $7.4 / \mathrm{NA}$ & 1,278 \\
\hline
\end{tabular}

\begin{tabular}{|c|c|c|c|c|}
\hline \multicolumn{2}{|c|}{ Total Stops } & \multicolumn{2}{c|}{ Stop Duration } \\
\hline $\begin{array}{c}\text { Distance From Home } \\
\text { Base (Miles) }\end{array}$ & Stops & Percentages & $\begin{array}{c}\text { Stop Duration } \\
\text { (Hours) }\end{array}$ & Stops \\
\hline Less than 10 & 102 & $87.2 \%$ & Less than 2 & 83 \\
\hline 10 to 20 & 10 & $8.5 \%$ & 2 to 4 & 5 \\
\hline 20 to 40 & 4 & $3.4 \%$ & 4 to 8 & 2 \\
\hline 40 to 60 & 1 & $0.9 \%$ & Greater than 8 & 27 \\
\hline
\end{tabular}

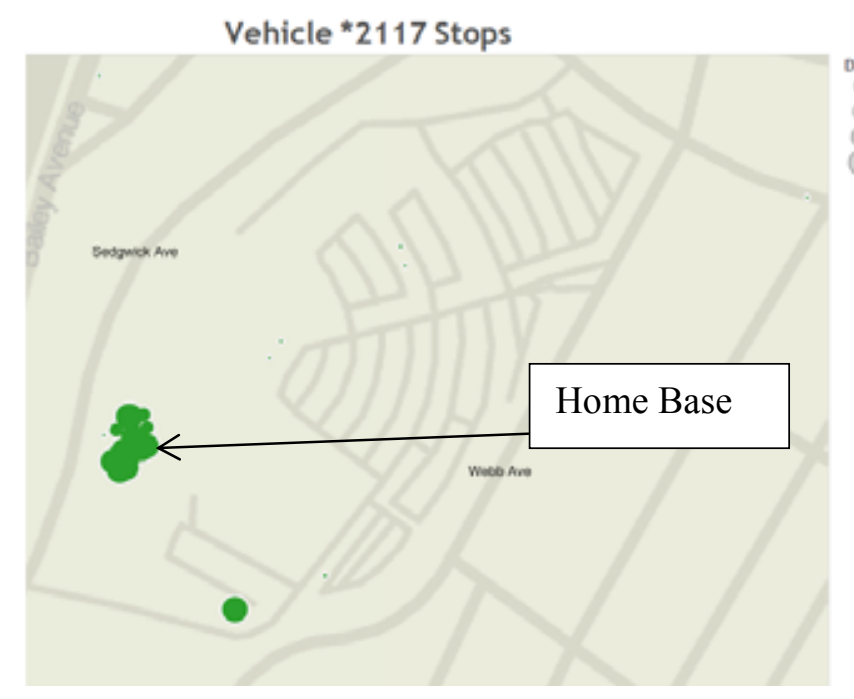

Figure B-7. Vehicle ***2117 stops.

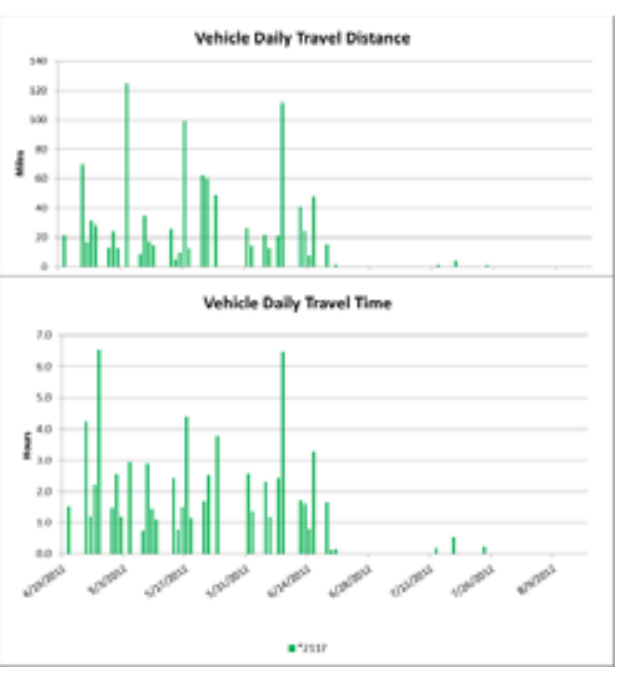

Figure B-8. Vehicle ***2117 history. 


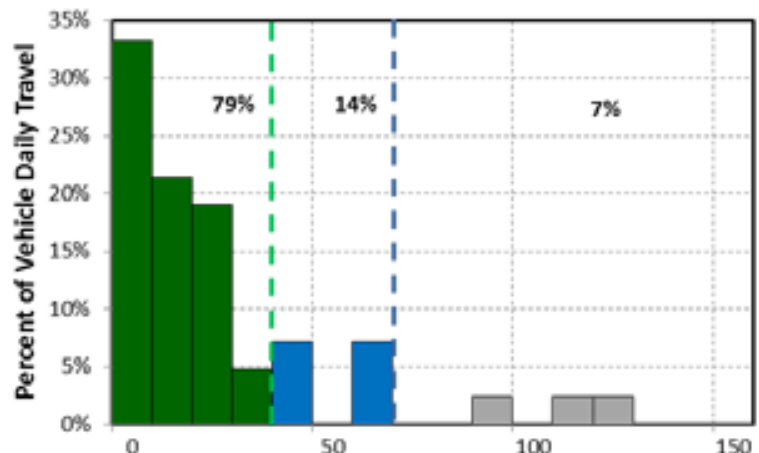

Daily Travel Distance (miles)

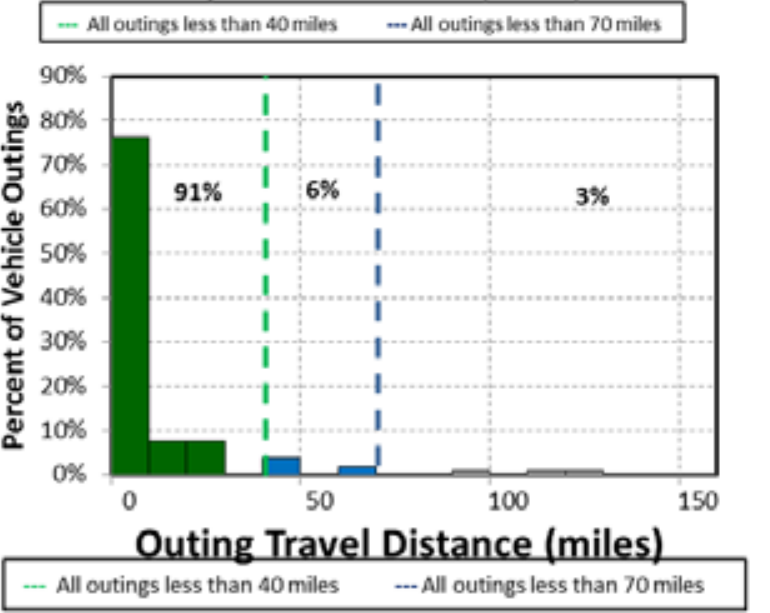

Figure B-3. Vehicle ***2117 travel graphs.
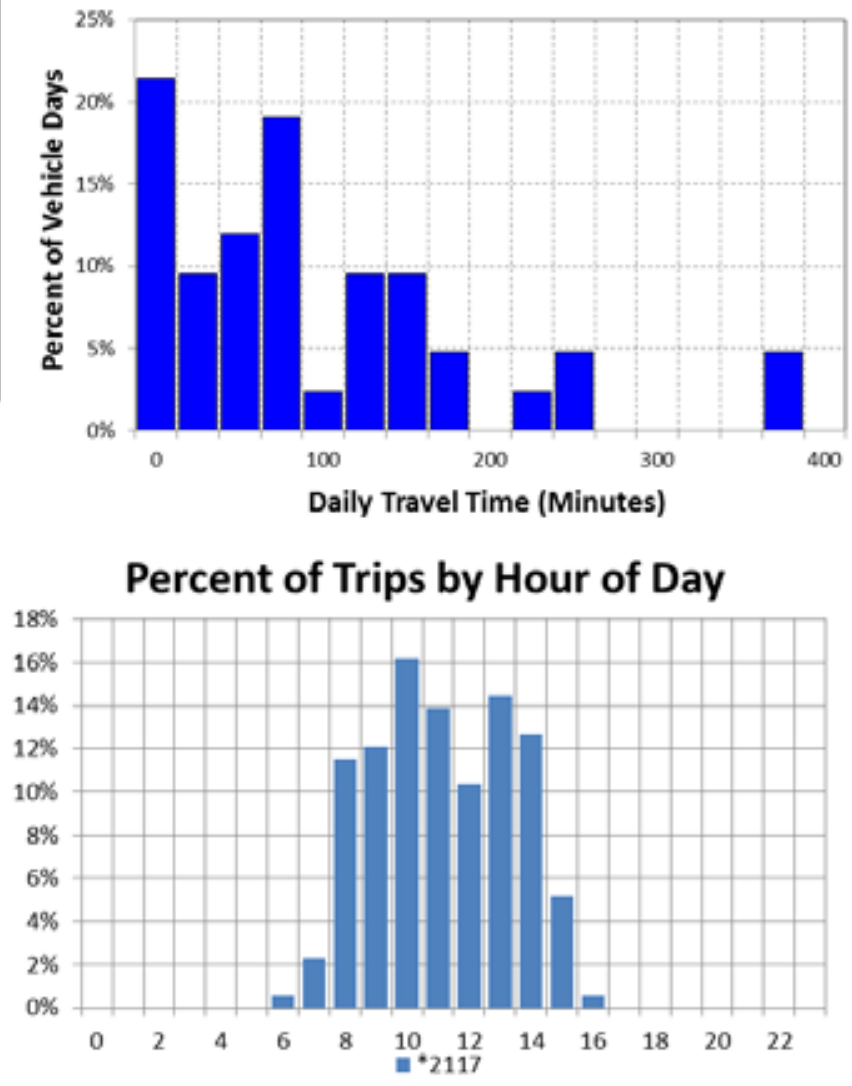

\section{Vehicle $^{* * *} 2117$ Observations}

Logger 25 collected data on this vehicle for 42 days of the 115-day study period. Validation occurred on $98.9 \%$ of the input data. VA - Bronx reports this vehicle has a pool mission and is used for staff transport. It typically parks near Sedgwick Avenue (Figure B-7 and Google Earth figure to the right).

VA - Bronx reports the vehicle odometer indicated 19,880 miles during the study and it travels 12,000 miles per year. The vehicle was used on $37 \%$ of available days, with an average daily usage of 2.0 hours and a peak daily usage of 6.6 hours on the days it was used. The vehicle was used during typical day shift hours.

Figure B-9 shows $93 \%$ of daily travel and $97 \%$ outings were within the typically advertised range of a BEV of

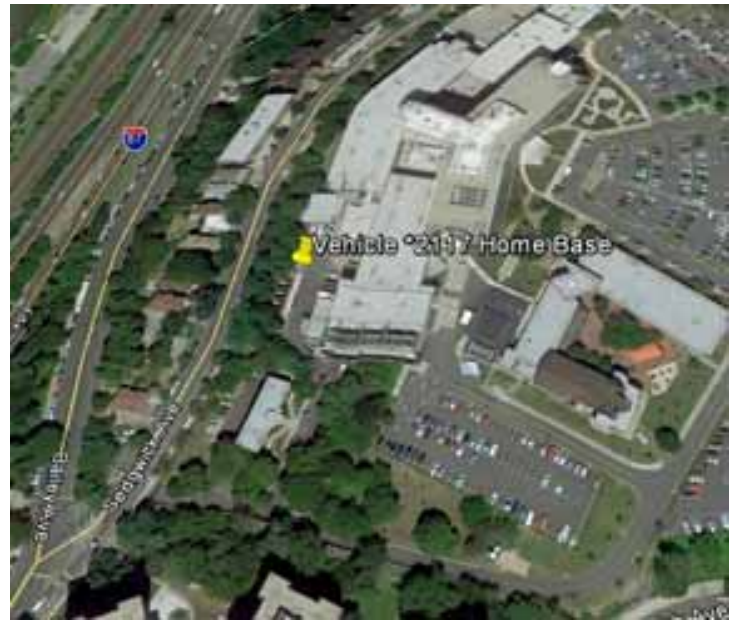
approximately 70 miles. Further, $79 \%$ of daily travel and $91 \%$ of outings were within the typically advertised CD mode of 40 miles for PHEVs. The peak outing of 124.6 miles occurred on May 4, 2014, on a single outing to Beacon, NY.

A BEV could not meet the daily travel without additional charging opportunities. A PHEV could provide benefits for a significant amount of travel that was local. Thus, a fleet of pool vehicles would likely contain a mix of BEVs and PHEVs. 


\section{Vehicle $^{* * *} 8065$}

\begin{tabular}{|l|l|c|}
\hline \multirow{4}{*}{} & Make/Model/Year & Chevrolet Impala/2007 \\
\cline { 2 - 3 } & EPA Class Size & Sedan - Large \\
\cline { 2 - 3 } & Mission & Pool \\
\hline VIN & Sedgwick Ave \\
\cline { 2 - 3 } & Parking Location & $* * * 8065$ \\
\cline { 2 - 3 } & Fleet Vehicle ID & Gas \\
\hline & Fuel Type & $18 / 28 / 22$ \\
\hline & EPA Label/MPG (City/Hwy/Combined) & 404 \\
\cline { 2 - 3 } & EPA GHG Emissions (Grams CO $/$ Mi) & 26 \\
\hline & Study Logger ID & $66 / 98$ \\
\hline
\end{tabular}

\begin{tabular}{|l|c|c|c|c|}
\hline \multicolumn{5}{|c|}{ Vehicle ***8065 Travel Summary } \\
\hline & Per Day Average/Peak & $\begin{array}{c}\text { Per Outing } \\
\text { Average/Peak }\end{array}$ & $\begin{array}{c}\text { Per Trip } \\
\text { Average/Peak }\end{array}$ & Total \\
\hline Travel Distance (Miles) & $32.6 / 95.0$ & $17.4 / 94.8$ & $5.2 / 42.0$ & 2,153 \\
\hline Travel Time (Minutes) & $120 / 271.0$ & $63.6 / 271.0$ & $19.2 / 132.0$ & 7,890 \\
\hline Idle Time (Minutes) & $39.1 / \mathrm{NA}$ & $20.8 / \mathrm{NA}$ & $6.3 / \mathrm{NA}$ & 2,582 \\
\hline
\end{tabular}

\begin{tabular}{|c|c|c|c|c|}
\hline \multicolumn{2}{|c|}{ Total Stops } & \multicolumn{2}{c|}{ Stop Duration } \\
\hline $\begin{array}{c}\text { Distance From Home } \\
\text { Base (Miles) }\end{array}$ & Stops & Percentages & Stop Duration (Hours) & Stops \\
\hline Less than 10 & 276 & $85.4 \%$ & Less than 2 & 259 \\
\hline 10 to 20 & 46 & $14.2 \%$ & 2 to 4 & 10 \\
\hline 20 to 40 & 1 & $0.3 \%$ & 4 to 8 & 0 \\
\hline Greater than 40 & 0 & $0 \%$ & Greater than 8 & 54 \\
\hline
\end{tabular}

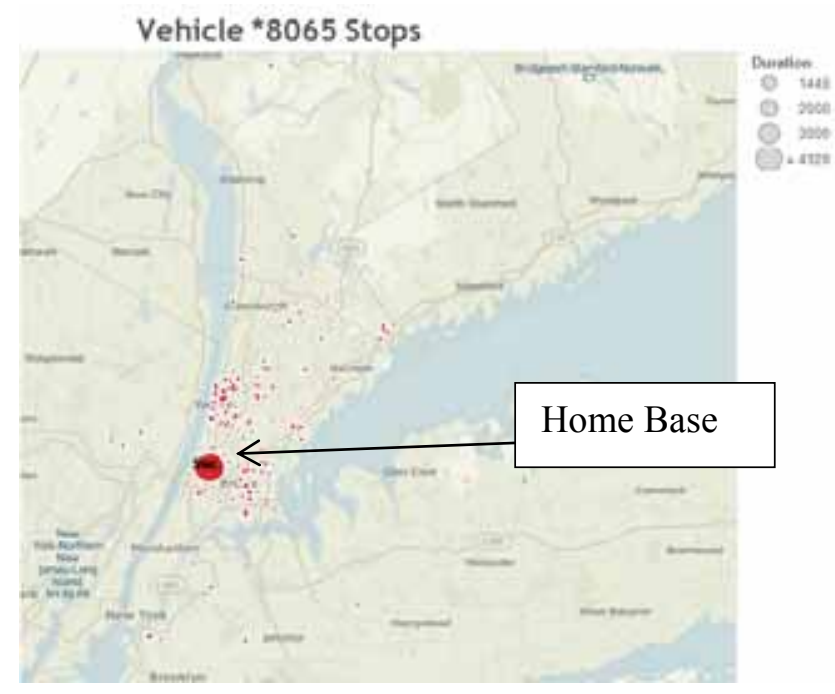

Figure B-10. Vehicle ***8065 stops.

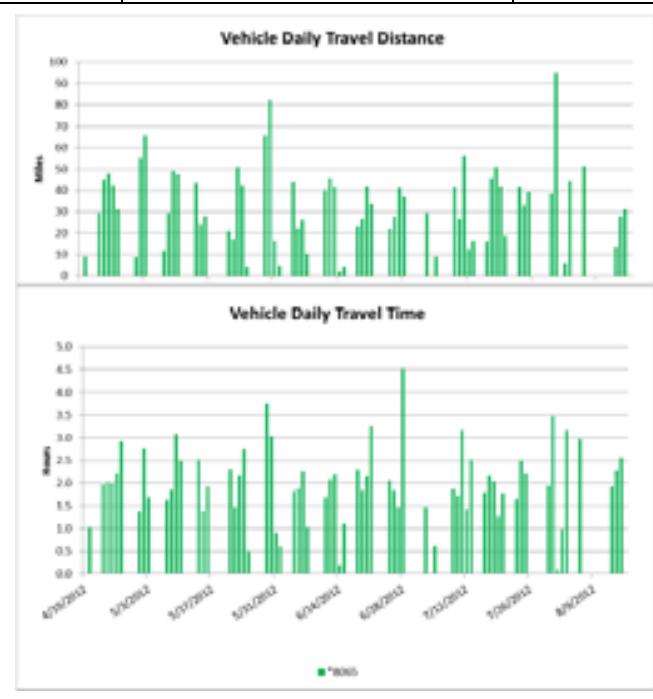

Figure B-11. Vehicle $* * * 8065$ history. 


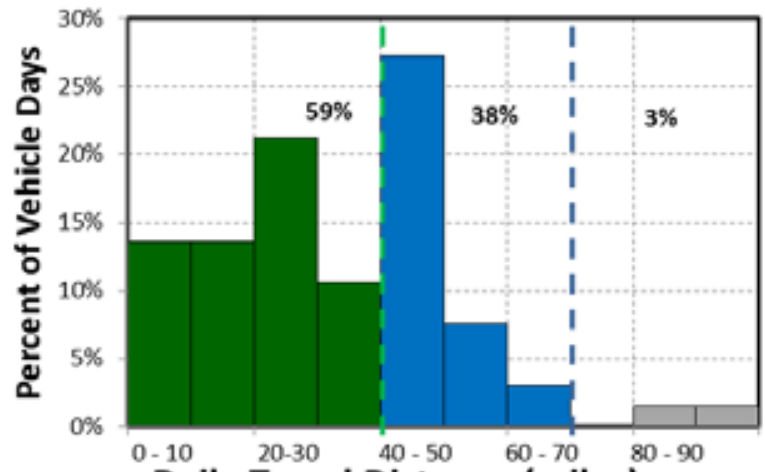

Daily Travel Distance (miles)

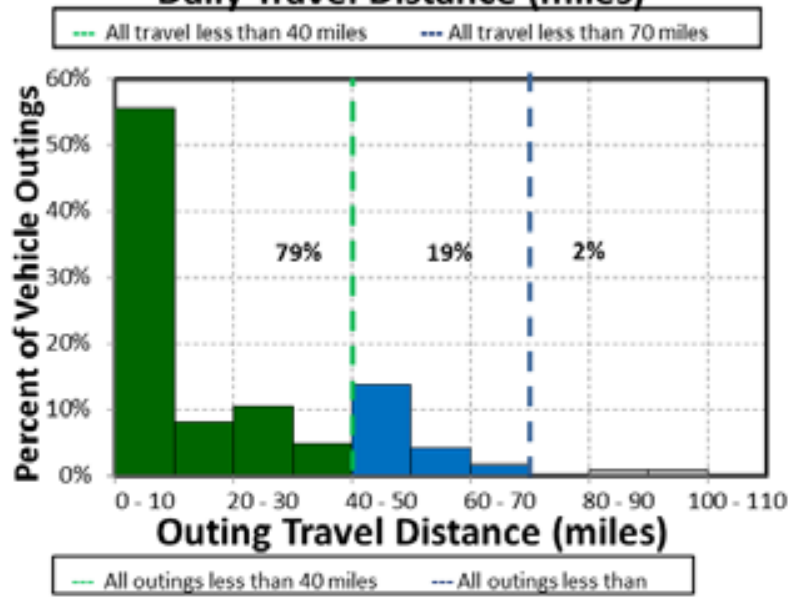

Figure B-4. Vehicle ***8065 travel graphs.

\section{Vehicle ${ }^{* *} 8065$ Observations}

Logger 26 collected data on this vehicle for 66 days of the 98-day study period. Validation occurred on $99.4 \%$ of the input data. VA - Bronx reports this vehicle has a pool mission for staff homecare visits. Data show it typically parks near Sedgwick Avenue or Webb Avenue (Figure B-10 and Google Earth figure to the right).

The vehicle odometer information was not available, but VA Bronx reports it travels 12,000 miles per year. The vehicle was used on $67 \%$ of the available days, with an average daily usage of 2.0 hours and a peak daily usage of 4.5 hours on the days it was used. The vehicle was used primarily during typical day shift hours.

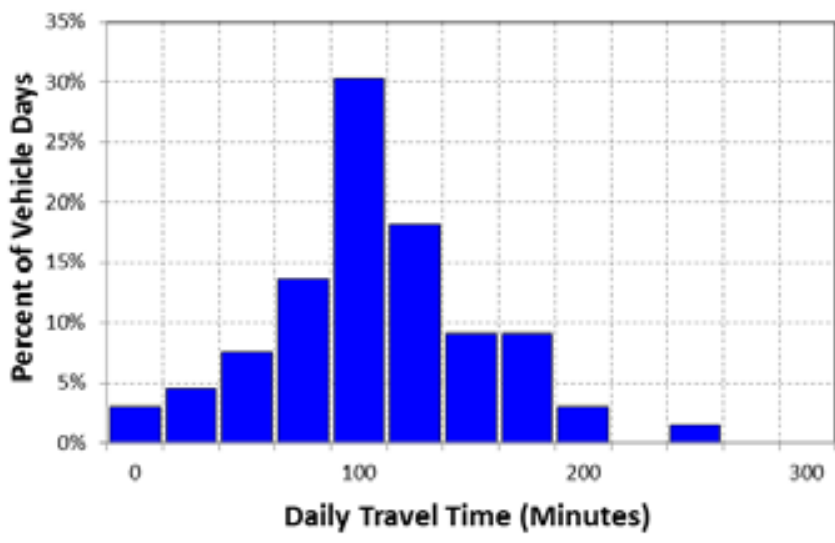

Percent of Trips by Hour of Day

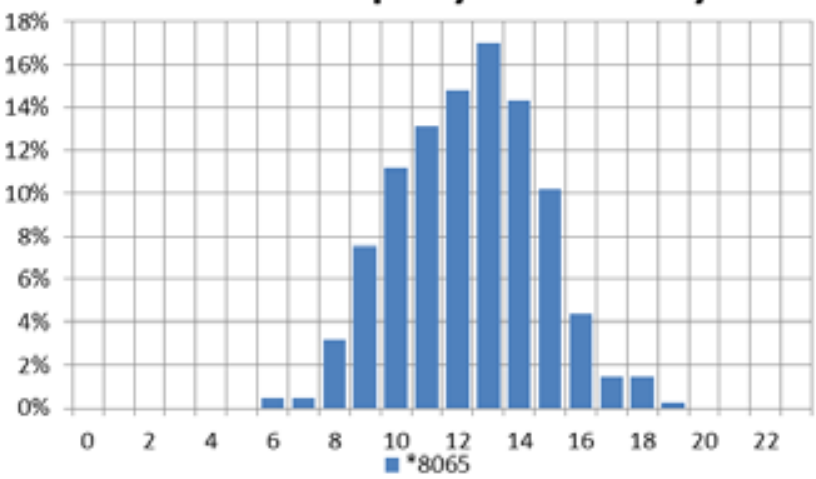

Figure B-12 shows $97 \%$ of daily travel and $98 \%$ of outings were within the typically advertised range of a BEV of approximately 70 miles. Further, $59 \%$ of daily travel and $79 \%$ of outings were within the typically advertised CD mode of 40 miles for PHEVs.

A BEV could not meet all daily travel noted without additional charging opportunities. A PHEV could provide benefits for a significant amount of travel that was local. Thus, a fleet of pool vehicles would likely contain a mix of BEVs and PHEVs. 


\begin{tabular}{|c|c|c|}
\hline 3 & Make/Model/Year & Ford Focus/2012 \\
\hline 18.6 & EPA Class Size & Sedan - Compact \\
\hline$+8 \theta_{0}$ & Mission & Pool \\
\hline 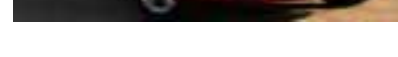 & VIN & 1FAHP3F25CL201202 \\
\hline & Parking Location & Sedgwick Ave \\
\hline & Fleet Vehicle ID & $* * * 1202$ \\
\hline & Fuel Type & Gas \\
\hline & EPA Label/MPG (City/Hwy) & $27 / 37 / 31$ \\
\hline & EPA GHG Emissions (Grams $\mathrm{CO}_{2} / \mathrm{Mi}$ ) & 287 \\
\hline & Study Logger ID & 27 \\
\hline & Total Vehicle Days/Total Study Days & $74 / 118$ \\
\hline
\end{tabular}

\begin{tabular}{|l|c|c|c|c|}
\hline \multicolumn{5}{|c|}{ Vehicle***1202 Travel Summary } \\
& Per Day Average/Peak & $\begin{array}{c}\text { Per Outing } \\
\text { Average/Peak }\end{array}$ & $\begin{array}{c}\text { Per Trip } \\
\text { Average/Peak }\end{array}$ & Total \\
\hline Travel Distance (Miles) & $44.4 / 296.3$ & $17.3 / 626.5$ & $7.3 / 260.4$ & 3,283 \\
\hline Travel Time (Minutes) & $142.0 / 362.0$ & $55.3 / 724.0$ & $23.3 / 246.0$ & 10,514 \\
\hline Idle Time (Minutes) & $33.3 / \mathrm{NA}$ & $13.0 / \mathrm{NA}$ & $5.5 / \mathrm{NA}$ & 2,466 \\
\hline
\end{tabular}

\begin{tabular}{|c|c|c|c|c|}
\hline \multicolumn{2}{|c|}{ Total Stops } & \multicolumn{2}{c|}{ Stop Duration } \\
\hline $\begin{array}{c}\text { Distance From Home } \\
\text { Base (Miles) }\end{array}$ & Stops & Percentages & $\begin{array}{c}\text { Stop Duration } \\
\text { (Hours) }\end{array}$ & Stops \\
\hline Less than 10 & 310 & $78.7 \%$ & Less than 2 & 303 \\
\hline 10 to 20 & 39 & $9.9 \%$ & 2 to 4 & 9 \\
\hline 20 to 40 & 13 & $3.3 \%$ & 4 to 8 & 10 \\
\hline Greater than 40 & 32 & $8.1 \%$ & Greater than 8 & 72 \\
\hline
\end{tabular}

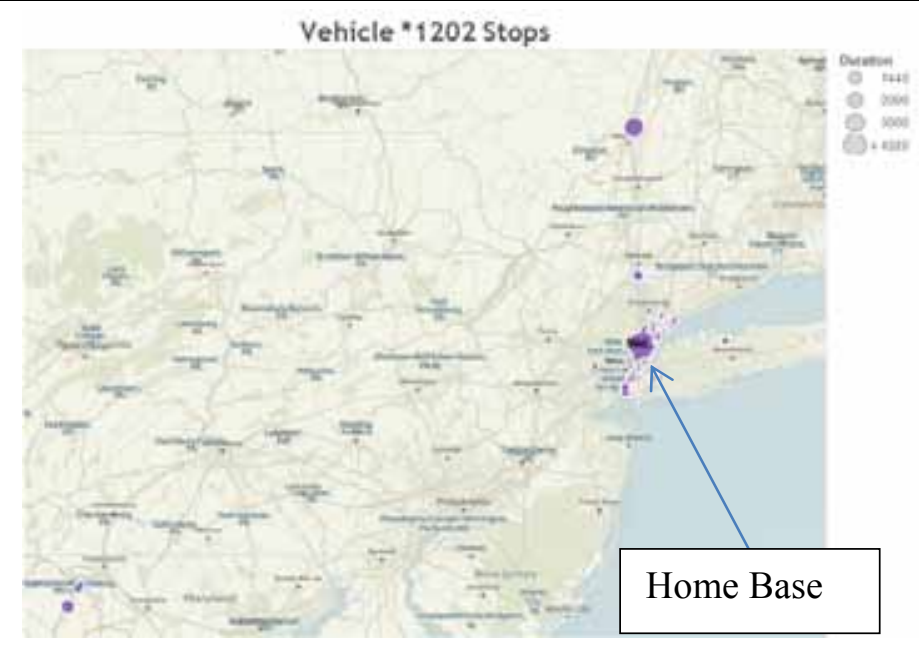

Figure B-13. Vehicle ***1202 stops.

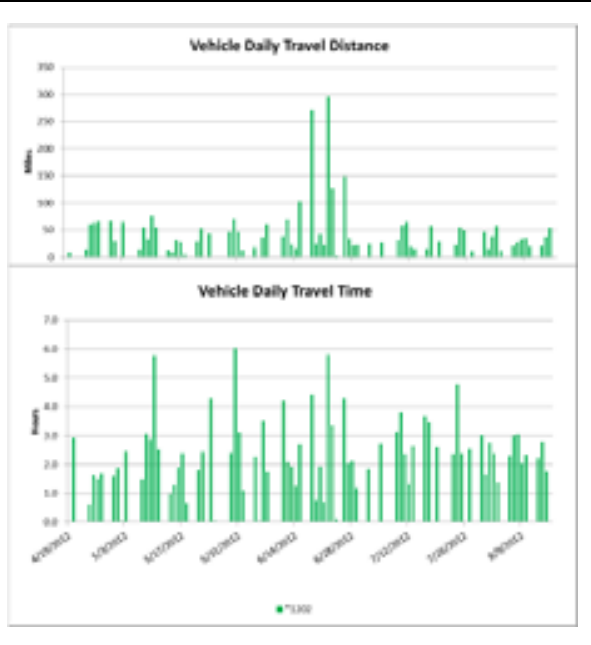

Figure B-14. Vehicle ***1202 history. 

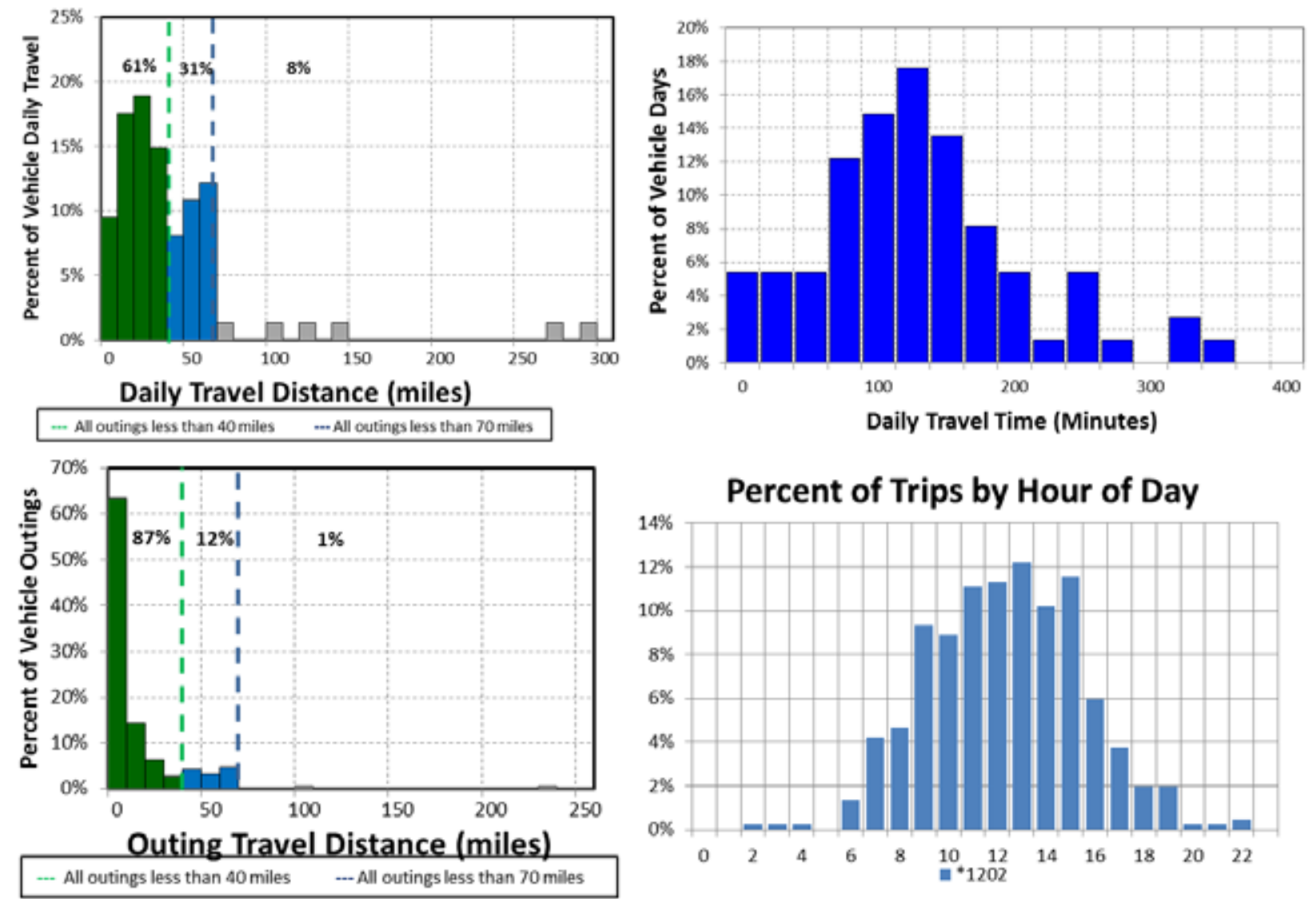

Figure B-5. Vehicle ***1202 travel graphs (note: the peak outing of 626.5 miles was not shown for clarity of scale).

\section{Vehicle $^{* * * 1202}$ Observations}

Logger 27 recorded information on this vehicle for 74 days of the 118-day study period. Validation occurred on $99.4 \%$ of the input data. VA - Bronx reports this vehicle has a pool mission supporting staff transport. Stop data suggests it typically parks on Sedgwick Avenue or Webb Avenue (Figure B-13 and Google Earth figure to the right).

VA - Bronx reports the vehicle odometer indicated 4,699 miles during the study and it travels approximately 12,000 miles per year. The vehicle was used on $63 \%$ of available days and is used primarily during normal dayshift hours.

Figure B-15 shows $92 \%$ of daily travel and $99 \%$ of outings are within the typically advertised range of a BEV of approximately 70 miles. Further, $61 \%$ of daily travel and $87 \%$ of outings are within the typically advertised CD mode of 40 miles for PHEVs. The largest

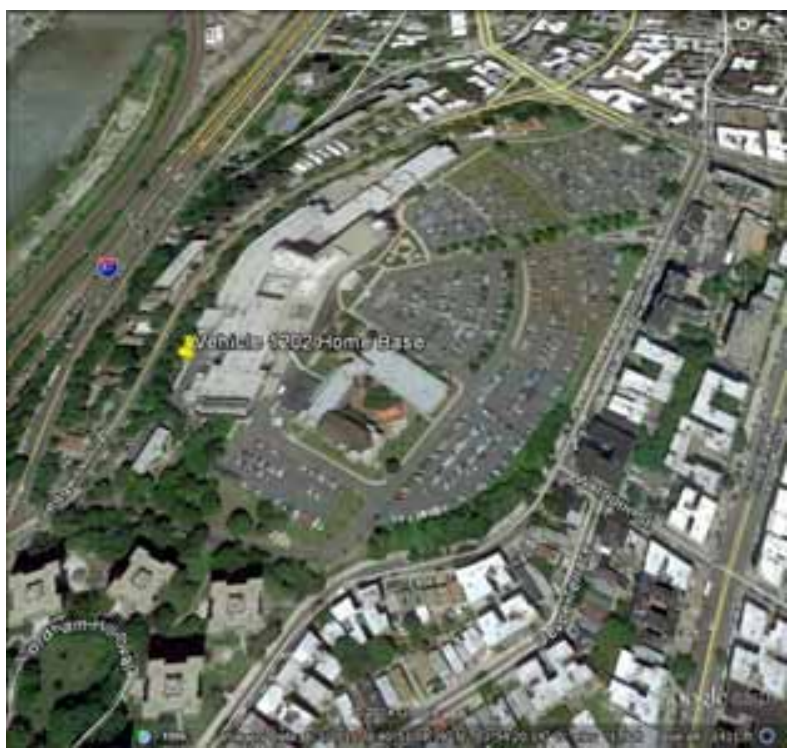
single outing came on a several day excursion to West Virginia.

A BEV could not meet all daily travel noted, especially considering the long trips. A PHEV could provide benefits for a significant amount of travel that was local. Thus, a fleet of pool vehicles would likely contain a mix of BEVs and PHEVs. 
Vehicle ${ }^{* * *} 9502$

\begin{tabular}{|l|l|c|}
\hline & Make/Model/Year & Chevrolet Venture/2004 \\
\cline { 2 - 3 } & EPA Class Size & Minivan \\
\hline Mission & Pool \\
\hline VIN & 1GNDX03E94D249502 \\
\cline { 2 - 3 } & Parking Location & Sedgwick Ave \\
\cline { 2 - 3 } & Fleet Vehicle ID & $* * * 9502$ \\
\hline & Fuel Type & Gas \\
\hline & EPA Label/MPG (City/Hwy/Combined) & $17 / 24 / 20$ \\
\cline { 2 - 3 } & EPA GHG Emissions (Grams CO $/$ Mi) & 444 \\
\hline & Study Logger ID & 28 \\
\hline & Total Vehicle Days/Total Study Days & $69 / 119$ \\
\hline
\end{tabular}

\begin{tabular}{|l|c|c|c|c|}
\hline \multicolumn{5}{|c|}{ Vehicle ***9502 Travel Summary } \\
\hline & $\begin{array}{c}\text { Per Day } \\
\text { Average/Peak }\end{array}$ & $\begin{array}{c}\text { Per Outing } \\
\text { Average/Peak }\end{array}$ & $\begin{array}{c}\text { Per Trip } \\
\text { Average/Peak }\end{array}$ & Total \\
\hline Travel Distance (Miles) & $69.0 / 164.4$ & $13.8 / 101.3$ & $9.6 / 101.3$ & 4,760 \\
\hline Travel Time (Minutes) & $257 / 613.0$ & $51.3 / 348.0$ & $35.6 / 348.0$ & 17,742 \\
\hline Idle Time (Minutes) & $54.3 / \mathrm{NA}$ & $10.8 / \mathrm{NA}$ & $7.5 / \mathrm{NA}$ & 3,750 \\
\hline
\end{tabular}

\begin{tabular}{|c|c|c|c|c|}
\hline \multicolumn{2}{|c|}{ Total Stops } & \multicolumn{2}{c|}{ Stop Duration } \\
\hline $\begin{array}{c}\text { Distance From } \\
\text { Home Base (Miles) }\end{array}$ & Stops & Percentages & Stop Duration (Hours) & Stops \\
\hline Less than 10 & 421 & $95.0 \%$ & Less than 2 & 370 \\
\hline 10 to 20 & 22 & $5.0 \%$ & 2 to 4 & 9 \\
\hline 20 to 40 & 0 & $0 \%$ & 4 to 8 & 4 \\
\hline Greater than 40 & 0 & $0 \%$ & Greater than 8 & 60 \\
\hline
\end{tabular}

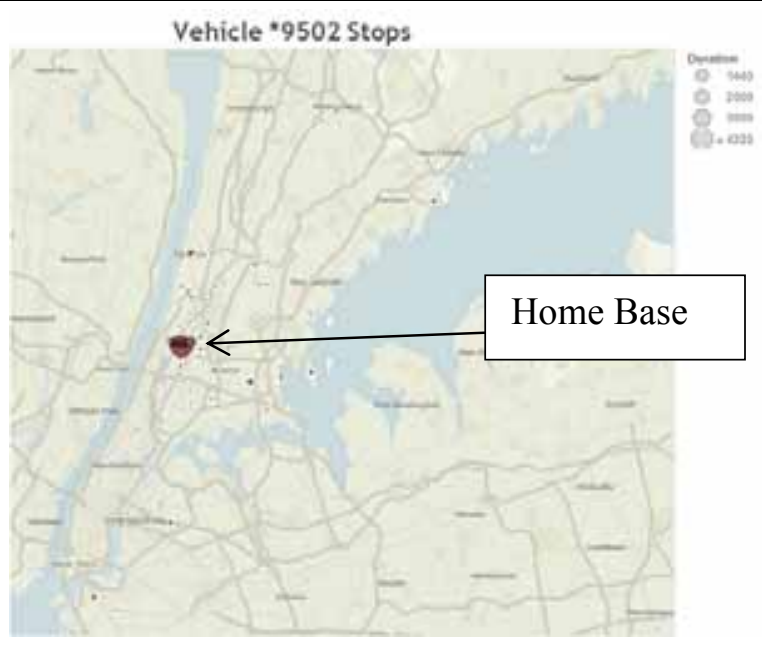

Figure B-16. Vehicle ***9502 stops.

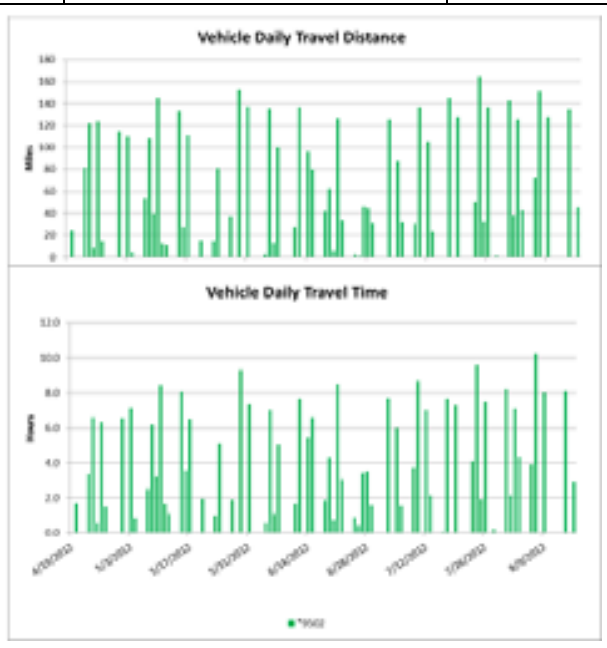

Figure B-17. Vehicle ***9502 history. 

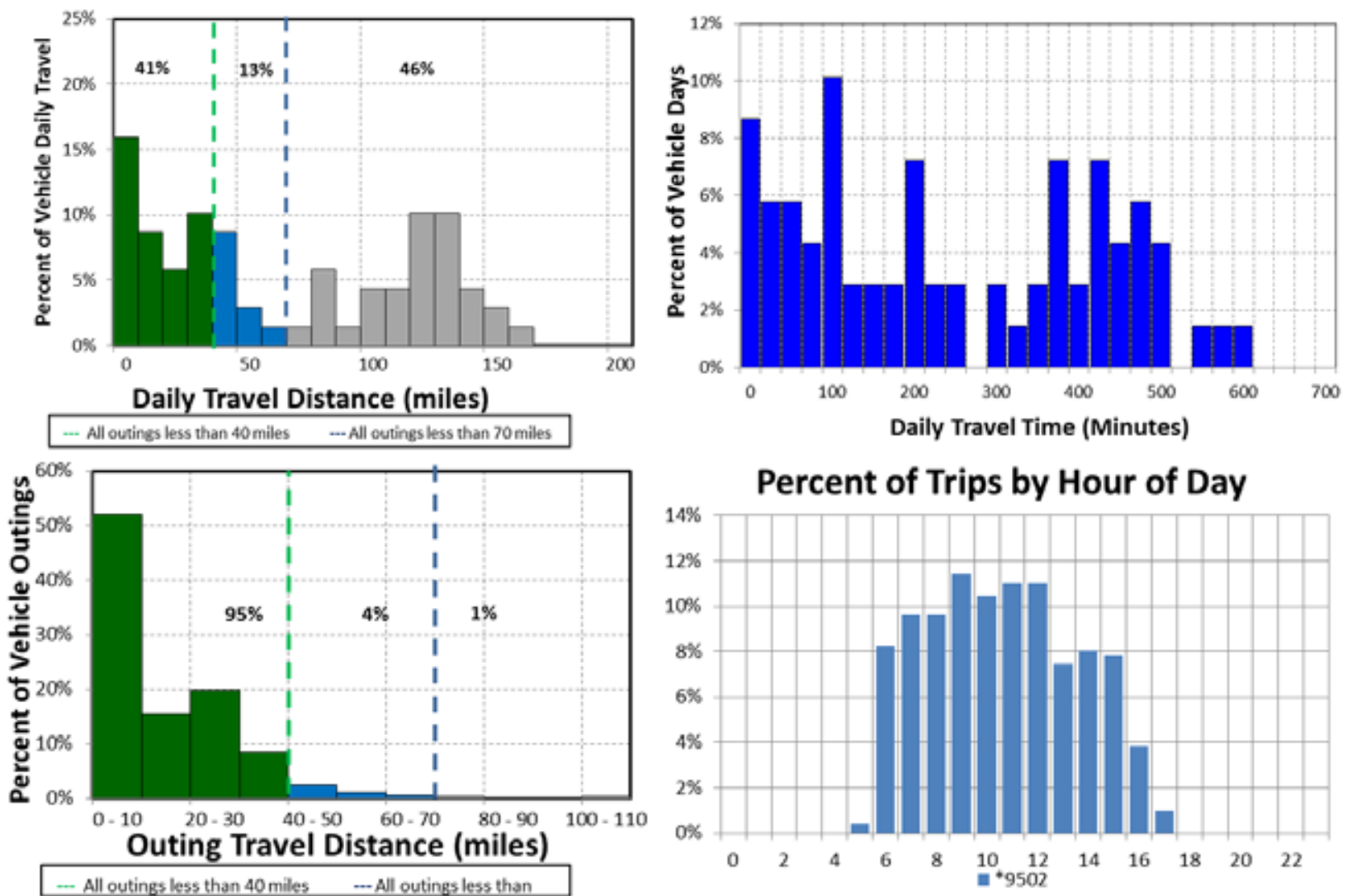

Figure B-6. Vehicle ***9502 travel graphs.

\section{Vehicle ${ }^{* *} 9502$ Observations}

Logger 28 collected data on this vehicle for 69 days of the 119-day study period. Validation occurred on $99.2 \%$ of the input data. VA - Bronx reported that this vehicle has a pool mission, supporting patient and staff transport. Data suggest it typically parks on Sedgwick Avenue (Figure B-16 and the Google Earth figure to the right).

VA - Bronx reports that the vehicle odometer indicated 44,998 miles during the study and it travels 12,000 miles per year. The vehicle was used on $58 \%$ of available days, with an average daily usage of 4.3 hours and a peak daily usage of 10.2 hours on the days it was used. The vehicle was used during typical day shift hours.

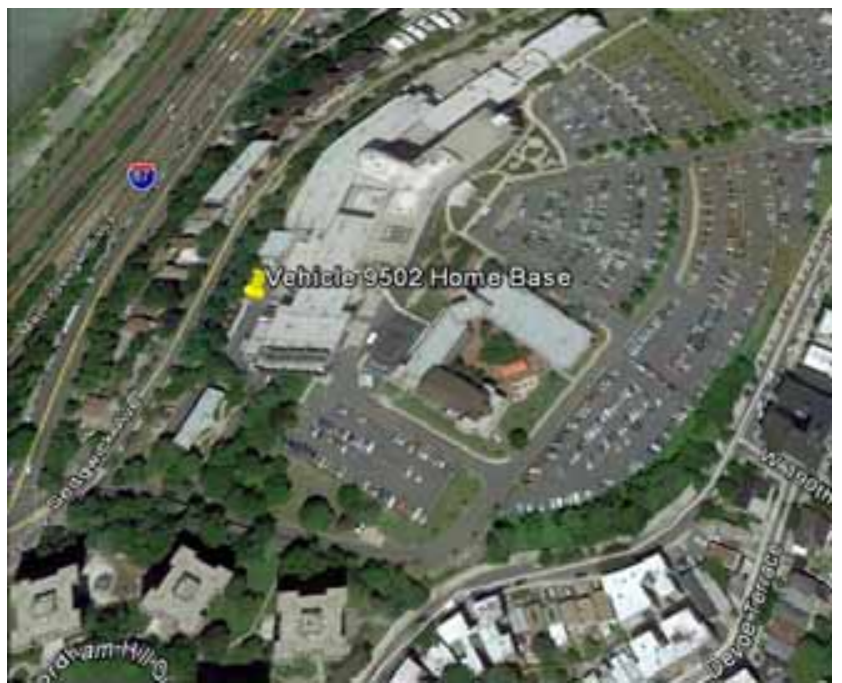

Figure B-18 shows $54 \%$ of daily travel and $99 \%$ of outings were within the typically advertised range of a BEV of approximately 70 miles. Further, $41 \%$ of daily travel and $95 \%$ of outings were within the typically advertised CD mode of 40 miles for PHEVs.

A BEV could not meet all daily travel noted without additional charge opportunities and some days do not allow for those charges. A PHEV could provide the benefits for a significant amount of travel that was local. Thus, a fleet of pool vehicles would likely contain a mix of BEVs and PHEVs. 


\begin{tabular}{|l|c|}
\hline Make/Model/Year & Chevrolet Express/2011 \\
\hline EPA Class Size & Van - Passenger \\
\hline Mission & Bus/Shuttle \\
\hline VIN & Sedgwick Ave \\
\hline Parking Location & $* * * 0240$ \\
\hline Fleet Vehicle ID & Gas \\
\hline Fuel Type & $13 / 17 / 14$ \\
\hline EPA Label/MPG (City/Hwy) & 635 \\
\hline EPA GHG Emissions (Grams $\left.\mathrm{CO}_{2} / \mathrm{Mi}\right)$ & 29 \\
\hline Study Logger ID & $75 / 117$ \\
\hline
\end{tabular}

\begin{tabular}{|l|c|c|c|c|}
\hline \multicolumn{5}{|c|}{ Vehicle $* * * 0240$ Travel Summary } \\
\hline & $\begin{array}{c}\text { Per Day } \\
\text { Average/Peak }\end{array}$ & $\begin{array}{c}\text { Per Outing } \\
\text { Average/Peak }\end{array}$ & $\begin{array}{c}\text { Per Trip } \\
\text { Average/Peak }\end{array}$ & Total \\
\hline Travel Distance (Miles) & $44.5 / 360.8$ & $9.4 / 913.0$ & $6.8 / 199.3$ & 3,338 \\
\hline Travel Time (Minutes) & $174.0 / 444.0$ & $36.6 / 1,726.0$ & $26.4 / 242.0$ & 13,033 \\
\hline Idle Time (Minutes) & $53.5 / \mathrm{NA}$ & $11.3 / \mathrm{NA}$ & $8.1 / \mathrm{NA}$ & 4,013 \\
\hline
\end{tabular}

\begin{tabular}{|c|c|c|c|c|}
\hline \multicolumn{3}{|c|}{ Total Stops } & \multicolumn{2}{c|}{ Stop Duration } \\
\hline $\begin{array}{c}\text { Distance From } \\
\text { Home Base (Miles) }\end{array}$ & Stops & Percentages & Stop Duration (Hours) & Stops \\
\hline Less than 10 & 359 & $84.5 \%$ & Less than 2 & 331 \\
\hline 10 to 20 & 4 & $0.9 \%$ & 2 to 4 & 16 \\
\hline 20 to 40 & 2 & $0.5 \%$ & 4 to 8 & 8 \\
\hline Greater than 40 & 60 & $14.1 \%$ & Greater than 8 & 70 \\
\hline
\end{tabular}

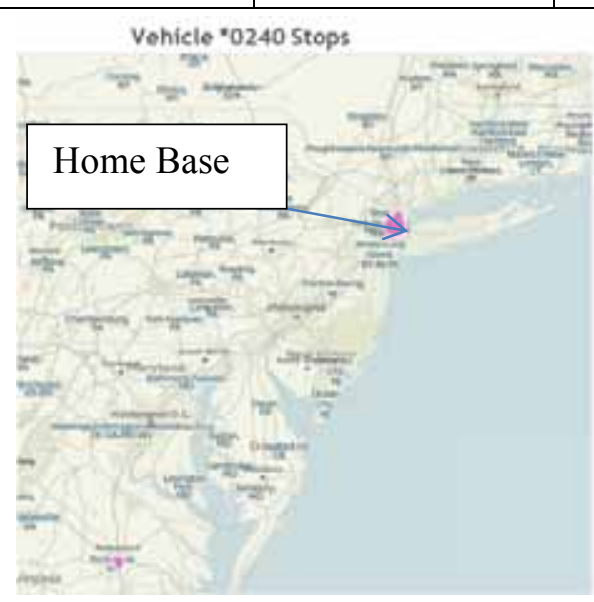

Figure B-19. Vehicle $* * * 0240$ stops.

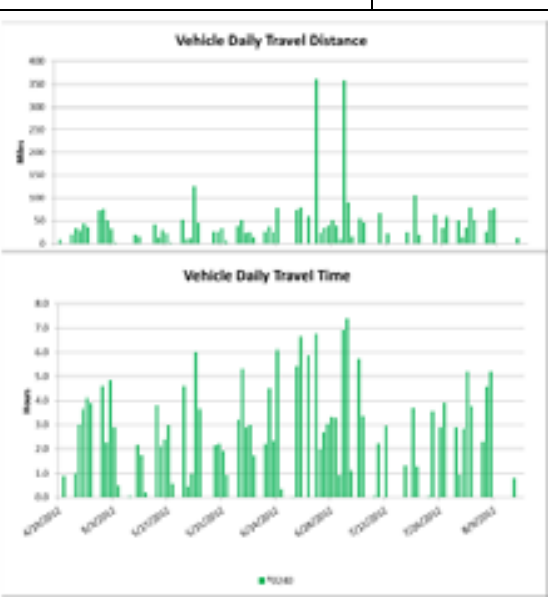

Figure B-20. Vehicle ${ }^{* * * 0240}$ history. 

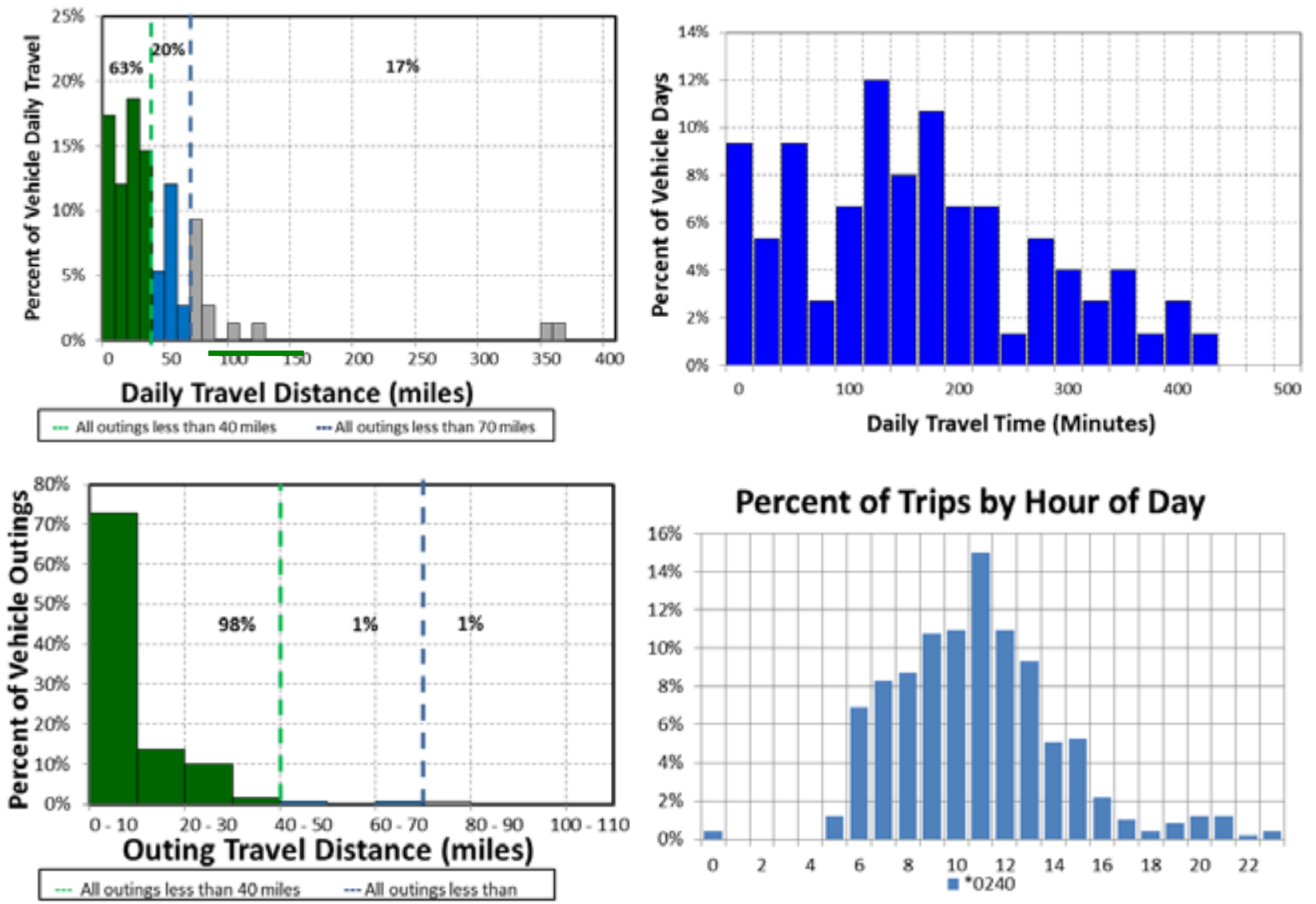

Figure B-7. Vehicle $* * * 0240$ travel graphs (note: the peak outing of 913 miles was not shown for clarity of scale).

\section{Vehicle ${ }^{* * *} 0240$ Observations}

Logger 29 collected data on this vehicle 75 days of the 117-day study period. Validation occurred on $98.4 \%$ of the input data. VA - Bronx reports this vehicle has a bus/shuttle mission as a patient and staff shuttle. Data indicate it typically parks on Sedgwick Avenue (Figure B-19 and Google Earth figure to the right).

VA - Bronx reports the vehicle odometer indicated 7,561 miles during the study and it travels 12,000 miles per year. The vehicle was used on $64 \%$ of available days, with an average daily usage of 2.9 hours and a peak daily usage of 4.8 hours on the days it was used. The vehicle was used during typical day-shift hours.

Figure B-21 shows $83 \%$ of daily travel and $99 \%$ of outings were within the typically advertised range of a

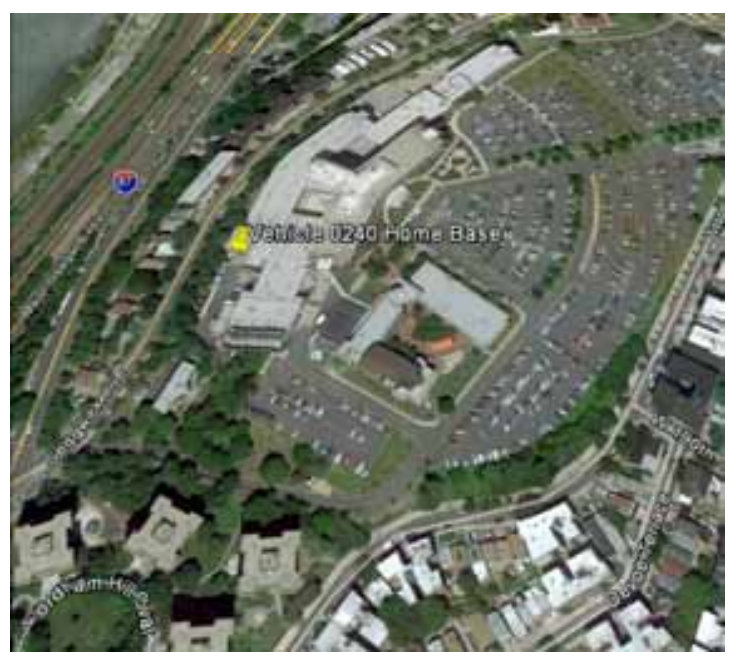
BEV of approximately 70 miles. Further, $63 \%$ of daily travel and $98 \%$ of all outings were within the typically advertised CD mode of 40 miles for PHEVs. The peak outing occurred on a several-day excursion to Richmond, Virginia.

A BEV could not meet all daily travel noted because of the long distance travel. A PHEV could provide benefits for a significant amount of travel that was local. Thus, a fleet of pool vehicles would likely contain a mix of BEVs and PHEVs. 


\begin{tabular}{|c|c|c|}
\hline 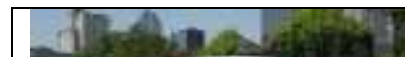 & Make/Model/Year & Chevrolet Express/2010 \\
\hline & EPA Class Size & Van - Passenger \\
\hline & Mission & Bus/Shuttle \\
\hline & VIN & 1FMRE11WX3HA99820 \\
\hline & Parking Location & Sedgwick Ave \\
\hline & Fleet Vehicle ID & $* * * 9820$ \\
\hline & Fuel Type & Gas \\
\hline & EPA Label/MPG (City/Hwy/Combined) & $13 / 17 / 14$ \\
\hline & EPA GHG Emissions (Grams $\left.\mathrm{CO}_{2} / \mathrm{Mi}\right)$ & 635 \\
\hline & Study Logger ID & 30 \\
\hline & Total Vehicle Days/Total Study Days & $7 / 12$ \\
\hline
\end{tabular}

\begin{tabular}{|l|c|c|c|c|}
\hline \multicolumn{5}{|c|}{ Vehicle ***9820 Travel Summary } \\
\hline & $\begin{array}{c}\text { Per Day } \\
\text { Average/Peak }\end{array}$ & $\begin{array}{c}\text { Per Outing } \\
\text { Average/Peak }\end{array}$ & $\begin{array}{c}\text { Per Trip } \\
\text { Average/Peak }\end{array}$ & Total \\
\hline Travel Distance (Miles) & $41.3 / 102.9$ & $5.5 / 41.5$ & $4.3 / 20.8$ & 289 \\
\hline Travel Time (Minutes) & $145.0 / 289.0$ & $19.2 / 120.0$ & $15.2 / 79.0$ & 1,018 \\
\hline Idle Time (Minutes) & $35.9 / \mathrm{NA}$ & $4.7 / \mathrm{NA}$ & $3.7 / \mathrm{NA}$ & 251 \\
\hline
\end{tabular}

\begin{tabular}{|c|c|c|c|c|}
\hline \multicolumn{2}{|c|}{ Total Stops } & \multicolumn{2}{c|}{ Stop Duration } \\
\hline $\begin{array}{c}\text { Distance From } \\
\text { Home Base (Miles) }\end{array}$ & Stops & Percentages & Stop Duration (Hours) & Stops \\
\hline Less than 10 & 48 & $94.1 \%$ & Less than 2 & 42 \\
\hline 10 to 20 & 3 & $5.9 \%$ & 2 to 4 & 3 \\
\hline 20 to 40 & 0 & $0 \%$ & 4 to 8 & 0 \\
\hline 40 to 60 & 0 & $0 \%$ & Greater than 8 & 6 \\
\hline
\end{tabular}

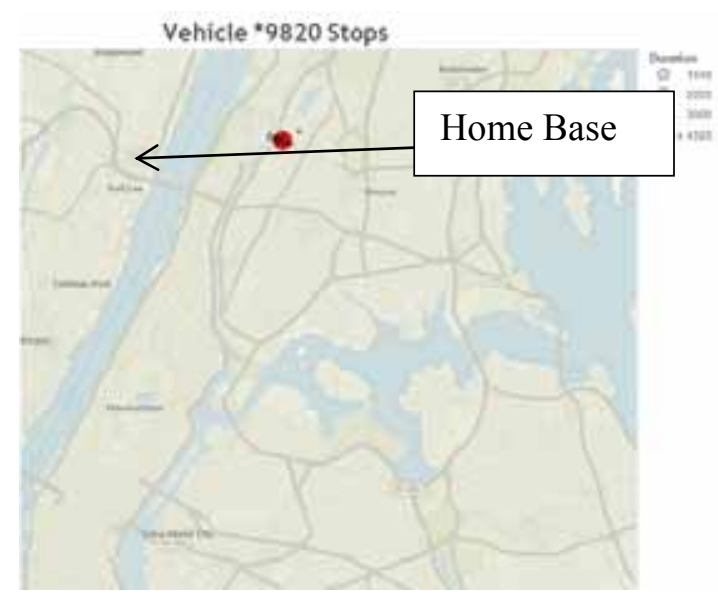

Figure B-22. Vehicle ***9820 stops.

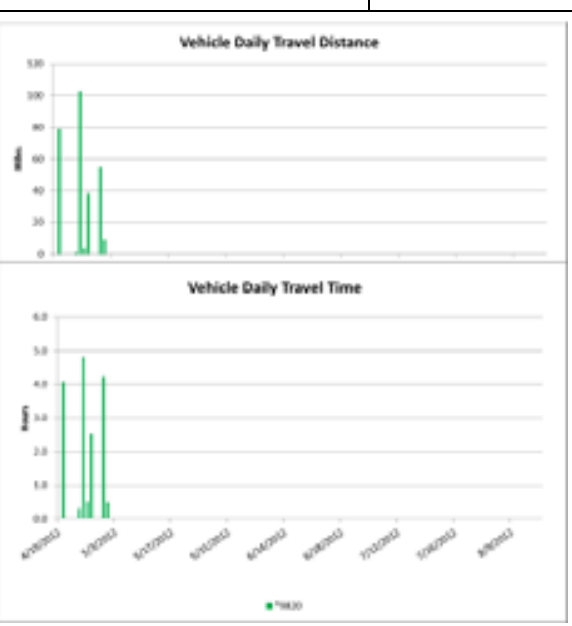

Figure B-23. Vehicle ***9820 history. 

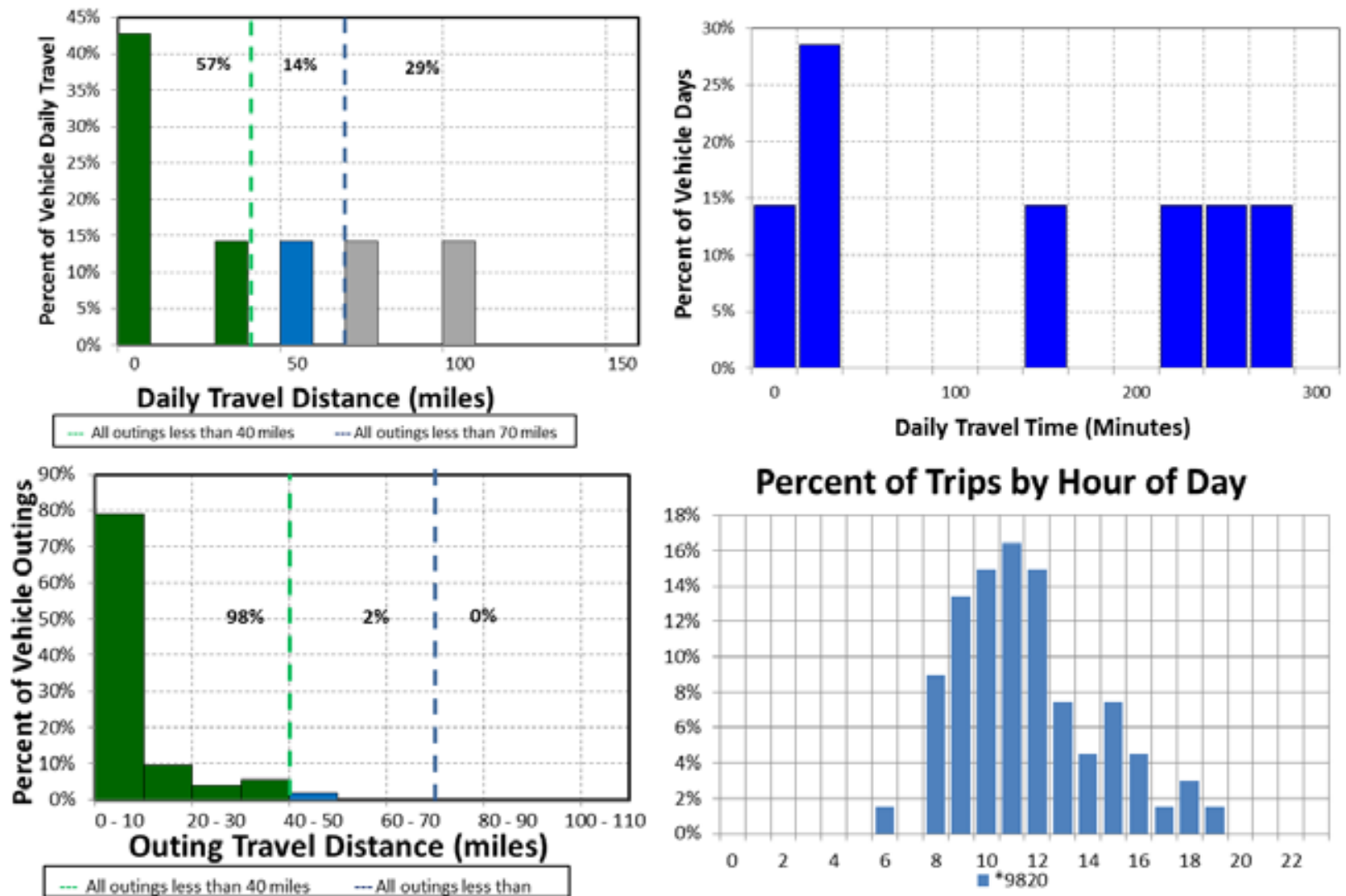

Figure B-8. Vehicle ***9820 travel graphs.

\section{Vehicle ${ }^{* *} 9820$ Observations}

Logger 30 reported data on this vehicle for 7 days of the 12-day study period. It is not known why the logger stopped providing data after these 12 days. Validation occurred on $98.8 \%$ of the input data. VA - Bronx reported this vehicle has a bus/shuttle mission as a staff and patient shuttle. Data indicate it typically parked near Sedgwick Avenue (Figure B-22 and Google Earth figure to the right).

VA - Bronx reports the vehicle odometer indicated 18,760 miles during the study and it travels 12,000 miles per year. The vehicle was used on $58 \%$ of available days, with an average daily usage of 2.4 hours and a peak daily usage of 4.8 hours on the days it was used. The vehicle was used during typical day shift hours.

Figure B-24 shows $71 \%$ of daily travel and $100 \%$ of

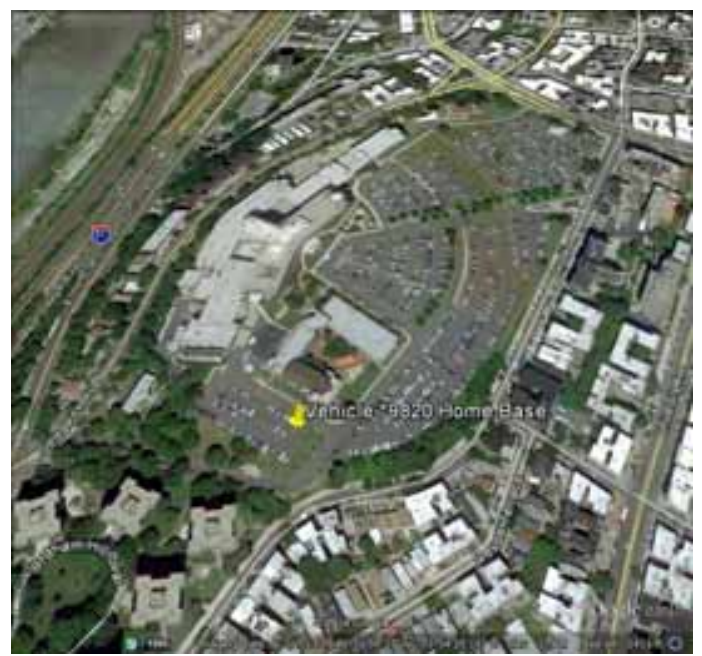
outings were within the typically advertised range of a BEV of approximately 70 miles. Further, $57 \%$ of daily travel and $98 \%$ of all outings were within the typically advertised CD mode of 40 miles for PHEVs.

A BEV could not meet all daily travel unless additional charge time is available. Vehicle usage suggests it is. A PHEV could provide benefits for a significant amount of travel that was local. Thus, a fleet of pool vehicles would likely contain a mix of BEVs and PHEVs. 


\begin{tabular}{|c|c|c|}
\hline & Make/Model/Year & Chevrolet Express/2008 \\
\hline, & EPA Class Size & Van - Passenger \\
\hline (1) & Mission & Bus/Shuttle \\
\hline & VIN & 1GAGG25K781204826 \\
\hline & Parking Location & Sedgwick Ave \\
\hline & Fleet Vehicle ID & $* * * 4826$ \\
\hline & Fuel Type & Gas \\
\hline & EPA Label/MPG (City/Hwy) & $12 / 16 / 14$ \\
\hline & EPA GHG Emissions (Grams $\mathrm{CO}_{2} / \mathrm{Mi}$ ) & 635 \\
\hline & Study Logger ID & 31 \\
\hline & Total Vehicle Days/Total Study Days & $66 / 114$ \\
\hline
\end{tabular}

\begin{tabular}{|l|c|c|c|c|}
\hline \multicolumn{5}{|c|}{ Vehicle ***4826 Travel Summary } \\
& Per Day Average/Peak & $\begin{array}{c}\text { Per Outing } \\
\text { Average/Peak }\end{array}$ & $\begin{array}{c}\text { Per Trip } \\
\text { Average/Peak }\end{array}$ & Total \\
\hline Travel Distance (Miles) & $71.0 / 174.6$ & $8.7 / 94.7$ & $6.6 / 94.7$ & 4,687 \\
\hline Travel Time (Minutes) & $281 / 513.0$ & $34.4 / 222.0$ & $26.0 / 222.0$ & 18,536 \\
\hline Idle Time (Minutes) & $97.1 / \mathrm{NA}$ & $11.9 / \mathrm{NA}$ & $9.0 / \mathrm{NA}$ & 6,409 \\
\hline
\end{tabular}

\begin{tabular}{|c|c|c|c|c|}
\hline \multicolumn{2}{|c|}{ Total Stops } & \multicolumn{2}{c|}{ Stop Duration } \\
\hline $\begin{array}{c}\text { Distance From Home } \\
\text { Base (Miles) }\end{array}$ & Stops & Percentages & $\begin{array}{c}\text { Stop Duration } \\
\text { (Hours) }\end{array}$ & Stops \\
\hline Less than 10 & 584 & $90.1 \% \%$ & Less than 2 & 564 \\
\hline 10 to 20 & 46 & $7.1 \%$ & 2 to 4 & 9 \\
\hline 20 to 40 & 2 & $0.3 \%$ & 4 to 8 & 9 \\
\hline Greater than 40 & 1 & $0.2 \%$ & Greater than 8 & 66 \\
\hline
\end{tabular}

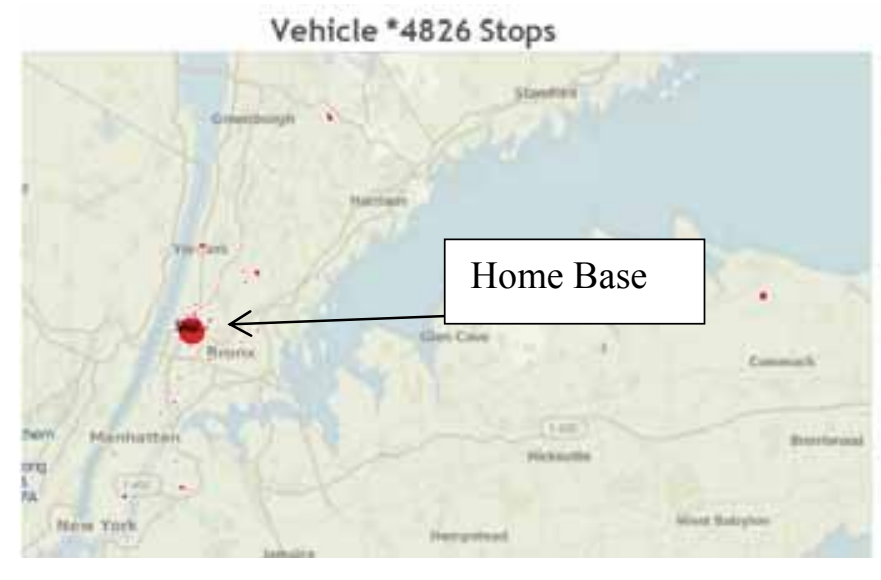

Figure B-25. Vehicle ***4826 stops.

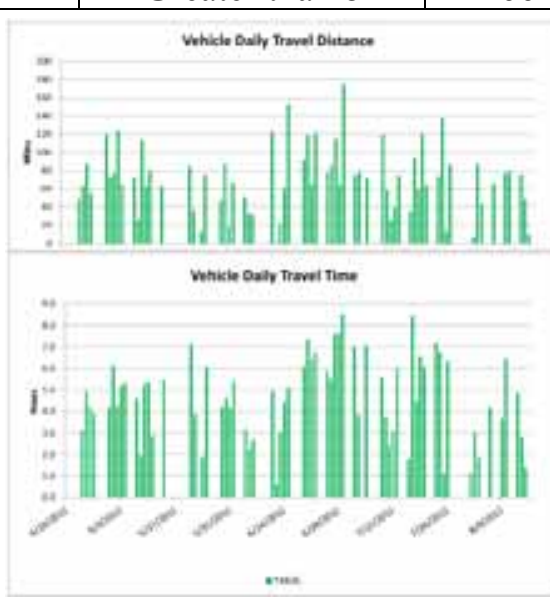

Figure B-26. Vehicle ***4826 history. 

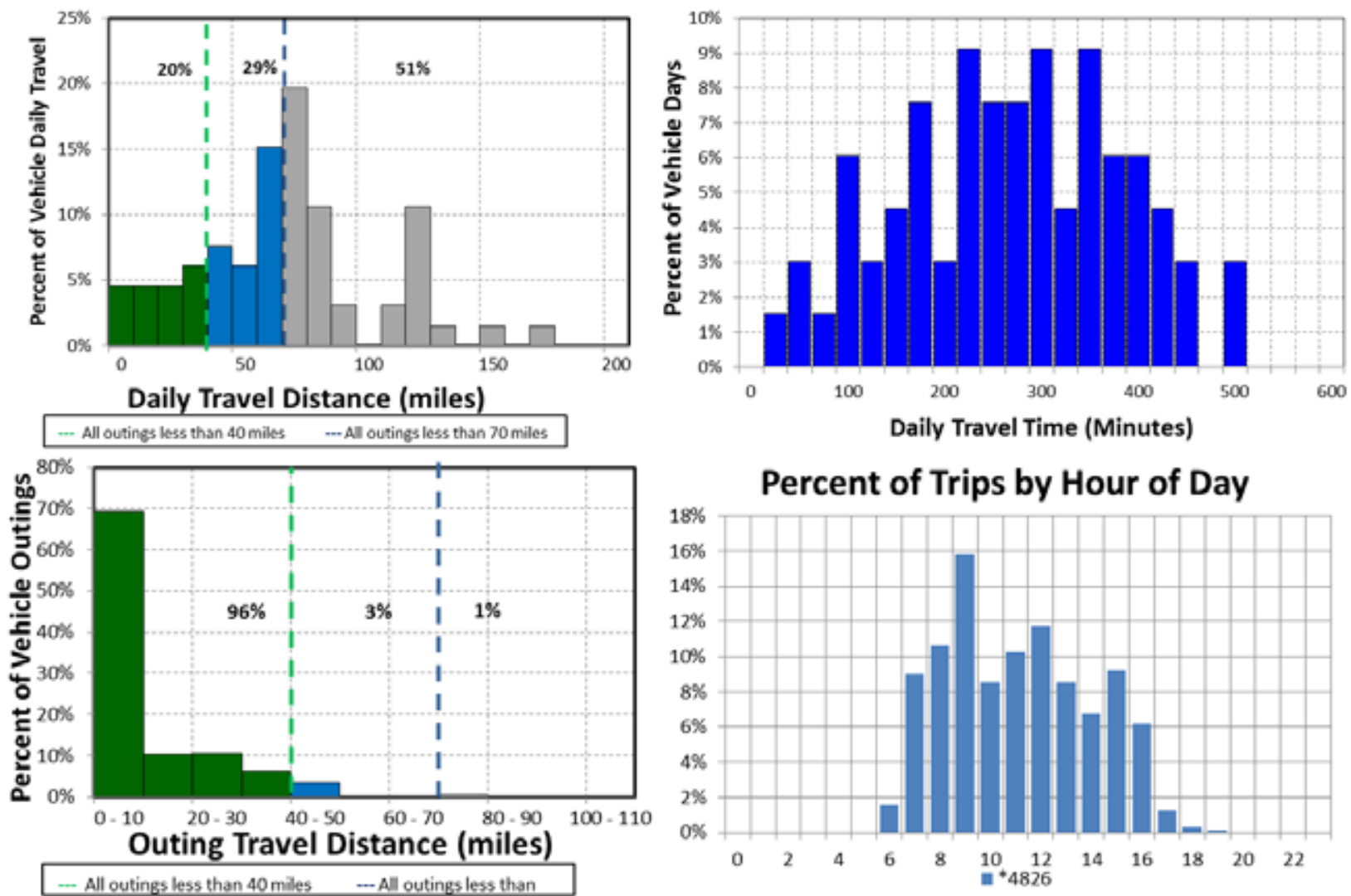

Figure B-9. Vehicle ***4826 travel graphs.

\section{Vehicle ***4826 Observations}

Logger 31 collected data on this vehicle for 66 days of the 114-day study period. Validation occurred on $99.4 \%$ of the input data. VA - Bronx reports this vehicle indicated that it has a bus/shuttle mission as a patient and staff shuttle. Data indicate it typically parks near Sedgwick Avenue or Webb Avenue (Figure B-25 and Google Earth figure to the right).

VA - Bronx reports the vehicle odometer indicated 54,700 miles during the study and an annual travel of 12,000 miles. The vehicle was used on $58 \%$ of available days, with an average daily usage of 4.7 hours and a peak daily usage of 8.6 hours on the days it was used. The vehicle was used during typical day shift hours.

Figure B-27 shows $49 \%$ of daily travel and $99 \%$ of outings were within the typically

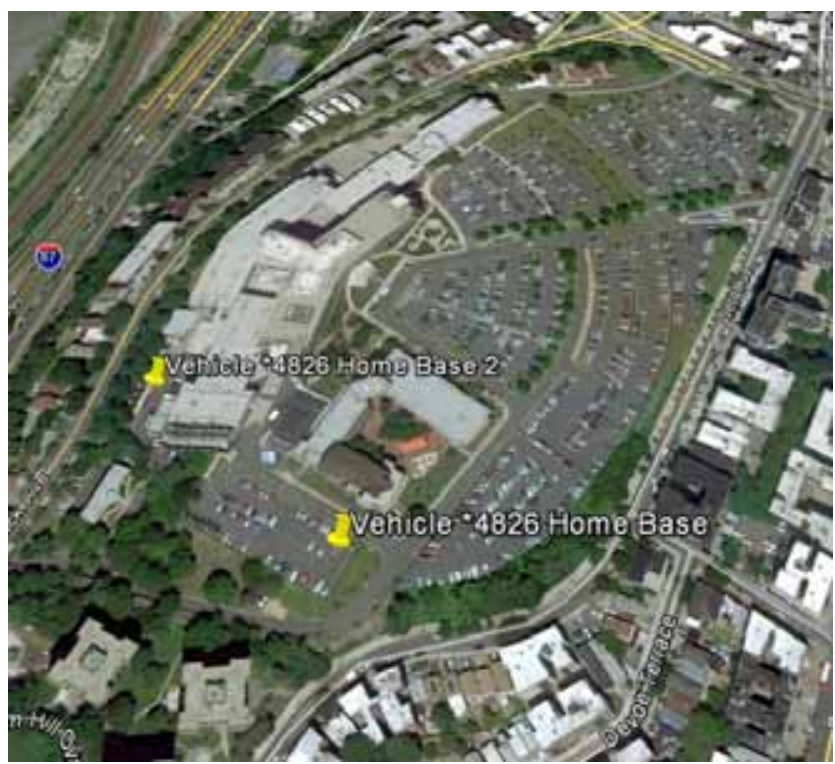
advertised range of a BEV of approximately 70 miles. Further, $20 \%$ of daily travel and $96 \%$ of outings were within the typically advertised CD mode of 40 miles for PHEVs.

A BEV could not meet all daily travel requirements without additional charging opportunities. However, with those charge opportunities, the BEV could meet the daily requirements if a BEV replacement could be identified. 


\section{Appendix C National Fuel Cost and GHG Savings}

Section 5 notes that fuel cost and GHG savings are calculated on a local and a national basis. Local savings are of higher interest to the facility, while national figures are of higher interest in evaluating all sites. Section 5 provides the savings on the local level. Table $\mathrm{C}-1$ presents these savings on a national basis for the PEV replacement of the monitored vehicles.

Table C-1. Fuel cost and GHG savings on a national basis.

\begin{tabular}{|c|c|c|c|c|c|}
\hline Mission & Replacement Model & $\begin{array}{c}\text { Extrapolated } \\
\text { National Yearly } \\
\mathrm{CO}_{2} \mathrm{e} \mathrm{Avoided} \\
\text { (lb-CO } \mathrm{CO}_{2} \mathrm{e} / \text { year) }\end{array}$ & $\%$ reduction & $\begin{array}{c}\text { Extrapolated } \\
\text { National Yearly } \\
\text { Fuel Cost } \\
\text { Reduction }\end{array}$ & $\%$ reduction \\
\hline Pool & Ford Fusion & $(218)$ & $-10 \%$ & $\$ 195$ & $55 \%$ \\
\hline Pool & Nissan Leaf & 564 & $11 \%$ & $\$ 522$ & $64 \%$ \\
\hline Pool & Ford Focus & 3,242 & $36 \%$ & $\$ 1,050$ & $74 \%$ \\
\hline Pool & Nissan Leaf & 5,456 & $50 \%$ & $\$ 1,384$ & $80 \%$ \\
\hline Pool & Chevrolet Volt & 826 & $17 \%$ & $\$ 500$ & $66 \%$ \\
\hline Pool & Mitsubishi Outlander & 1,632 & $33 \%$ & $\$ 571$ & $73 \%$ \\
\hline Bus & NA & NA & NA & NA & NA \\
\hline Bus & NA & NA & NA & NA & NA \\
\hline \multirow[t]{2}{*}{ Bus } & NA & NA & NA & NA & NA \\
\hline & Total & 11,502 & $31 \%$ & $\$ 4,221$ & $72 \%$ \\
\hline
\end{tabular}

Note that while the Ford Fusion PHEV as a replacement for the Ford Fusion Hybrid provides a reduction in GHG locally, as shown in Section 6, it produces more GHG using national figures. This is because the power plant emissions in the Consolidated Edison service territory are less than the national average.

As presented in Section 5, 11 BEVs and 12 PHEVs could replace most ICE vehicles in the fleet of 23 pool vehicles. Using an average savings per vehicle, Table C-2 provides the avoided GHG and fuel cost savings should these replacements occur.

Table C-2. Extrapolated GHG emissions avoided and fuel cost savings for the entire fleet.

\begin{tabular}{ccccc}
\hline Mission & $\begin{array}{c}\text { Extrapolated U.S. Yearly } \mathrm{CO}_{2} \mathrm{e} \\
\text { Avoided }\left(\mathrm{lb}-\mathrm{CO}_{2} \mathrm{e} / \text { year) }\right.\end{array}$ & $\begin{array}{c}\text { Extrapolated U.S. Yearly Fuel } \\
\text { Cost Reduction (\$/year }\end{array}$ & \% reduction \\
\hline Pool & 36,522 & $27 \%$ & $\$ 14,913$ & $71 \%$ \\
\hline
\end{tabular}

